Demóstenes Zegarra Rodríguez

\title{
Proposta da métrica eVSQM para avaliação de QoE no serviço de streaming de vídeo sobre TCP
}

Tese apresentada à Escola Politécnica da Universidade de São Paulo para obtenção do Título de Doutor em Engenharia. 
Demóstenes Zegarra Rodríguez

\section{Proposta da métrica eVSQM para avaliação de QoE no serviço de streaming de vídeo sobre TCP}

Tese apresentada à Escola Politécnica da Universidade de São Paulo para obtenção do Título de Doutor em Engenharia.

Área de concentração:

Sistemas Digitais

Orientador:

Profa. Dra. Graça Bressan 


\section{Ficha Catalográfica}

Rodríguez, Demóstenes Zegarra

Proposta da métrica eVSQM para avaliação de QoE no serviço de streaming de vídeo sobre TCP. São Paulo, 2014. 105 p.

Tese (Doutorado) — Escola Politécnica da Universidade de São Paulo. Laboratório de Redes.

1. Vídeo. 2. Protocolo de comunicação. 3. Telecomunicação. 4. Multimídia. I. Universidade de São Paulo. Escola Politécnica. Laboratório de Redes. II. Título. 
Aos meus pais, Demóstenes e Julia 


\section{Agradecimentos}

A Deus, por ter me guiado ao longo dessa caminhada.

Aos meus pais, irmãos e sobrinhos pela paciência, compreensão e amor.

À minha orientadora, Profa. Dra. Graça Bressan, pela confiança e apoio dispensado para participar do doutorado e pelas inúmeras e valiosas orientações que foram essenciais para o cumprimento deste trabalho. Devo destacar que este aprendizado é tanto no aspecto acadêmico quanto no pessoal.

À Profa. Dra. Regina Silveira e ao Prof. Denis Gabos pelas observações e sugestões realizadas na qualificação deste trabalho.

Ao Prof. Marcelo Zuffo por me permitir participar do projeto de TV Digital na fase inicial de meu doutorado.

À Profa. Dra. Julia Abrahão pelos valiosos conselhos e sugestões dadas nas varias reuniões durante o período de professora visitante na USP. Sem duvida, o caráter interdisciplinar desta tese deve-se a ela.

Ao Prof. Dr. Zhou Wang da Universidade de Waterloo de Canadá pelas valiosas sugestões e contribuições na fase final deste trabalho.

A minha colega Renata Lopes pela enorme e valiosa ajuda nos diferentes trabalhos que formam parte desta tese.

A meus colegas Juan Casavílca e Dante Coaquira pela ajuda e motivação durante os anos no qual foi realizado este trabalho.

Ao Laboratório de Arquitetura e Redes de Computadores (LARC) pela infraestrutura que utilizei e a todos os seus membros.

À Fundação de Amparo à Pesquisa no estado de São Paulo (FAPESP) pelo apoio financeiro para a realização deste trabalho, permitindo me assistir a diversas conferências nacionais e internacionais. 


\section{Resumo}

Atualmente existem inúmeros serviços multimídia que são transportados através da rede IP, dos quais, o tráfego dos serviços de vídeo experimentou um maior crescimento nos últimos anos. O sucesso de aplicações de streaming de vídeo é um dos fatores pelo qual, esse tráfego se incrementou. Alguns recentes estudos projetam que esse tipo de serviço no ano 2016, alcançará aproximadamente o $55 \%$ do tráfego total da Internet. Considerando a importância que os serviços de vídeo alcançarão nos próximos anos, este trabalho foca-se na avaliação da qualidade de experiência (QoE) dos usuários ao utilizar esses serviços. Assim, nesta tese é proposta uma métrica de avaliação de vídeo denominada eVsQM, do inglês enhanced Video streaming Quality Metric, a qual é baseada principalmente no número, duração e localização temporal dos congelamentos de imagens (pausas) durante uma transmissão de vídeo, considerando também o tipo de conteúdo do vídeo transmitido. Esta métrica foi determinada a partir de um modelo matemático que utilizou os resultados de testes subjetivos de avaliação de vídeo, pois, este tipo de testes são os que melhor se aproximam da QoE real do usuário. Cabe destacar, que na realização dos testes subjetivos foi utilizada uma metodologia concordante com o tipo de degradação que o vídeo possui, ou seja, a pausa. Por outro lado, no streaming de vídeo novas soluções são criadas com a finalidade de melhorar a QoE do usuário. O DASH, do inglês Dynamic Adaptive Streaming over HTTP, muda a resolução do vídeo transmitido de acordo com as características da rede. Porém, se a rede é muito flutuante existirão muitas variações de resolução e a QoE do usuário será degradada. Neste trabalho é proposto um parâmetro a ser utilizado no algoritmo DASH que funciona como um limiar para controlar a frequência destas comutações de resolução. Este parâmetro é denominado como Fator de Degradação de Comutação (FDC), do inglês Switching Degradation Factor (SDF) e permite que a QoE seja mantida em níveis aceitáveis, inclusive em situações onde a rede apresenta variações de capacidade de uma forma constante.

Palavras-chave: Streaming de vídeo. Qualidade de Experiência. Avaliação de Qualidade de Vídeo. Métricas Objetivas. DASH. 


\section{Abstract}

Nowadays, there are several multimedia services, which are carried via IP networks. From these all services; the traffic regarding video applications had the greatest growth in the last years. The success of video streaming applications is one of the major contributors to video traffic growth. Some recent studies project that video services, will reach approximately $55 \%$ of the total Internet traffic in 2016. Considering the relevance that video services will achieve in the coming years, this work focuses on the users' Quality of Experience (QoE) when using these services. Thus, this thesis proposes an evaluation metric named enhanced Video streaming Quality Metric (eVsQM), which is based primarily on the number, duration and temporal location of the image freezes (pauses) during a video transmission. Also, this metric considers the video content type and was determined from a mathematical model that used as inputs, the video quality assessment results from subjective tests due, these types of test are the most correlated with real user's QoE. It is worth noting that to perform these subjective tests was used a methodology consistent with the kind of video degradation (pause). For another hand, new video streaming solutions are created for the purpose of improving the user's QoE of the user. Dynamic Adaptive Streaming over HTTP (DASH) changes the video resolution according to the network characteristics. However, if the network is very fluctuant, many video resolution switching events will be performed and user's QoE will be degraded. This thesis proposes a parameter to be used in DASH algorithms that works as a threshold to control the resolution switching frequency. This parameter is named Switching Degradation Factor (SDF) and is responsible to maintain the QoE in acceptable levels, inclusive in scenarios in which the network capacity is very fluctuating.

Keywords: Video streaming. Quality of Experience. Video Quality Assessment. Objective Metrics. DASH. 


\section{Sumário}

\section{Lista de Figuras}

\section{Lista de Tabelas}

\section{Lista de Abreviaturas}

1 Introdução 1

1.1 Contexto e Motivação . . . . . . . . . . . . . . . . . . . . . . 1

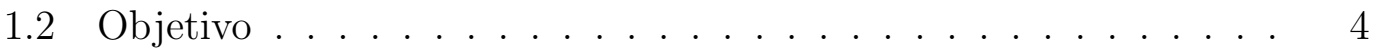

1.3 Estrutura da Tese . . . . . . . . . . . . . . . 5

$\begin{array}{lll}2 & \text { Revisão Teórica } & 7\end{array}$

2.1 Aspectos técnicos de streaming de vídeo f . . . . . . . . . . . . 7

2.1.1 Aplicações Multimídia . . . . . . . . . . . . . 7

2.1.2 Elementos e funcionamento de um streaming de vídeo armazenado . . . . . . . . . . . . . . 8

2.1.3 Protocolo de Transporte e as degradações no streaming de vídeo . . . . . . . . . . . . . . . . . . . . 10

2.1.4 Codificação de Vídeo . . . . . . . . . . . . . . . . . . . . . 13

2.1.4.1 Codificador de Vídeo ITU-T H.264 . . . . . . . 15

2.1.5 Principais fatores de degradação de Qualidade em uma Rede IP . . . . . . . . . . . . . . . . . . . . . . . 16

2.2 Processos Perceptivos e Cognitivos _. . . . . . . . . . . . . 17

2.2 .1 O Processo de Atenção . . . . . . . . . . . . . . . . . . . 19

2.2.2 A Memória . . . . . . . . . . . . . . . . . . 20

2.2.3 Preferência do usuário no Conteúdo de Vídeo . . . . . . . 22 
2.3 Efeito das pausas de um vídeo na capacidade da atenção . . . . .

3.1 Métodos de Avaliação de Qualidade de Vídeo . . . . . . . . . . . 24

3.1.1 Classificação dos Métodos de Avaliação de Vídeo .... 24

3.1.1.1 Métodos Objetivos de Avaliação de Qualidade de Vídeo ..................... . . 25

3.1.1.2 Métodos Subjetivos de Qualidade de Vídeo . . . 31

3.2 Adaptação dinâmica de streaming utilizando o protocolo HTTP 39

\section{A Métrica eVsQM}

4.1 Recomendações Práticas na Avaliação Subjetiva de Qualidade do Streaming de Vídeo utilizando TCP . . . . . . . . . . . . . . 43

4.2 Métrica VsQM para o serviço de Streaming de Vídeo sobre TCP . 44

4.2.1 Base de Dados dos Vídeos e Ambiente de Teste . . . . . . 46

4.2.2 Determinação do índice MOS por meio de testes subjetivos presenciais . . . . . . . . . . . . . . . 4. 48

4.2.3 Metodologia utilizada para determinar a métrica VsQM . . 49

4.2.4 Resultados obtidos com a Métrica VsQM . . . . . . . . 50

4.3 Melhora da métrica VsQM considerando o tipo de conteúdo de vídeo ................................ 54

4.3.1 Metodologia de Teste na Avaliação de Qualidade de vídeo utilizando Crowdsourcing . . . . . . . . . . 56

4.3.2 Desempenho da métrica proposta eVsQM . . . . . . . 58

5 Estudo de Caso

5.1 Efeitos das mudanças de resolução de vídeo na QoE . . . . . . . 63

5.1.1 Problemas dos atuais algoritmos de controle do DASH . . 64

5.1.1.1 Frequência de eventos de comutação de qualidade

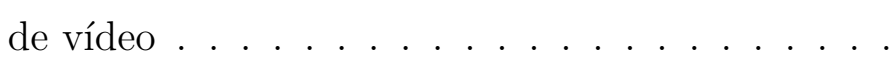


5.1.1.2 Pesos de Degradação de diferentes eventos de comutação de nível de qualidade de vídeo . . . . . . 68

5.1.1.3 Localização Temporal de eventos de comutação do nível de qualidade de vídeo . . . . . . . . . . 68

5.1.2 Proposta do fator de degradação por mudanças de resoluções 69

5.1.3 Metodologia e Cenário de Teste . . . . . . . . . . . . . 74

5.1 .4 Resultados . . . . . . . . . . . . . . . 75

5.2 Efeito global das mudanças de resolução de vídeo e das pausas na QoE do usuário . . . . . . . . . . . . . . . . . . . . . 78

5.3 Considerações finais . . . . . . . . . . . . . . . . . . . . . . . . . . . 79

$\begin{array}{llr}6 & \text { Conclusões } & 81\end{array}$

6.1 Contribuições . . . . . . . . . . . . . . . . . . . 82

6.2 Limitações . . . . . . . . . . . . . . . . . . . . . . . . 83

6.3 Trabalhos Futuros . . . . . . . . . . . . . . . . . . . . 83

6.4 Produção Cientifica . . . . . . . . . . . . . . . . . . . 84

$\begin{array}{ll}\text { Referências } & 87\end{array}$

$\begin{array}{ll}\text { Apêndice A - Sistema Visual Humano } & 93\end{array}$

A.1 Anatomia do Olho Humano . . . . . . . . . . . . . . . 93

A.2 Funcionamento do Olho Humano . . . . . . . . . . . . . . . . 95

Apêndice B - Avaliação da qualidade de TV digital com diferentes $\begin{array}{lr}\text { modelos de desvanecimento } & 98\end{array}$

B.1 Canal de Radiofreqüência e Desvanecimentos . . . . . . . . . . . . 98

B.2 Cenário de Teste e Resultados . . . . . . . . . . . . . . . . . . . 99

Apêndice C - Parâmetros de Informação Temporal (TI) e Informação Espacial (SI) 102

C.1 Parâmetro de Informação Espacial . . . . . . . . . . . . . . . . . . 102

C.2 Parâmetro de Informação Temporal . . . . . . . . . . . . . . . . 102 
C.3 Código empregado para calcular TI e SI . . . . . . . . . . . . 103 


\section{Lista de Figuras}

2.1 Elementos que compõem o serviço de streaming de vídeo. Adaptado de (KUROSE; ROSS, 2004) . . . . . . . . . . . . . 9

2.2 Degradações no streaming de vídeo devido ao protocolo de transporte: (a) Protocolo TCP. (b) Protocolo UDP em um cenário com perda de pacotes. . . . . . . . . . . . . . . . 11

2.3 Estados de um Buffer. . . . . . . . . . . . . . . . . . . . . . 12

2.4 Tipos de degradações nos serviços de Vídeo e sua relação com a QoE............................... 12

2.5 Imagem YUV e imagens de cada um dos seus componentes. . . . 14

2.6 Elementos do vídeo digital: (a) no domínio espacial: pixel e (b) no domínio do tempo: quadro. . . . . . . . . . . . . . . 14

2.7 Evolução da eficiência na compressão dos codificadores de vídeo. Adaptada de (Ericsson, 2012) . . . . . . . . . . . . 16

2.8 Processos Perceptivos e Cognitivos (ABRAHAO, 2009). . . . . . . 19

3.1 Classificação dos métodos de avaliação de vídeo. . . . . . . . . . . 25

3.2 Diagrama de blocos do método Referência Total. . . . . . . . . . 28

3.3 Diagrama de blocos do método Referência Parcial. . . . . . . . . . 28

3.4 Diagrama de blocos do método sem Referência. . . . . . . . . . . 29

3.5 Diagrama funcional da métrica SSIM, adaptada de (WANG et al., 2004). . . . . . . . . . . . . . . . 30

3.6 Diagrama de blocos da métrica VQM de (XIAO, 2000). . . . . . . 31

3.7 Formato de apresentação das seqüências de vídeos no método ACR. 32

3.8 Formato de apresentação das seqüências de vídeos em DCR. . . . 34

3.9 Formato de apresentação das seqüências de vídeos no método PC. 34

3.10 Escala de pontuação utilizada na metodologia DSCQS. . . . . . . 35 
3.11 Resultados de um teste de avaliação de qualidade de vídeo utilizando-se a Metodologia SSCQE. . . . . . . . . . . . 36

3.12 Descrição geral do Sistema de DASH. . . . . . . . . . . . . . . . . 40

4.1 Parâmetros que compõem a métrica VsQM. . . . . . . . . . . . . 45

4.2 Parâmetros TI e SI dos arquivos de vídeos sem pausas. . . . . . . 47

4.3 Exemplo de cenários de teste com diferente distribuição de pausas no domínio do tempo. . . . . . . . . . . . . . . . . . . . 48

4.4 Ambientes de teste. (a) Sala do Laboratório de Processamento de Sinais - LPS. (b) Sala do Laboratório de Computação Gráfica da FAUUSP.

4.5 Peso dos segmentos temporais: $W_{A}, W_{B}, W_{C}$ e $W_{D}$ (RODRIGUEZ et al., 2012b). . . . . . . . . . . . . . . . . 51

4.6 Relação entre MOS, $V s Q M_{M O S}$ e VsQM: (a) Relação entre os índices MOS obtidos em testes subjetivos e $V s Q M_{M O S}$ para os 20 cenários avaliados (b) Exemplo para um cenário de teste (Cenário 5) que relaciona a métrica $\mathrm{VsQM}, V s Q M_{M O S}$ e o MOS subjetivo.

4.7 Relação entre o MOS obtido da métrica $V s Q M_{M O S}$ e a duração da pausa.

4.8 MOS obtidos considerando e sem considerar o parâmetro W, com seqüências de vídeo de 2 e 4 minutos. . . . . . . . . . . . . . 53

4.9 Distribuiçao temporal de pausas em um mesmo vídeo. . . . . . . . 55

4.10 Peso de degradação de qualidade que cada segmento temporal adicionado à degradação total da qualidade do vídeo. . . . . . . . . . 56

4.11 Algoritmo para determinação da métrica eVSQM no cliente. . . 57

4.12 Framework - Interface do portal utilizado na Avaliação de Qualidade de Vídeo. . . . . . . . . . . . . . . . . . . . . . . 58

4.13 Relação dos resultados obtidos para vídeos de 5 minutos de duração. (a) Relação da métrica $V S Q M_{M O S} \operatorname{com}$ (MOS/Crowd). (b) Relação da métrica $e V s Q M_{M O S}$ com (MOS/Crowd) . . . . . 60

4.14 Relação dos resultados obtidos para vídeos de 8 minutos de duração. (a) Relação da métrica $V S Q M_{M O S}$ com (MOS/Crowd). (b) Relação da métrica eVsQM $M_{M O S}$ com (MOS/Crowd) . . . . 
5.1 Um exemplo de eventos de comutação de resolução de vídeo com o algoritmo de controle de qualidade DASH, que não considera a frequência de eventos de comutação. . . . . . . . . . . . . . .

5.2 Frequência de eventos de comutação como um fator de decisão para realizar um evento de comutação. . . . . . . . . . . . . . . . . .

5.3 Um exemplo de eventos de comutação de qualidade de vídeo com um algoritmo de controle de qualidade DASH que considera a freqüência de eventos de comutação. . . . . . . . . . . . . . . . . . . .

5.4 Diferentes tipos de comutação utilizando cinco níveis de qualidade do mesmo vídeo. . . . . . . . . . . . . . . . . . . 68

5.5 Eventos de comutação de resoluções de vídeo localizados em diferentes segmentos temporais. . . . . . . . . . . . . . . 69

5.6 Cenário de teste. . . . . . . . . . . . . . . . . . 74

5.7 Fluxograma do algoritmo de controle de adaptação DASH, que inclui o parâmetro FDC proposto. . . . . . . . . . . . . 75

5.8 Degradação de peso dos cinco tipos diferentes de comutação de VQL. 76

5.9 O peso de degradação dos segmentos temporais, em que TS-B, TSM TS-E representam o segmento temporal, no início, meio e final do vídeo, respectivamente. . . . . . . . . . . . . . 76

5.10 MOS subjetivo e objetivo de cenários com diferentes tipos de comutação entre VQLs. . . . . . . . . . . . . . . . . . . . .

5.11 Valores MOS Objetivo de cenários com eventos de comutação VQL localizados nos diferentes segmentos temporais (A, B, C representam o segmento temporal, inicial, intermediária e final, respectivamente). . . . . . . . . . . . . . . . . 77

5.12 Comparação de desempenho baseada em valores MOS entre algoritmos DASH que considera ou não o parâmetro FDC. . . . . . . 78

5.13 Eventos de comutação de qualidade de vídeo e pausas durante um congestionamento crítico na rede. . . . . . . . . . . . . . 79

A.1 Estruturas funcionais do olho humano (NISHIDA, 2012). . . . . . 93 
A.2 Funcionamento de olho humano: (a) Esquema ilustrativo que compara o funcionamento de uma câmera fotográfica ao olho humano. (b) Diagrama que apresenta como o cérebro retifica a imagem capturada pela retina. Adaptada de (SCARAZATTO, 2012). . . . . . 96

A.3 Transmissão das informações ópticas ao cérebro (NISHIDA, 2012). 97

A.4 Campo visual do olho humano (NISHIDA, 2012). . . . . . . . . . 97

B.1 Cenário de teste para TV Digital (RODRIGUEZ; BRESSAN, 2012). 99 


\section{Lista de Tabelas}

3.1 ITU-T Escala ACR . . . . . . . . . . . . . . . . . . . . . . . 32

3.2 ITU-T Escala DCR . . . . . . . . . . . . . . . . . 34

3.3 Características das Metodologias de Testes Subjetivos . . . . . . . 37

4.1 Características dos vídeos utilizados nos testes . . . . . . . . . 47

4.2 Resultados de testes subjetivos de qualidade de vídeo para cada tipo de conteúdo de vídeo . . . . . . . . . . . . . . 55

4.3 Resultados de testes com avaliadores remotos e presenciais . . . . 59

4.4 Resultados obtidos pelas métricas $e V S Q M_{M O S}, V s Q M_{M O S}$ e nos testes de usuários remotos (MOS/Crowd) com vídeos de 5 minutos de duração . . . . . . . . . . . . . . . . . . . . . . . . . . 59

4.5 Resultados obtidos pelas métricas $e V S Q M_{M O S}, V s Q M_{M O S}$ e nos testes de usuários remotos (MOS/Crowd) com vídeos de 8 minutos de duração . . . . . . . . . . . . . . . . . . . . . . . . . . . .

4.6 Resultados obtidos pelas métricas $e V S Q M_{M O S}, V s Q M_{M O S}$ e nos testes de usuários remotos (MOS/Crowd) com vídeos de 11 minutos de duração . . . . . . . . . . . . . . . . . . . . .

5.1 Eventos de comutação de qualidade no cenário 1, utilizando um algoritmo DASH sem considerar a frequência de eventos de comutação 66

5.2 Eventos de comutação de qualidade de vídeo no cenário 2, utilizando um algoritmo DASH considerando a frequência de eventos de comutação . . . . . . . . . . . . . . . . 67

5.3 Casos de comutação de nível de resolução de vídeo . . . . . . . . . 70

5.4 Características dos vídeos usados como material de teste . . . . . 74

B.1 Efeito do Fading na qualidade do vídeo-1 . . . . . . . . . . . . 100

B.2 Efeito do Fading na qualidade do vídeo-2 . . . . . . . . . . . . 100

B.3 Efeito do Fading na qualidade do vídeo-3 . . . . . . . . . . . . . . 100 


\section{Lista de Abreviaturas}

ACR Absolute Category Rating

ACR-HR Absolute Category Rating with Hidden Reference

AVC Advanced Video Coding

CIF Common Intermediate Format

DCR Degradation Category Rating

DNS Domain Name System

DSCQS Double Stimulus Continuous Quality Scale

DSIS Double Stimulus Impairment Scale

FR Full Reference

HTML Hypertext Markup Language

HDTV High Definition Television

HTTP HyperText Transfer Protocol

IETF Internet Engineering Task Force

IMS IP Multimedia Subsystem

IP Internet Protocol

ITU-T International Telecommunications Union - Telecommunications Standardization Sector

JVT Joint Video Team

KPI Key Performance Indicators

LAN Local Area Network

MOS Mean Opinion Score

MPEG Moving Picture Experts Group 
MSE Mean Squad Error

NETEM Network Emulator

NR No Reference

PC Pair Comparison

PDT Packet Delay Transfer

PDV Packet Delay Variance

PLR Packet Loss Rate

PSNR Peak Signal to Noise Ratio

QoE Quality of Experience

QoS Quality of Service

RFC Request for Comments

RTCP Real Time Control Protocol

RTP Real Time Protocol

SAMVIQ Subjective Assessment Methodology for Video Quality

SDSCE Simultaneous Double Stimulus for Continuous Evaluation

SIP Session Initiation Protocol

SSCQE Single Stimulus Continuous Quality Scale

SSIM Structural Similarity Index

TCP Transport Control Protocol

THRU Throughput

TS Technical Specification

UDP User Datagram Protocol

URL Universal Resource Locator

VCEG Video Coding Experts Group

VLC VideoLan Client 
VoIP Voice over IP

VQEG Video Quality Expert Group

VQM Video Quality Measure

VsQM Video streaming Quality Metric

WAN Wide Area Network

3GPP 3rd Generation Partnership Project 


\section{Introdução}

Nesta seção serão abordados os tópicos que mostram a importância deste trabalho no contexto atual, juntamente com a descrição da organização dos temas que serão tratados.

\subsection{Contexto e Motivação}

O tráfego projetado para vídeo em Internet, excluindo compartilhamento de arquivos e jogos, alcançará em 2016, 55 \% do tráfego total da Internet (CISCO, 2012). Com esse aumento de tráfego de vídeo, os fornecedores de serviços de vídeo devem-se preparar para atender o volume de informação (CHEN; LIN; WEI, 2009). Nesse cenário, cabe salientar que o estudo de métodos e métricas de avaliação de qualidade do sinal do vídeo é de suma importância, para que os serviços prestados possam garantir um nível aceitável de satisfação do usuário final.

Atualmente existem diferentes serviços de aplicações de vídeo sobre uma rede IP, sendo que um dos serviços que mais evolucionou nos últimos anos foi o de streaming de áudio e vídeo armazenados. Exemplos do sucesso desse tipo de serviço considerando a popularidade que alcançaram são: Youtube, Dailymotion, Vimeo, Microsoft Vídeo, entre outros. Por outro lado, os serviços em tempo real, como a videoconferência (exemplo, NetMeeting da Microsoft e vídeo Skype) ou streaming de áudio e vídeo ao vivo que são mais conhecidas como radio da Internet e IPTV, também experimentaram um incremento considerável no número de usuários. Nesse contexto, é importante destacar que cada um dos serviços possui certos requisitos no transporte da informação, a fim de se obter um melhor desempenho. Dessa forma, segundo as características do serviço, diferentes protocolos de transporte podem ser utilizados.

Existem protocolos de transporte que não são orientados a conexão e conseqüentemente não garantem a entrega da informação no destino; esses protocolos são geralmente utilizado em serviços de tempo real como VoIP, algumas 
aplicações de vídeo ou em aplicações básicas de requisições e respostas como o Domain Name System (DNS). Dentro desses tipos de protocolos, o UDP é o mais utilizado. Por outro lado, existem protocolos orientados a conexão assegurando que toda a informação chegue ao ponto destino, na seqüência correta, por esse motivo a maior parte dos serviços de streaming de vídeo utiliza esse tipo protocolo. O TCP (Transmission Control Protocol) é o mais representativo dos protocolos do tipo orientado a conexão.

Dessa forma, dependendo do tipo de protocolo de transporte que está sendo utilizado, o serviço de streaming de vídeo pode apresentar diferentes tipos de degradações. Ao utilizar um protocolo não orientado à conexão (UDP), o vídeo no receptor, tem perda de informação ou apresenta algum ruído no sinal, mas as informações das seqüências de vídeo, mesmo degradadas, são apresentadas ao usuário de uma forma contínua. Essas degradações são ocasionadas devido a fatores como: perda de pacote, atraso e variação de atraso. Por outro lado, no caso do protocolo orientado a conexão (TCP), a principal degradação do sinal de vídeo que o usuário experimenta é o congelamento de uma imagem por um determinado período de tempo (pausa), sendo que durante esse período, nenhuma informação dinâmica do conteúdo de vídeo é apresentada ao usuário. Assim, pode-se dizer que o streaming de vídeo via um protocolo não orientado a conexão está mais relacionado às degradações espaciais, ou seja, existe uma degradação na imagem (quadros); e os que usam um protocolo orientado a conexão são mais afetados por degradações no domínio do tempo.

Em (PORTER; PENG, 2011) (MOK; CHAN; CHANG, 2011) encontramos os trabalhos mais importantes referente à métrica que avalia o cenário onde as degradações são as pausas, nos quais é apresentada a métrica pause intensity. Essa métrica é definida somente como o resultado da somatória dos produtos do número de pausas e a duração delas em um determinado período de tempo. Porém, essa métrica não considera a importância que a localização das pausas, no domínio do tempo, tem sobre a determinação da qualidade do vídeo; por exemplo, como podemos saber se uma pausa no início do vídeo tem um impacto mais negativo que uma pausa no meio ou final do vídeo. Cabe destacar que o número de trabalhos de pesquisa sobre esse tipo de métrica específica é limitado e foram publicados nos últimos três anos. Por ser um tópico de pesquisa atual e porque a maior parte dos serviços de streaming de vídeo utiliza o protocolo TCP, o presente trabalho foca na proposta de uma métrica para avaliação de QoE no serviço de streaming de vídeo sobre TCP, denominada eVsQM, do inglês, enhanced Video streaming Quality Metric. 
Os resultados de testes subjetivos são muito importantes, pois, baseado nos requisitos dos usuários são determinadas as melhoras de um produto (PARK; HAR, 2011), daí a importância do estudo dos métodos de avaliação de qualidade de vídeo. Atualmente, existem diversas metodologias de teste subjetivo para avaliar a qualidade do sinal do vídeo, sendo que cada um desses métodos foi elaborado considerando fatores de degradação de qualidade de vídeo específico. As metodologias existentes de avaliação de qualidade de vídeo de maior aceitação na literatura atual são descritas nas recomendações ITU-T P.910 (ITU-T R. P.910, 2008) e ITU-R BT-500.13 (ITU-T R. 500-13, 2012), ou outras metodologias como SAMVIQ descrita em (BLIN, 2006). Outro aspecto importante a considerar nos testes subjetivos é a variabilidade do conjunto de avaliadores, pois cada pessoa tem suas próprias características perceptivas, cognitivas e de preferência sobre determinados conteúdos de vídeo (ABRAHAO, 2009) (LAGHARI et al., 2011).

Os testes subjetivos presenciais demandam um alto custo nos recursos de ambiente de teste e principalmente períodos longos de tempo para sua execução. Por esse motivo, outra abordagem de avaliação de qualidade de vídeo utilizando usuários remotos, conectados na Internet vem sendo pesquisada atualmente. Em (XU; HUANG; YAO, 2012) (RIBEIRO; FLORENCIO; NASCIMENTO, 2011) esse método é utilizado para avaliar qualidade de imagens. Os trabalhos atuais utilizam, na maioria dos casos, soluções denominadas como Mechanical Turk, onde os usuários realizam tarefas em troca de uma compensação econômica, sendo que atualmente as ferramentas de maior aceitação são: Microworkers (MICROWORKERS, 2013) e Amazon Mechanical Turk (Mturk) (AMAZON, 2013).

A Qualidade da Experiência (LU et al., 2009) (ZAPATER; BRESSAN, 2007) (JAIN, 2004) pode ser definida como as características das sensações, percepções (HARMAN, 1990) e as opiniões de pessoas da forma que interagem com seus ambientes. Essas características podem ser boas ou ruins. Assim, QoE é o resultado final da interação das pessoas com tecnologias, no caso deste trabalho está relacionado somente com a qualidade de vídeo. O conceito de QoE é ampliado em (BAUER; PATRICK, 2004), no qual a QoE também é relacionada com fatores das necessidades humanas, como: segurança e custos dos serviços recebidos.

A solução DASH, do inglês Dynamic Adaptive Streaming over HTPP, é uma especificação técnica desenvolvida pela 3GPP e MPEG (3GPP TS 26.247, 2011) que permite ao usuário assistir durante uma mesma sessão de streaming de vídeo diferentes resoluções do mesmo vídeo, sendo que a seleção de uma determinada resolução depende das condições da rede no ponto do usuário. A especificação técnica sobre o DASH descreve que o terminal do usuário é capaz de capturar 
parâmetros da rede, os quais são empregados na determinação da qualidade do próximo segmento de vídeo. Assim, a solução DASH permite desenvolver diferentes aplicações no terminal do usuário, assim como também modelos de negócio para os provedores do serviço de streaming de vídeo.

Por outro lado, devido ao fato de que o DASH realiza mudanças na resolução do vídeo que dependem das condições da rede, é importante estudar os efeitos que o DASH pode causar na QoE do usuário, quando a rede apresenta flutuações de capacidade ou algum outro tipo de problema, de uma forma frequente. Nessas condições, o usuário pode experimentar varias mudanças de resolução em um curto período de tempo, as quais degradarão a QoE dele. Neste ponto, é relevante destacar a importância de que os algoritmos de controle do DASH devem considerar um limiar para as frequências de mudança de resolução. Também, deve-se considerar que se a capacidade da rede só permite a transmissão da mais baixa resolução do vídeo disponível no servidor, em um cenário de streaming de vídeo com a solução DASH, a QoE do usuário será afetada pelas mudanças de resolução e pelas pausas acontecidas durante a transmissão do vídeo.

\subsection{Objetivo}

A tese tem por objetivo principal propor uma métrica de qualidade de vídeo denominada eVsQM, para o serviço do streaming de vídeo que utiliza como protocolo de transporte o TCP. Destacando-se a importância de que a métrica eVsQM foi definida por uma formulação matemática baseada nos resultados de testes subjetivos. Isto é, a métrica eVsQM considera critérios dos processos perceptivos e cognitivos do ser humano, por exemplo, como a QoE do usuário do serviço de streaming de vídeo é degradada pelo número de pausas e sua localização temporal, assim como também pelo tipo de conteúdo de vídeo. Também, para cenários de streaming de vídeo que utilizam a solução DASH, é proposto um parâmetro denominado Fator de Degradação de Comutação (FDC), do inglês Switching Degradation Factor(SDF).

Os principais objetivos específicos da pesquisa são:

- Análise e críticas das metodologias existentes de avaliação subjetiva de qualidade de vídeo na avaliação vídeos com degradações temporais (pausas).

- Definição de recomendações práticas na execução de testes de avaliação subjetiva de vídeo sobre protocolos orientados a conexão, baseada nos critérios dos processos perceptivos e cognitivos do ser humano. 
- Demonstrar a efetividade e confiabilidade de métodos de avaliação de qualidade de vídeo por meio de usuários remotos conectados via internet.

- Estudo detalhado do comportamento da solução DASH em cenários nos quais a rede IP apresenta variações de capacidade de uma forma contínua. Assim, o parâmetro FDC formará parte do algoritmo de controle do DASH.

- Estudo referente à estimação da QoE do usuário de streaming de vídeo que utiliza a solução DASH, considerando que as degradações de qualidade correspondem às pausas e às mudanças de resolução.

\subsection{Estrutura da Tese}

Neste Capítulo, apresenta-se uma seção introdutória expondo o contexto e motivação da definição de métricas de qualidade de vídeo no serviço de streaming de vídeo.

O Capitulo 2 constitui uma revisão teórica dos tópicos: conceitos básicos envolvidos no serviço de streaming de vídeo, a codificação de vídeo, os processos perceptivos e cognitivos do ser humano.

Em seguida, no Capítulo 3 apresentam-se os trabalhos relacionados mais importantes na literatura atual.

A métrica eVsQM proposta é descrita no Capítulo 4. Nesse capítulo descrevese a metodologia empregada na definição dessa métrica, incluindo os métodos subjetivos de avaliação de qualidade de vídeo realizados e os cenários de teste utilizados para definir o modelo matemático da métrica. Também, são apresentados os resultados da validação da métrica eVsQM.

O Capítulo 5 apresenta um estudo de caso, o qual trata sobre os efeitos de mudanças de resolução de vídeo têm sobre a QoE do usuário que assiste um streaming de vídeo com a solução DASH. Também, neste capítulo é estudado como as mudanças de resolução de vídeo e as pausas degradam a QoE do usuário.

O Capitulo 6 encerra a tese apresentando as conclusões, contribuições, limitações deste trabalho e as sugestões para trabalhos futuros.

No Apêndice A são apresentadas as características básicas da anatomia e o funcionamento do Sistema Visual Humano. No Apêndice B é apresentado um estudo de caso, correspondente á avaliação da qualidade de vídeo no serviço de TV Digital. Por último, no Apêndice C é apresentada a definição e o código 
para obter os parâmetros de informação temporal e espacial para classificação de vídeos. 


\section{Revisão Teórica}

Neste capítulo serão abordados os tópicos sobre os aspectos técnicos de streaming de vídeo, os conceitos fundamentais de codificação de vídeo, os processos perceptivos e cognitivos do ser humano e sua relação com um ambiente de testes subjetivos para avaliação de qualidade de vídeo.

\subsection{Aspectos técnicos de streaming de vídeo}

Nesta seção serão abordados resumidamente, alguns exemplos de aplicações multimídia, os elementos que compõem um sistema de streaming de vídeo armazenado, os protocolos de transporte utilizados, as características de um codificador de vídeo e os fatores de degradação de qualidade de vídeo em uma rede IP.

\subsubsection{Aplicações Multimídia}

Atualmente existem diversas aplicações multimídia sobre a rede IP, e para cada uma dessas aplicações existem alguns requisitos a ser seguidos para obter uma qualidade de serviço aceitável para o usuário final. Algumas aplicações são altamente sensíveis a atraso, se esse atraso passa de certo limite de tolerância, os pacotes atrasados já são inúteis ao receptor. Por outro lado, algumas aplicações são mais tolerantes a perdas de pacotes (poucas), pois só causam pequenas perturbações na recepção do vídeo.

Entre os principais serviços multimídia temos:

- Streaming de vídeo armazenado, nesse tipo de serviço, os usuários fazem a requisição de vídeos os quais estão armazenados em servidores em um formato comprimido. As principais características desse serviço são:

- Mídia Armazenada, o conteúdo do vídeo foi pré-gravado e está armazenado em um servidor, dessa forma o usuário pode fazer pausa, voltar ou avançar durante a transmissão do vídeo. Para que se tenha um serviço 
adequado, a requisição do usuário e a execução da ação devem ocorrer em torno de 1 a 10 segundos (KUROSE; ROSS, 2004).

- Fluxo contínuo, o que comumente denominamos de streaming. O cliente reproduz uma parte do vídeo recebido alguns instantes antes, e ao mesmo tempo está recebendo do servidor partes do arquivo de vídeo que serão visualizadas depois. Assim se evita descarregar o arquivo inteiro para logo poder reproduzi-lo.

- Reprodução contínua, iniciada a reprodução do conteúdo do vídeo, ela deve prosseguir de acordo com a temporização original da gravação. Assim, os dados são recebidos a tempo para ser reproduzidos, caso contrario podem existir atrasos no buffer e conseqüentemente a possibilidade de acontecer pausas.

- Streaming de vídeo e áudio ao vivo, esse tipo de aplicação é análoga a uma transmissão de radio e televisão, só que nesse caso a transmissão é realizada pela Internet. Como a informação transmitida não é armazenada, o cliente não pode adiantar o programa que está recebendo, mas como existe um armazenamento local no dispositivo do cliente, sim é possível retroceder ou pausar o vídeo. Exemplos dessa aplicação são, radio por Internet e IPTV. Atrasos de até dezenas de segundos desde a requisição de um vídeo até o início da reprodução podem ser tolerados.

- Áudio e Vídeo interativos em tempo real. Essas aplicações permitem que os usuários possam utilizar áudio e vídeo para se comunicar em tempo real. O áudio interativo pela Internet é conhecido como telefone por Internet e as comunicações com vídeo são chamadas de videoconferências. No caso de chamadas de voz, os atrasos menores a 150 milissegundos não são percebidos pelo ouvido humano, os atrasos entre 150 e 400 milissegundos podem ser aceitáveis e os atrasos que excedem os 400 milissegundos podem ser inteligíveis (KUROSE; ROSS, 2004).

\subsubsection{Elementos e funcionamento de um streaming de vídeo armazenado}

Um serviço de streaming de vídeo está composto principalmente pelos elementos apresentados na Figura 2.1.

Nesta figura podemos observar que os vídeos armazenados residem no mesmo servidor Web. Essa configuração é a mais básica, mas muitos serviços possuem 


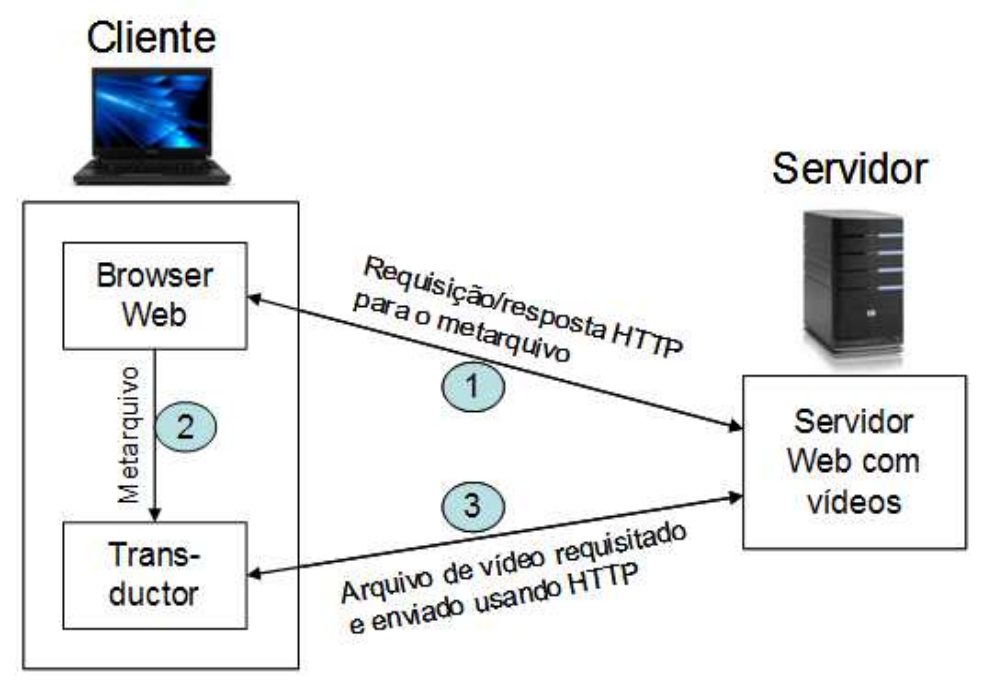

Figura 2.1: Elementos que compõem o serviço de streaming de vídeo. Adaptado de (KUROSE; ROSS, 2004)

uma arquitetura de rede com dois servidores, um servidor Web e outro especializado no streaming de vídeo. No lado do usuário, o dispositivo consta de:

- Cliente Web ou browser, por meio do qual requisitam o vídeo.

- Transdutor, o qual desempenha duas principais funções (KUROSE; ROSS, 2004):

- A descompressão do vídeo enquanto são reproduzidos, já que no servidor os vídeos são armazenados comprimidos.

- Eliminação da variação de atraso, devido ao fato de que o vídeo deve ser reproduzido à mesma taxa do que foi gravado, o receptor coloca os pacotes recebidos em um buffer durante um curto período de tempo para eliminar tal variação.

A seqüência de passos para estabelecer o funcionamento de um streaming de vídeo, nesse caso utilizando HTTP/TCP, e considerando a arquitetura de um servidor Web com vídeos é descrita a seguir:

- O usuário clica em um hiperlink de um arquivo de vídeo, o qual não aponta para um arquivo de vídeo, mas para um metarquivo que contem o URL do arquivo de vídeo. O metarquivo, o qual está encapsulado na mensagem HTTP de resposta, contém uma linha de cabeçalho de tipo de conteúdo, que indica a aplicação de vídeo específica.

- O browser no cliente examina a linha de cabeçalho de tipo de conteúdo (resposta HTTP), e envia o metarquivo para o transdutor. 
- O transdutor estabelece uma conexão TCP diretamente com o servidor HTTP e envia uma mensagem de requisição HTTP do arquivo de vídeo, ao que o servidor responde com o arquivo de vídeo. Por fim, o transdutor exibe o streaming de vídeo.

Adicionalmente, para permitir que um usuário controle a reprodução do streaming de vídeo, ou seja, adiante, retroceda ou pause durante a transmissão de um vídeo é necessário um protocolo para trocar informações de controle de reprodução. O RTSP (Real Time Streaming Protocol) definido na RFC 2326 realiza essa função de controle. O RTSP pode ser utilizado independentemente do protocolo de transporte utilizado (TCP ou UDP). As mensagens RTSP são enviadas fora de banda, isto é não são enviadas na mesma porta que o fluxo das seqüências de vídeo.

\subsubsection{Protocolo de Transporte e as degradações no strea- ming de vídeo}

Como explicado anteriormente, no serviço de streaming de vídeo o cliente solicita arquivos de vídeo comprimidos que residem em servidores. Como resposta a essa requisição, o servidor envia ao cliente o arquivo de vídeo por uma porta. Essa porta pode corresponder tanto a protocolos orientados a conexão ou a protocolos não orientados a conexão, usaremos como referencia o TCP e UDP respectivamente, por ser os mais utilizados.

O protocolo TCP é orientado a conexão assegurando que toda a informação chegue ao ponto destino, na seqüência correta, por esse motivo a maior parte dos serviços de streaming de vídeo utiliza esse protocolo já que os quadros do vídeo são apresentados na sua totalidade. Por outro lado o protocolo UDP é um protocolo não orientado a conexão e conseqüentemente não garante a entrega da informação no destino, por tal motivo há uma falta de informação nos quadros da seqüência de vídeo.

O uso de um determinado protocolo de transporte para o envio do vídeo nesse tipo de serviço origina diferentes degradações do vídeo no receptor, quando a rede apresenta algum problema, por exemplo, de capacidade (largura de banda) ou perda de pacotes. No caso do TCP, a degradação principal no receptor é o congelamento de uma imagem por um período de tempo (pausa), o usuário não recebe novos quadros do vídeo durante o período da pausa. Para o caso do protocolo UDP, os problemas da rede se manifestam como um tipo de ruído na seqüência do vídeo, mas essas são apresentadas continuamente ao cliente. 
Assim, pode-se dizer que o streaming de vídeo via UDP está mais relacionado às degradações espaciais, ou seja, existe uma degradação na imagem (quadros); e o streaming que usa o protocolo TCP é mais afetado por degradações no domínio do tempo (pausas). A Figura 2.2 ilustra esses dois tipos de degradações.

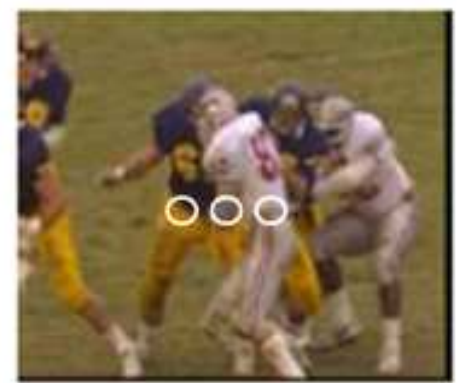

(a)

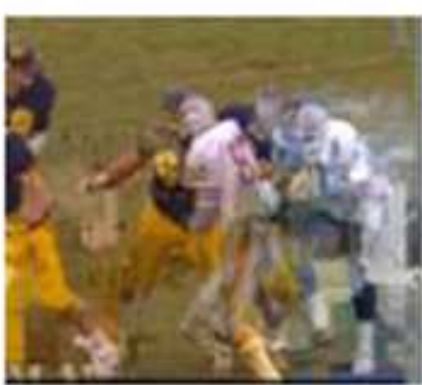

(b)

Figura 2.2: Degradações no streaming de vídeo devido ao protocolo de transporte: (a) Protocolo TCP. (b) Protocolo UDP em um cenário com perda de pacotes.

É importante destacar que atualmente a maior parte do tráfego de streaming de vídeo é transportada utilizando o TCP. Isto acontece devido ao fato que administradores de rede configuram os Firewalls para bloquear o trafego UDP.

No caso do protocolo TCP, o buffer do transdutor pode passar por diferentes estados dependendo da relação da taxa da rede e a taxa com a qual o vídeo é apresentado ao usuário. Em seguida, é descrito o comportamento do buffer e a relação com as pausas.

As pausas são originadas por diversos problemas na rede IP, como: capacidade de largura de banda, perdas de pacotes, atrasos, congestionamento nos elementos da rede. Quando o TCP detecta perdas de pacotes, o algoritmo de congestionamento (do TCP) reduz o tamanho da janela e, conseqüentemente, o TCP diminui a taxa de transferência e se essa nova taxa é menor do que a taxa de reprodução do player será utilizada toda a informação do buffer e depois disso ele irá entrar em um processo de rebuffering. A Figura 2.3 apresenta os diferentes estados do transdutor de vídeo (player), os quais são descritos em seguida.

- Buffer inicial: é o período de tempo para armazenamento mínimo da informação a ser mostrada no início do vídeo. Esse parâmetro é configurável, assim, para redes rápidas podem ser períodos curtos, por exemplo, dois segundos. Para redes de baixa taxa de transmissão devem ser tempos maiores como de cinco segundos. 


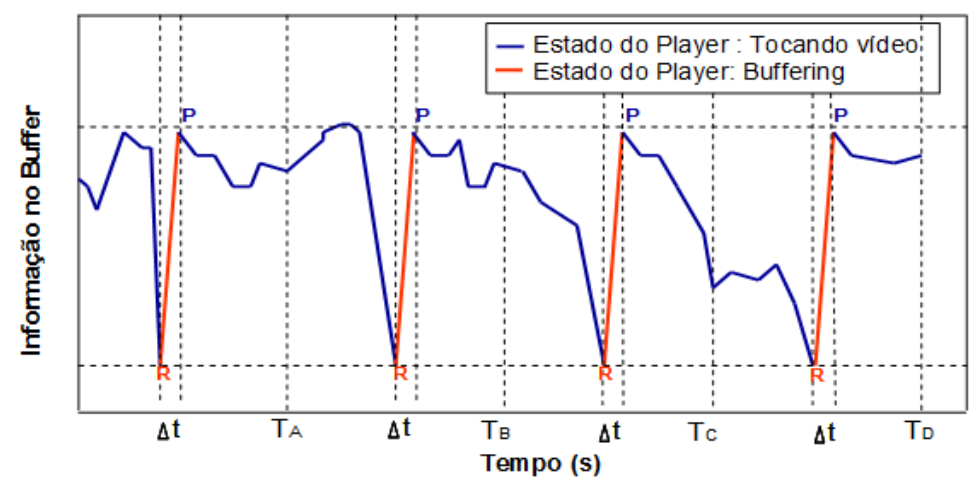

Figura 2.3: Estados de um Buffer.

$\quad$ Serviços
Streaming de
Vídeo (protocolo
não orientado a
conexão; exemplo
UDP).
Streaming de
Vídeo (protocolo
orientado a
conexão; exemplo
TCP)
IPTV (protocolo
não orientado a
conexão; exemplo
UDP).
Vídeo Conferência
(protocolo não
orientado a
conexão; exemplo
UDP)

\begin{tabular}{|c|c|}
\hline $\begin{array}{c}\text { Problemas na } \\
\text { rede }\end{array}$ & $\begin{array}{l}\text { Parâmetros } \\
\text { mesuráveis }\end{array}$ \\
\hline $\begin{array}{l}\text { Congestão na rede (falta de } \\
\text { capacidade), sobrecarga nos } \\
\text { roteadores, perda no canal } \\
\text { de transmissão. }\end{array}$ & $\begin{array}{l}\text { Taxa de transmissão, } \\
\text { perda de pacotes, atraso } \\
\text { fim a fim, e variação de } \\
\text { atraso. }\end{array}$ \\
\hline $\begin{array}{l}\text { Congestão na rede (falta de } \\
\text { capacidade), sobrecarga nos } \\
\text { roteadores, perda no canal } \\
\text { de transmissão. }\end{array}$ & $\begin{array}{l}\text { Pausa, número de } \\
\text { pausas, localização } \\
\text { temporal das pausas. } \\
\text { (No transdutor do } \\
\text { dispositivo do usuário). }\end{array}$ \\
\hline $\begin{array}{l}\text { Congestão na rede (falta de } \\
\text { capacidade), sobrecarga nos } \\
\text { roteadores, perda no canal } \\
\text { de transmissão. }\end{array}$ & $\begin{array}{l}\text { Taxa de transmissão, } \\
\text { perda de pacotes, atraso } \\
\text { fim a fim, e variação de } \\
\text { atraso. }\end{array}$ \\
\hline $\begin{array}{l}\text { Congestão na rede (falta de } \\
\text { capacidade), sobrecarga nos } \\
\text { roteadores, perda no canal } \\
\text { de transmissão. }\end{array}$ & $\begin{array}{l}\text { Taxa de transmissão, } \\
\text { perda de pacotes, atraso } \\
\text { fim a fim, e variação de } \\
\text { atraso }\end{array}$ \\
\hline
\end{tabular}

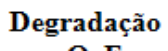

Degradação espacial (perda de informação nos quadros)

Degradação temporal (congelamento de imagem)

\section{Degradação espacial (perda de informação nos quadros), chaveamento do canal. Degradação espacial (perda de informação nos quadros); latência}

Figura 2.4: Tipos de degradações nos serviços de Vídeo e sua relação com a QoE.

- Período de reprodução do vídeo, o vídeo é apresentado de forma contínua sem interrupções e sem perda de informação, devido a que é utilizado o protocolo TCP que garante a entrega da informação.

- Período de rebuffering, no qual o buffer não tem um mínimo de informação para ser apresentada, nesse período se armazena informação para logo ser novamente apresentada.

Em seguida, na Figura 2.4 são apresentados os principais serviços de vídeo na Internet, indicando-se os possíveis problemas que causam as degradações, os parâmetros que podem ser medidos e como a QoE do usuário é afetado. 


\subsubsection{Codificação de Vídeo}

Frente à grande demanda dos serviços de vídeo nos últimos anos, o estudo e melhoramento das técnicas de compressão do sinal do vídeo são de suma importância. Os codificadores de vídeo realizam a compressão de sinais de vídeo (ORTEGA; RAMCHANDRAN, 2008), considerando-se de forma geral os critérios de maior compressão possível e a menor perda da informação no processo da codificação, com o intuito que na reconstrução do sinal a qualidade seja mantida.

A codificação de vídeo pode ser utilizada principalmente para armazenamento e transmissão do sinal do vídeo. Atualmente, a maioria das técnicas de compressão de vídeo são focadas ao serviço de broadcasting. Nesse tipo de serviço existe um codificador de alta complexidade, geralmente no lado do servidor de vídeo, e vários codificadores de menor complexidade no lado do usuário final. Essa complexidade é devido a que tipicamente, o codificador precisa de uma demanda de operações computacionais maiores que o decodificador (WIEGAND et al., 2003), devido principalmente à função de estimação de movimento. Portanto, eles são adequados em aplicações de vídeo, como o streaming de vídeo, no qual a codificação é realizada apenas uma vez e a decodificação é feita várias vezes.

O vídeo analógico é um sinal contínuo, o qual ao ser amostrado no domínio do espaço e do tempo resulta no vídeo digital. Assim, o vídeo digitalizado tem uma estrutura tridimensional, da seguinte forma: duas dimensões no domínio espacial (eixos horizontal e vertical) e uma terceira dimensão no domínio do tempo. A unidade mínima de representação no domínio do espaço é denominada como pixel, o qual possui as informações de brilho (luminância) e de cor (crominância), no que se fundamenta o sistema de transmissão de cores YUV (PRATT, 2001).

O Padrão YUV é um modelo de representação da cor em termos de um componente de luminância e dois de crominância. Esse padrão é utilizado em sinais de vídeo analógico. O componente Y representa a luminosidade (o brilho), e os componentes: U e V representam a cor da imagem. Especificamente, U é a diferença entre a cor azul e a luminância, e V é a diferencia entre a cor vermelha e a luminância, pelo que também o padrão YUV é conhecido como YCbCr. A Figura 2.5 apresenta a imagem com os seus três componentes (YUV) assim como também as imagens correspondentes a cada componente.

No domínio do tempo, uma amostra do sinal de vídeo é denominada como quadro, da palavra inglesa frame. Onde cada quadro representa toda informação em um instante, ou seja, o conjunto de todos os pixels correspondentes a um 


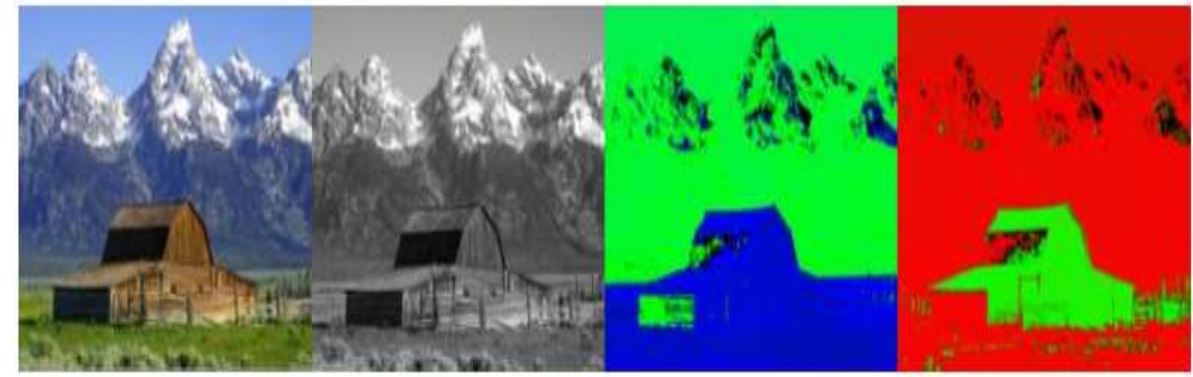

Figura 2.5: Imagem YUV e imagens de cada um dos seus componentes.

único instante de tempo.

Por outro lado, o conceito de resolução de um vídeo é definido tanto ao domínio espacial e temporal. A resolução espacial se refere ao número de pixels em cada quadro, e a resolução temporal refere-se ao número de quadros em um segundo. A Figura 2.6 ilustra o conceito de pixel e quadro no domínio espacial e temporal respectivamente.

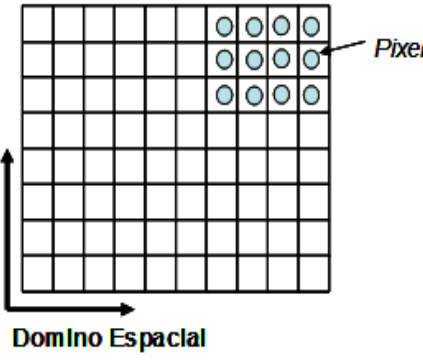

(a)

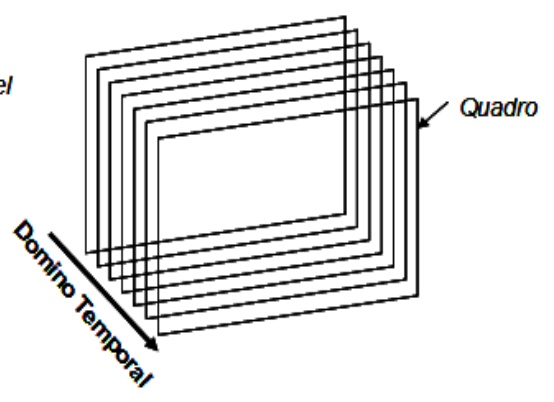

(b)

Figura 2.6: Elementos do vídeo digital: (a) no domínio espacial: pixel e (b) no domínio do tempo: quadro.

De uma forma geral, os codificadores de vídeo podem ser classificados em dois grupos: os codificadores sem perda (lossless code) e os codificadores com perdas (lossy code), os quais são explicados brevemente a seguir:

- Codificadores de vídeo sem perdas: também recebem o nome de compactadores, a característica principal deles é diminuir o tamanho de um arquivo sem alterar a qualidade do vídeo, conseguindo no processo de decodificação um vídeo de alta qualidade. Entre as técnicas de codificação sem perda, temos como a mais importante o codificador de Huffman. A eficiência na compressão do arquivo de vídeo é de duas a três vezes menores em relação do original. 
- Codificadores de vídeo com perdas: com respeito à compressão do vídeo, esse tipo de codificadores pode chegar a comprimir até 300 vezes. Porém, o arquivo codificado apresenta degradações na qualidade de vídeo, sendo que não é possível obter exatamente o mesmo arquivo utilizado na entrada do processo de codificação. Atualmente, o codificador com perda de maior aceitação é o especificado na recomendação H.264/AVC (ITU-T H.264, ).

\subsubsection{Codificador de Vídeo ITU-T H.264}

O padrão de codificação H.264 foi definido em 2003, como resultado de um projeto conjunto entre o Video Coding Experts Group (VCEG) da International Telecommunication Union (ITU) e o Moving Picture Experts Group (MPEG) da International Organization for Standardization / International Electrotechnical Commission (ISO/IEC). A parceria desses dois grupos é conhecida por Joint Video Team (JVT). Atualmente o codificador mais utilizado para gravação, compressão, codificação e distribuição de vídeo em alta definição é o H.264 (MPEG4 v.10), o qual foi desenvolvido para melhorar em alguns aspectos os padrões anteriores de codificação de vídeo, como o MPEG-2. Essas melhorias que o codificador H.264 oferece são:

- Melhor eficiência na compressão de vídeo; reduzindo a taxa de bits (ou tamanho do arquivo), 50\% em relação aos padrões anteriores;

- Manter a qualidade do sinal de vídeo no processo de decodificação;

- Maior flexibilidade na compressão, transmissão e armazenamento de vídeo;

- Robustez de erro, com tolerância a erros de transmissão;

- Processo de decodificação com maior grau de exatidão, evitando acúmulos de erros;

- Compatibilidade com vídeos de alta e baixa resolução;

O H.264 oferece suporte a uma ampla gama de aplicações com diferentes necessidades na taxa de transmissão de bits. Por exemplo, para serviços de telecomunicações pode fornecer um desempenho abaixo de 1Mbit/s mas com uma baixa latência. Entretanto, para serviços de transmissão de vídeo que não são em tempo real, o H.264 pode fornecer um desempenho entre 1 a $10 \mathrm{Mbit} / \mathrm{s}$ com alta latência. Assim, entre as principais aplicações, nas quais pode ser empregado 
o codificador H.264, tem-se: videoconferência, transmissão de sinal de televisão, streaming de vídeo e armazenamento de dados.

Por outro lado é importante destacar que o grupo JVT está encarregado da padronização de um novo codificador de vídeo denominado High Efficiency Video Coding (HEVC). O objetivo desse novo padrão de codificador de vídeo é duplicar a eficiência de compressão conservando a mesma qualidade do vídeo recuperado no processo de decodificação. Essa melhoria da eficiência de compressão ocorre com o decorrer do tempo, assim o codificador H.264 substituiu o codificador MPEG-2 (ITU-T H.263). A Figura 2.7 adaptada de (Ericsson, 2012) apresenta a evolução da eficiência da compressão dos codificadores nos últimos 20 anos.

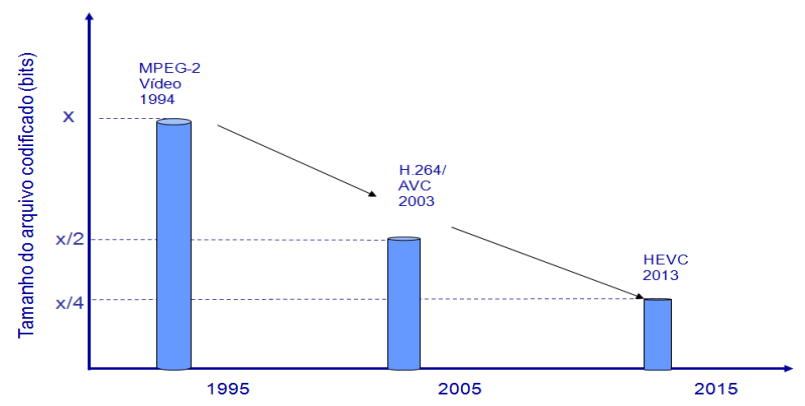

Figura 2.7: Evolução da eficiência na compressão dos codificadores de vídeo. Adaptada de (Ericsson, 2012).

\subsubsection{Principais fatores de degradação de Qualidade em uma Rede IP}

Os principais fatores de degradação de qualidade nos serviços multimídia são descritos em seguida:

- Taxa de perda de pacotes - PLR: está representada pelo número de pacotes que foram transmitidos pela rede, mas não alcançaram seu destino em um determinado tempo.

- Atraso ponto a ponto - PDT: é definido pelo tempo que uma mensagem demora em chegar desde o ponto de origem até o ponto destino, esse atraso é devido a diversos fatores como: o algoritmo de codificação, o meio de transmissão e o atraso de filas em roteadores.

- Variação de Atrasos (Jitter) - PDV: chamado de jitter é definido em (ITU$\mathrm{T}$ 1540, ) como o intervalo entre a chegada de dois pacotes consecutivos em relação ao intervalo de sua transmissão. Ele é baseado na medição 
do atraso fim a fim e é definido para pares consecutivos de pacotes. Em uma rede de transmissão de pacotes é necessário programar algoritmos de controle para diminuir a variação de atrasos e conseqüentemente melhorar o nível de satisfação do usuário final, como os algoritmos apresentados em (JAGADISH; MANIVASAKAN, 2011) e (CHEN; LIN; WEI, 2009).

\subsection{Processos Perceptivos e Cognitivos}

Os seres humanos possuem cinco sistemas de sentido: visão, audição, olfato, gustação e tato, dos quais o sistema da visão é o que proporciona maior informação em relação aos outros sentidos, conseqüentemente o ser humano é mais dependente desse sentido em relação aos outros. No Apêndice A, do presente trabalho, são descritas a anatomia e o funcionamento do sistema visual humano. Em seguida são descritos os principais conceitos dos processos perceptivos e cognitivos do ser humano.

A percepção é um conjunto de processos pelos quais recebemos, reconhecemos, organizamos e entendemos as sensações recebidas dos estímulos ambientais. As modalidades perceptivas geralmente são classificadas de acordo com os nossos cinco sentidos.

Para o caso desse trabalho, no qual o foco principal é a avaliação da qualidade de diferentes seqüências de vídeo, a modalidade perceptiva de interesse é a visão. Nessa linha, será descrita brevemente a abordagem da psicologia da Gestalt (GINGER; GINGER, 1995), a qual considera que o todo não é mais um elemento que se adiciona. Suas propriedades são emergentes, não existindo nas partes de forma individual. Essas propriedades decorrem das relações estabelecidas entre suas partes constitutivas, onde cada parte depende das demais (ALVAREZ; COELHO, 2006).

Os princípios da percepção na teoria de Gestalt são os seguintes:

- Figura - fundo: Quando se percebe um campo visual, alguns objetos tomam um primeiro plano e outros objetos do campo visual são relegados a um segundo plano.

- Proximidade: Ao perceber um arranjo de objetos (no sentido de figuras), tendemos a ver os objetos que estão próximos como formando um grupo.

- Similaridade: Por este princípio, nós tendemos a agrupar objetos com base em sua similaridade no domínio do espaço. 
- Acabamento: Tendemos a completar perceptivamente os objetos que não estão totalmente completos na sua estrutura.

- Simetria: Cujo conceito se baseia na tendência de perceber os objetos como formadores de imagem espalhadas em torno de seu centro.

- Continuidade: Quando tendemos a perceber objetos ou formas contínuas em vez de formas isoladas e desarticuladas.

É importante destacar que o conceito de similaridade foi aplicado para criar uma métrica objetiva de avaliação de qualidade de vídeo denominada como SSIM, do inglês Structural Similarity, tratada na seção 3.1.1.1. Assim também poderia ser estudado como cada um ou vários desses conceitos podem ser úteis no estabelecimento de uma nova métrica.

A cognição humana é um conjunto de processos mentais que permite às pessoas buscar, tratar, armazenar e utilizar diferentes tipos de informações do ambiente. É a partir dos processos cognitivos que o individuo adquire e produz conhecimento.

Os processos perceptivos e cognitivos são divididos para um melhor entendimento, mas esses processos ocorrem de uma forma contínua; cada estímulo proveniente do meio ambiente apresenta uma série de características como: cor, textura, tamanho, forma, brilho, movimento os quais são captadas pelos nossos sentidos, denominando-se esse processo como processos sensoriais de baixo nível (low sensory process). Essas informações são transformadas em estímulos eletroquímicos, transmitidas a nosso sistema nervo central e interpretadas, organizadas, armazenadas e evocadas. Esses tratamentos ocorrem por diferentes processos cognitivos, como: memória, categorização, atenção, resolução de problemas e processos decisórios que fornecem indicadores para ação. A Figura 2.8 ilustra como as características sensoriais de um objeto se convertem em uma imagem. Assim podemos afirmar que a figura da rosa só é uma rosa quando a informação sensorial é traduzida no córtex cerebral pelo que comumente denominamos rosa, ou flor (ABRAHAO, 2009).

Por essa razão não é adequado considerar unicamente os processos sensoriais de baixo nível para determinar a qualidade perceptual do vídeo (NYMAN et al., 2006), (NYMAN RADUN; VUORI, 2005); para essa tarefa têm que ser considerados aspectos adicionais como as características individuais dos avaliadores, como por exemplo: idade, experiência em uso de tecnologia, utilização previa de serviços de vídeo, entre outros. 


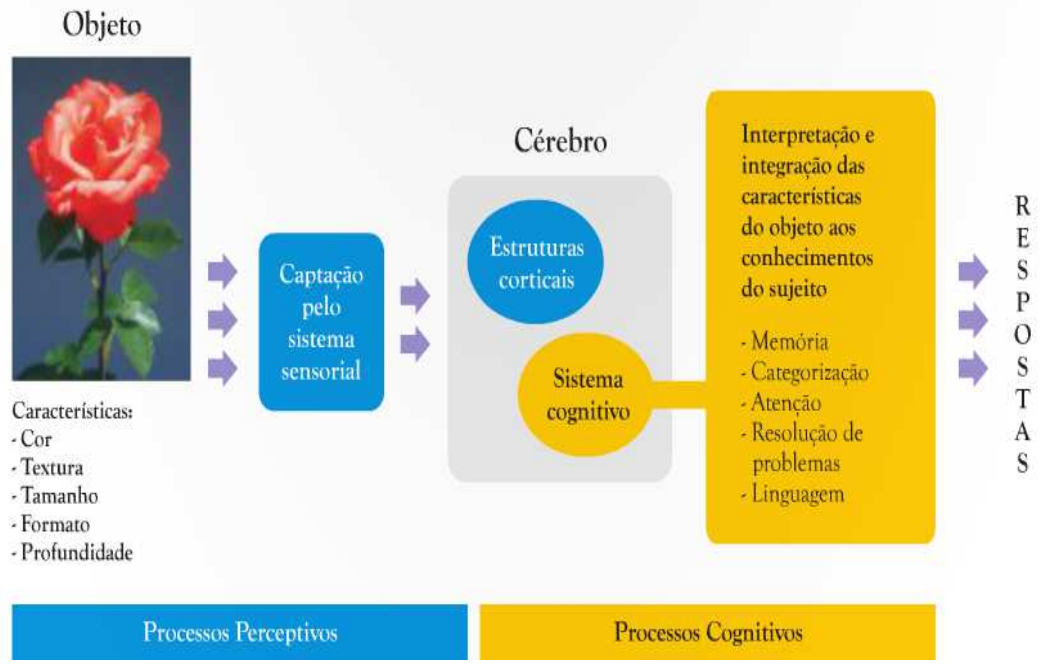

Figura 2.8: Processos Perceptivos e Cognitivos (ABRAHAO, 2009).

Como mencionado anteriormente, existem diversos processos cognitivos, dos quais serão tratados brevemente: a atenção e a memória, pois esses processos estão mais relacionados com um ambiente de teste de avaliação subjetiva de qualidade de vídeo.

\subsubsection{O Processo de Atenção}

Segundo (STERNBERG, 2000) a atenção ativa os processos cognitivos de maneira a processar as informações provenientes dos sentidos ou as informações armazenadas na memória. O ser humano com a capacidade de atenção é capaz de manter presente o objetivo, os dados necessários e as estratégias do processamento para alcançar o objetivo final, que no caso dos testes subjetivos é outorgar uma pontuação ao vídeo avaliado.

A solicitação da atenção está relacionada à quantidade de estímulos diferentes presentes nas diversas situações. Nesse sentido, seria inviável para o ser humano processar cada um dos inúmeros elementos do contexto. Assim, o objetivo das teorias sobre a atenção é explicar como o ser humano processa determinadas informações, privilegiando somente algumas delas, e avaliando as conseqüências do desempenho em determinadas tarefas (ABRAHAO, 2009).

Os processos envolvidos na atenção não ocorrem sob nosso controle total; muitas vezes, prestamos atenção em estímulos que não temos interesse, sem obedecer a nossa vontade. É possível, até certo ponto, controlar o foco de nossa atenção para estímulos e contextos específicos, filtrando as informações irrelevantes para execução de determinada tarefa. Por outro lado, devemos considerar que, o ser 
humano tem capacidades limitadas na percepção, ou seja, na capacidade de captura dos dados no ambiente e também na cognição, referida a capacidade de tratamento e armazenamento das informações. Um exemplo claro dessa limitação de capacidade é a dificuldade que temos na execução de diferentes tarefas ao mesmo tempo, por mais simples que elas sejam. Essa dificuldade está associada ao processo cognitivo da atenção e como ele influencia em nossas ações.

A atenção pode ser classificada em:

- Seletiva, na qual existe uma escolha de atenção, enfatizando ou ignorando certos estímulos.

- Vigilância, caracterizada pela espera passiva por estímulos do ambiente ou contexto em uma situação determinada.

- Sondagem, a qual se caracteriza pela busca ativa de sinais e estímulos do ambiente ou contexto.

- Dividida, onde a atenção, ou os recursos dessa, são alocados a mais de um estímulo ou tarefa.

É importante destacar que na realização de testes de avaliação subjetiva de vídeo, a atenção dos avaliadores é predominantemente seletiva, pelo fato do estímulo principal ser os vídeos assistidos. O ambiente de teste deve ser adequado para não ter outros estímulos externos (distúrbios) como ruídos sonoros e visuais que podem interferir na atenção dos avaliadores.

Segundo (NEWELL; SIMON, 1972) os processos decisórios estão fundamentados principalmente na atenção e na memória de trabalho. Esses processos decisórios em um ambiente de teste de avaliação subjetiva estão relacionados com o fato de outorgar uma pontuação aos vídeos.

\subsubsection{A Memória}

O ser humano é capaz de realizar uma variedade de operações pelo fato de possuir memória. De um lado, a memória humana nos permite identificar e classificar sons, sinais, cheiros, gostos e sensações. De outro lado, ela é capaz de reter e manipular informações que adquirimos durante nossas vidas (DIVINO; FAIGLE, 2004).

A memória como processo cognitivo, não se refere exclusivamente ao armazenamento de informações. Existem três processos ou operações da memória: 
- Codificação: Para que a informação seja armazenada em nossa memória, primeiro essa informação tem que ser codificada como um fato, ou seja, realiza uma associação de significando a um padrão sensorial.

- Armazenamento: A informação já codificada é alocada na memória. Essa informação pode ser retida por alguns segundos ou minutos, para que essas sejam utilizadas, descartadas ou organizadas para serem armazenadas.

- Evocação: A informação armazenada é evocada de uma maneira apropriada em um contexto específico.

Os estudos sobre a memória visam entender como o conhecimento é mantido, recuperado e transformado. Um dos primeiros modelos sobre a memória foi apresentado em (STERNBERG, 2000), no qual é definida a estrutura da memória em três níveis:

- Memória Sensorial: a qual é responsável pela manutenção, em curtíssimo período de tempo, dos estímulos captados pelos órgãos sensoriais.

- Memória de Curto Prazo: manutenção de estímulos relevantes por um período de curto tempo.

- Memória de Longo Prazo: no qual as informações são armazenadas sem uma limitação temporal.

$\mathrm{Na}$ atualidade, existem outros modelos de uma maior aceitação, nos quais a memória é constituída por: memória de trabalho e memória de longo prazo. Onde a memória de trabalho funciona como um gestor de memória e as informações recuperadas são reconstruídas a partir das informações que se encontram na memória de longo prazo (ANDERSON, 2000).

Em um ambiente de testes de avaliação subjetiva de vídeo a memória dos avaliadores também pode ser considerada com um fator importante, devido a que os avaliadores evocam situações ou experiências nas quais eles já assistiram aos vídeos. Assim, por exemplo, no caso específico do serviço do streaming de vídeo via internet, eles retiveram na memória que se acontecem muitas pausas no início do vídeo, o mais provável é que durante todo o vídeo essas pausas continuem acontecendo.

Por outro lado, ao assistir um determinado conteúdo de vídeo, esse conteúdo é associado com as preferências individuais de cada pessoa, isso pode determinar 
certo grau de atenção para cada tipo de conteúdo de vídeo. Como a preferência sobre um conteúdo de vídeo afeta a QoE do usuário/avaliador é tratado em seguida.

\subsubsection{Preferência do usuário no Conteúdo de Vídeo}

A percepção e cognição humana são complexas e envolvem muitos processos. Nos testes subjetivos de avaliação de qualidade de vídeo, os avaliadores têm características individuais diferentes, as quais podem ser, por exemplo: conhecimentos prévios (como conhecimento em tecnologia), atitudes, expectativas e emoções, sendo que cada um dessas características individuas podem determinar diferentes níveis de qualidade de experiência ao avaliar um vídeo (OATLEY; JENKINS, 2003), (SILVA; BRADSHAW, 2006) (RODRIGUEZ et al., 2012a).

As diferentes características de cada um dos avaliadores são denominadas de variabilidade interindividual. Para o caso dos testes subjetivos dos serviços de vídeo e em geral de multimídia, a variabilidade interindividual deve ser considerada. Ou seja, os perfis dos usuários devem ser analisados, isso facilitaria a interpretação e acurácia dos resultados dos testes.

A abordagem da preferência do usuário sobre um determinado tipo de conteúdo de vídeo e sua relação com a qualidade de experiência que recebe durante a transmissão do vídeo, não foram consideradas nas recomendações existentes na área de avaliação de qualidade de vídeo.

Quando um usuário tem preferência explicita sobre um determinado conteúdo de vídeo, o usuário fica mais motivado a assistir vídeos de sua preferência. Se, durante a transmissão do vídeo existem degradações na qualidade do sinal do vídeo, essas degradações por mínimas que sejam, podem afetar grandemente a QoE desse usuário. Por outro lado, se o usuário assiste um vídeo no qual não tem interesse (ou pouco interesse), as mesmas degradações não afetam muito a QoE. Isso poderia ser explicado, devido a que o grau de atenção do usuário em cada um desses dois casos é diferente.

Neste trabalho, propõe-se quantificar, através de testes subjetivos, como o conteúdo do vídeo está relacionado com a QoE do usuário.

Por outro lado, o tipo de conteúdo de vídeo, desde o ponto de vista de mobilidade espacial nos quadros (informação espacial) do vídeo codificado, também é considerado como um fator de influencia na qualidade do vídeo, como é apresentado em (KORHONEN; YOU, 2010). Em (HAM; KIM; CHOI, 2012) 
se usa o termo de Preferência de usuário para indicar as preferências de: acesso de rede, custo e qualidade de serviço. Porém, a preferência por um conteúdo de vídeo não é referenciado.

\subsection{Efeito das pausas de um vídeo na capaci- dade da atenção}

Nesta seção o objetivo principal é estudar como os conceitos que integram os mecanismos dos processos perceptivos e cognitivos devem ser relacionados com um ambiente de teste de avaliação subjetiva de vídeo, o qual será mais focado para o serviço de streaming de vídeo transmitido via HTTP/TCP. Principalmente, será tratado como os distúrbios durante a transmissão de um vídeo sobre TCP afetam a atenção do avaliador e conseqüentemente no seu nível de satisfação.

O ambiente de teste de avaliação subjetiva de vídeo considerado nesta seção está limitado para o serviço de vídeo streaming transmitido via TCP. Nesse serviço, como será tratado na seção 4.2, os principais fatores de degradação na qualidade de experiência do avaliador são: a pausa, sua duração, freqüência (número de pausas em um determinado período de tempo) e localização temporal de cada pausa.

Durante o período no qual o buffer não tem mais informação e começa a carregar até um mínimo de informação, nenhuma seqüência de vídeo é exibida, originando um período onde a imagem fica congelada (pausa), as quais degradam a QoE do usuário final, devido a que as pausas perturbam os mecanismos dos processos cognitivos relacionados á atenção do usuário que assiste a um vídeo. Assim, a atenção e o interesse pelo vídeo podem diminuir na medida da freqüência das pausas e sua duração, sendo também considerado o parâmetro de localização temporal de cada pausa. Esse ultimo parâmetro nos indica que as pausas no início, na parte intermédia ou no final do vídeo não tem o mesmo peso na degradação da QoE do usuário final. 


\section{Trabalhos Relacionados}

Na literatura é possível encontrar uma vasta quantidade de trabalhos acadêmicos referentes à avaliação de qualidade de vídeo nos serviços de streaming de vídeo. O objetivo deste capítulo consiste na análise de trabalhos encontrados na literatura, nos últimos 10 anos, nos quais são definidas métricas de avaliação de qualidade de vídeo considerando aspectos específicos de degradação.

\subsection{Métodos de Avaliação de Qualidade de Vídeo}

Os serviços de telecomunicações nos quais é utilizada uma transmissão de vídeo estão sujeitas a diferentes tipos de degradação, com a finalidade de que o usuário perceba uma qualidade de vídeo aceitável, o estudo de métodos de avaliação de qualidade de vídeo é de muita importância. De forma geral, os métodos de avaliação de vídeo podem ser classificados em dois grupos: métodos subjetivos e métodos objetivos.

Em seguida, serão descritos os diferentes métodos de avaliação de qualidade de vídeo, apresentando-se uma classificação e uma breve descrição de cada método.

\subsubsection{Classificação dos Métodos de Avaliação de Vídeo}

Existem diferentes critérios para classificar os métodos de avaliação de qualidade de vídeo, dependendo do tipo de informação avaliada, da forma como são realizados os testes de avaliação, os que serão tratados nesta seção. A partir de cada um desses métodos são definidas diferentes métricas de avaliação de qualidade, as quais têm uma escala própria de avaliação.

Os métodos de avaliação de vídeo podem ser classificados considerando diferentes critérios. No caso de se utilizar a pontuação outorgada por uma pessoa ou a pontuação obtida por um algoritmo, o método de avaliação pode ser considerado como método: 
- Objetivo: o método que por meio de um algoritmo ou fórmula matemática tenta estimar as degradações inseridas no vídeo.

- Subjetivo: baseado no julgamento de um observador que outorga uma pontuação à qualidade de vídeo.

Na Figura 3.1 é apresentada uma classificação dos métodos de avaliação de qualidade de vídeo, considerando alguns critérios. Essa classificação dependendo do critério a ser considerado pode sofrer modificações. Por exemplo, pode aplicarse um critério de métodos de avaliação que possam ser utilizados em aplicações em tempo real; ou nos casos de análise do conteúdo da imagem podem classificarse os métodos em: métodos de análise no domínio da freqüência ou no domínio do espaço (considerando pixels). Outra classificação é considerando a definição (definição padrão ou alta definição) e a resolução da imagem do sistema utilizado na recepção do vídeo. Adicionalmente, nos últimos anos propõe-se a avaliação de vídeo por usuários remotos via internet, que permite classificar os testes subjetivos em testes presencias e remotos.

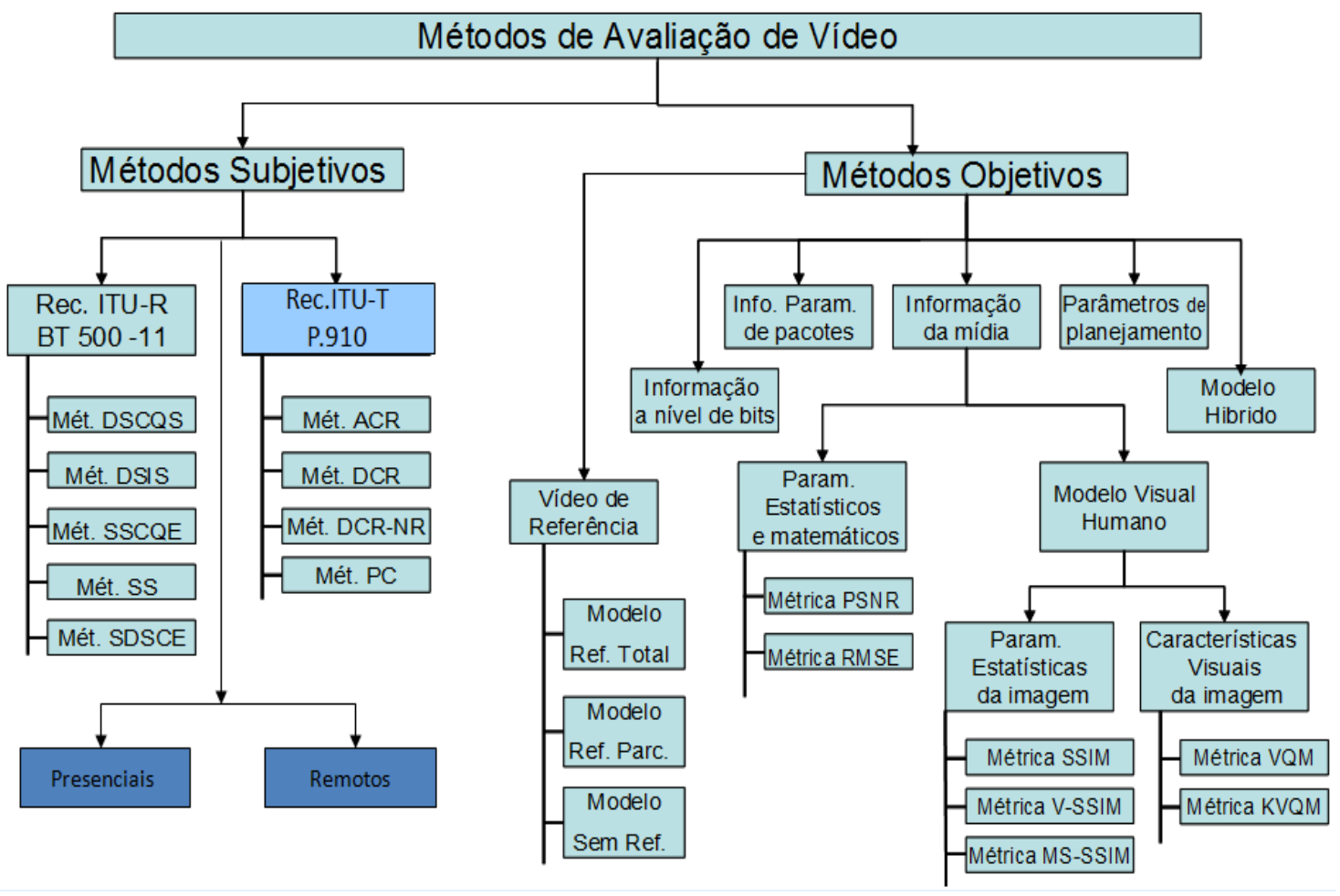

Figura 3.1: Classificação dos métodos de avaliação de vídeo.

\subsubsection{Métodos Objetivos de Avaliação de Qualidade de Vídeo}

A União Internacional de Telecomunicações - ITU - define diferentes categorias para os métodos objetivos dependendo do tipo de informação considerada 
na entrada do algoritmo de avaliação, sendo essas categorias (TAKAHASHI; HANDS; BARRIAC, 2008):

- Modelo baseado na mídia, nesse modelo é utilizado como entrada o sinal de voz ou de vídeo para estimar a qualidade do sinal recebido, que determina a QoE do usuário final. Para esse método não é necessário conhecer a rede onde foi transportado o sinal de voz ou vídeo.

- Modelo baseado no nível dos parâmetros dos pacotes, esse modelo não considera a informação total contida nos pacotes transmitidos, só considera os cabeçalhos para estimar uma qualidade do sinal recebido.

- Modelo baseado no nível de parâmetros de planejamento, para realizar a estimação de qualidade utilizando esse método é necessário um conhecimento prévio dos parâmetros da rede e dos elementos que fazem parte da comunicação, como os codificadores empregados. Esse método pode ajudar ao encarregado do planejamento da rede a otimizar os recursos da rede, um bom planejamento da rede ajuda a garantir a qualidade dos serviços.

- Modelo baseado no nível de fluxo contínuo de bits, esse método, para predizer a qualidade do sinal recebido, utiliza os bits transmitidos e, portanto, também utiliza a informação utilizada no modelo do nível de parâmetros de pacotes.

- Modelos Híbridos são os métodos que misturam dois ou mais dos modelos descritos anteriormente.

Os métodos baseados nas informações de rede, ou seja, os modelos que são baseados nos parâmetros de pacotes, parâmetros de planejamento, e do fluxo continuo de bits são tratados em (Siller and Woods, 2003) (KIM et al., 2008) (CERMAK, 2009) (BOUTEN et al., 2008) (GARCIA; RAAKE, 2010), (CALYAM et al., 2009) considerando em cada caso diferentes aspectos. Dependendo do tipo de cenário empregado na estimação da qualidade e do tempo de processamento envolvido nesses métodos, para nosso critério, podem ser aproveitados em serviços de tempo real. O método onde é empregado o conteúdo da mídia poderia precisar de maior processamento, o qual dificultaria a utilização em aplicações em tempo real.

Os modelos paramétricos permitem predizer o valor da qualidade do vídeo utilizando alguns parâmetros como: informação da rede, processos de codificação e conteúdo de vídeo. 
Em (RAAKE et al., 2008) (GARCIA; RAAKE, 2010) é apresentado um método de avaliação no qual a métrica de avaliação é determinada pela taxa de codificação e as características da rede, mas não considera as características do conteúdo do vídeo transmitido em uma aplicação de televisão por IP. Também é apresentada uma equação matemática de tipo exponencial para determinar a métrica de qualidade.

Em (GARCIA; RAAKE; LIST, 2008) são apresentados como as características temporais e espaciais de um vídeo têm influencia na determinação da qualidade, especialmente nas taxas de codificação mais baixas, porém só é efetuada uma análise qualitativa e não quantitativa desse efeito, ou seja, não é apresentado um método de como se determinar o grau de dinamismo de um vídeo.

Em (KOUMARAS et al., 2007) é apresentado um modelo similar a (RAAKE et al., 2008) definindo-se uma equação exponencial para determinação da métrica de qualidade, que considera os formatos de visualização (CIF e QCIF) para aplicações multimídia, que distribui conteúdo audiovisual em redes de $3 \mathrm{G}$ e 4G. Em (JOSKOWICZ et al., 2009) é apresentada uma relação entre uma avaliação subjetiva e os parâmetros de codificação, definida mediante uma equação, mas não considera as degradações que podem ocorrer no meio de transmissão, nesse caso, a rede IP.

A recomendação ITU-T G.1070 descreve um modelo computacional para aplicações de vídeo em redes IP, que depende do tipo de codificador e o formato de visualização, sendo que nessa recomendação só é considerado o codificador MPEG-2. Em (YAMAGISHI; HAYASHI, 2008) (JOSKOWICZ et al., 2009) são apresentados modelos referenciados na Rec. G.1070, mas que estão voltados para aplicações de televisão por IP, onde também é definida a dependência da qualidade estimada com o tipo de conteúdo do vídeo. Esses métodos não consideram a estimação quantitativa das degradações na etapa de transmissão do vídeo.

Por outro lado, existe outro critério de classificação das métricas objetivas que considera a existência ou não de uma fonte original de vídeo a qual será comparada com o vídeo degradado. No apêndice I de (ITU-T R. J.143, 2000) são descritos as três metodologias para avaliação de qualidade de vídeo, elas apresentam diferentes níveis na exatidão das medidas e requerem diferente informação das entradas/referência de vídeo. Essas três metodologias são:

- Método de Avaliação Referência Total, do inglês Full Reference (FR): Este método compara o sinal de vídeo de entrada e o sinal processado de saída 
do sistema. Essa comparação requer um processo de alinhamento no tempo e no espaço para compensar qualquer deslizamento horizontal ou vertical da imagem. Esse método pode ser empregado em sistemas digitais, sistemas analógicos e em sistemas de compressão. Em relação aos outros métodos, o FR apresenta a maior exatidão. A Figura 3.2, adaptada de (ITU-T R. J.143, 2000), apresenta um diagrama de blocos desse método.

- Método de Avaliação Referência Parcial, do inglês Reduced Reference (RR): Este método utiliza sistemas de medidas nos pontos A e B apresentados na Figura 3.3, adaptada de (ITU-T R. J.143, 2000). Nesses pontos A e B são extraídos parâmetros específicos de ambas as imagens. Esses parâmetros podem incluir: informação temporal e espacial do sinal e do ruído.

- Método de Avaliação sem Referência, do inglês Non Reference (NR): Este método não utiliza um sinal de referência, como é apresentado na Figura 3.4, adaptada de (ITU-T R. J.143, 2000). A falta de uma imagem de referência pode significar uma possibilidade maior de falta de exatidão na estimação da qualidade. Porém, para aplicações que requerem que a avaliação de qualidade do vídeo possa ser feita em tempo real, esse método seria o mais adequado.

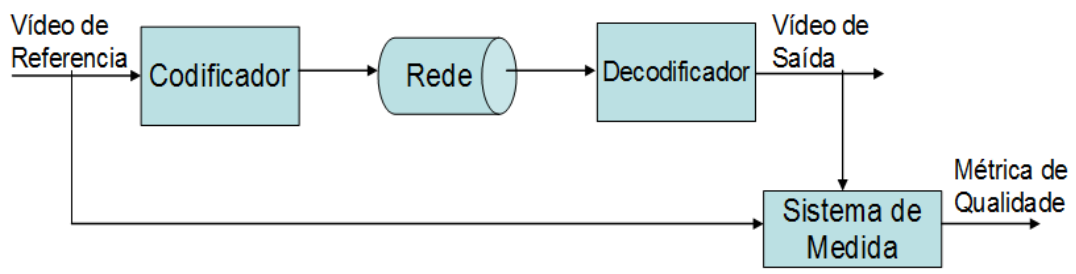

Figura 3.2: Diagrama de blocos do método Referência Total.

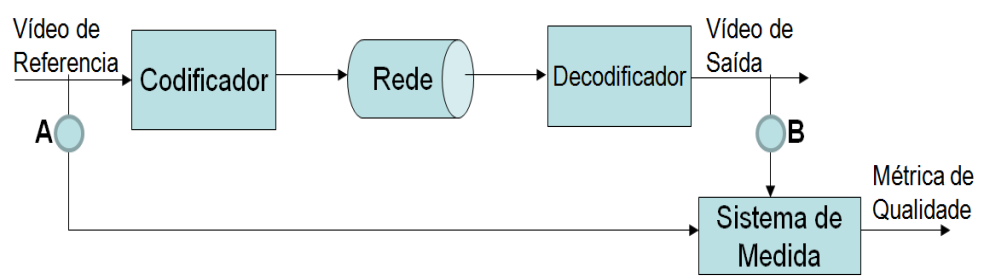

Figura 3.3: Diagrama de blocos do método Referência Parcial.

As métricas objetivas de avaliação de qualidade de vídeo, mas citadas na literatura atual, e que foram utilizadas no estudo de caso apresentado no Apêndice B, são descritas em seguida: 


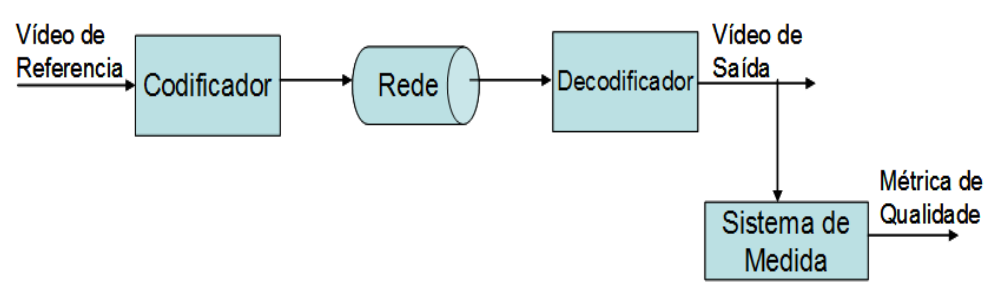

Figura 3.4: Diagrama de blocos do método sem Referência.

- PSNR (Peak Signal to Noise Ratio): Esta métrica é uma das mais empregadas na literatura, pois, pode ser calculada de uma forma fácil, tem um significado geométrico claro, mas em alguns casos não tem uma relação muito próxima com os resultados de testes subjetivos (WANG; BOVIK, 2002a), (WANG, 2001), (WANG; BOVIK, 2002b). Essa métrica depende da diferença entre a imagem original e a imagem degradada. O PSNR é calculado a partir do RMSE (Root Mean Square Error), o qual é obtido ao calcular o valor médio da subtração entre o quadro de imagem original e o quadro da imagem degradada, segundo a equação 3.1.

$$
\mathrm{RMSE}=\sqrt{\frac{1}{M \times N} \sum_{m=0}^{M-1} \sum_{n=0}^{N-1}\left[f^{\prime}(m-n)-f(m-n)\right]^{2}}
$$

Onde, $f$ é o quadro original, $f^{\prime}$ é o degradado, $\mathrm{N}$ e M são as dimensões da matriz que representa a imagem. O PSNR é obtido a partir da equação 3.2.

$$
\mathrm{PSNR}=20 \times \log _{10}\left(\frac{255}{R M S E}\right)
$$

- SSIM (Structural SIMilarity): Esta métrica está fundamentada no modelo visual humano, pois parte do princípio que considera que as imagens são altamente estruturadas, e essas dependências contêm informações muito importantes referente à estrutura do objeto (WANG et al., 2004). O sistema visual humano é altamente adaptado para extrair informação estrutural, assim mede-se cada mudança na informação estrutural, podendo-se prover uma aproximação da degradação da imagem.

A informação estrutural em uma imagem é definida, pelos autores desse método, como os atributos que representam a estrutura do objeto, independente da luminosidade e do contraste. Na Figura 3.5, adaptada de (WANG et al., 2004) é apresentado o diagrama funcional do sistema utilizado para 
obter a métrica SSIM.

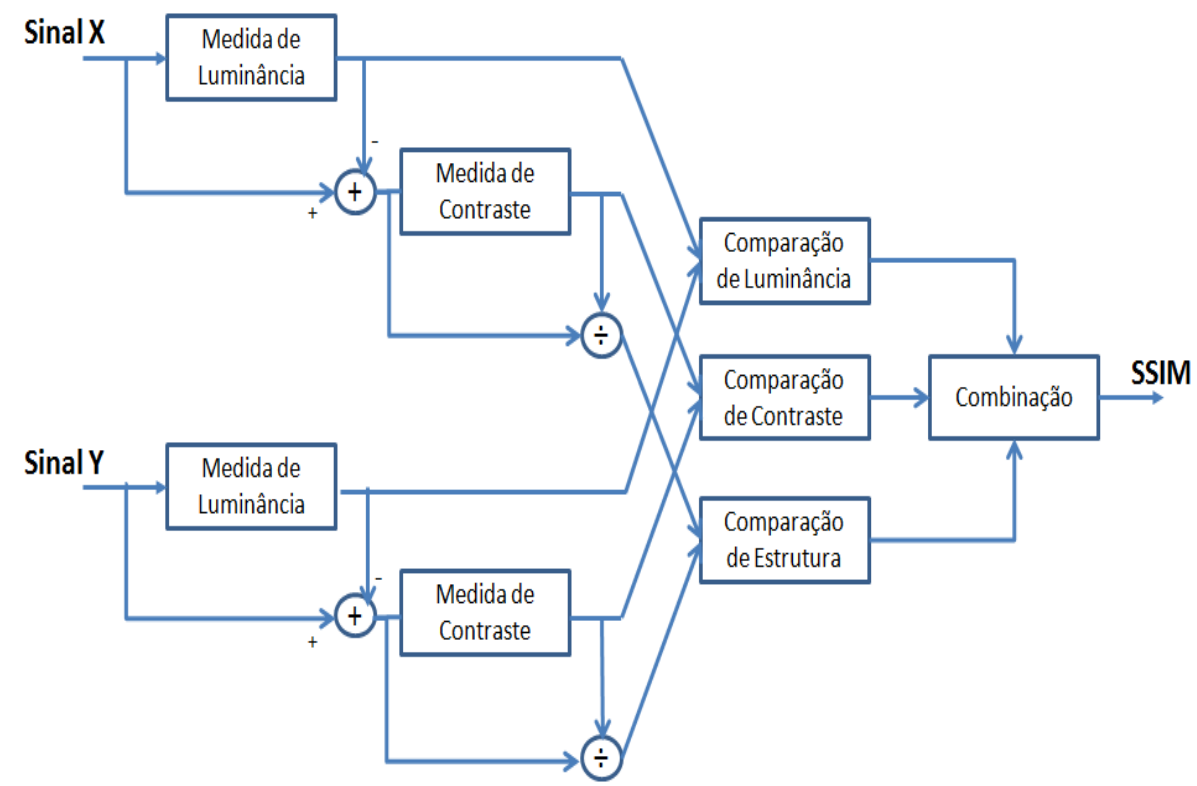

Figura 3.5: Diagrama funcional da métrica SSIM, adaptada de (WANG et al., 2004).

A equação 3.3 define a relação dos três elementos considerados: luminosidade, contraste e estrutura da imagem.

$$
\mathrm{S}(\mathrm{x}, \mathrm{y})=\mathrm{f}(\mathrm{l}(\mathrm{x}, \mathrm{y}), \mathrm{c}(\mathrm{x}, \mathrm{y}), \mathrm{s}(\mathrm{x}, \mathrm{y}))
$$

Onde a função de comparação de brilho é representada pela equação 3.4, onde $\mu$ denota a intensidade do brilho médio das imagens x e y, e $C_{1}$ é um fator de correção.

$$
\mathrm{l}(\mathrm{x}, \mathrm{y})=\frac{2 \mu_{x} \mu_{y}+C_{1}}{\mu_{x}^{2}+\mu_{y}^{2}+C_{1}}
$$

A função de comparação de contraste é representada pela equação 3.5, onde $\sigma$ representa o desvio padrão da amostra do brilho das duas imagens, e C2 é um fator de correção.

$$
\mathrm{c}(\mathrm{x}, \mathrm{y})=\frac{2 \sigma_{x} \sigma_{y}+C_{2}}{\sigma_{x}^{2}+\sigma_{y}^{2}+C_{2}}
$$


A equação 3.6 representa a função de comparação estrutura, onde $\sigma_{x y}$ é a covariância de amostras de luminosidade das duas imagens.

$$
\mathrm{s}(\mathrm{x}, \mathrm{y})=\frac{\sigma_{x y}+C_{3}}{\sigma_{x} \sigma_{y}+C_{3}}
$$

Finalmente, para simplificar a expressão é considerado que $C_{2}=C_{3} / 2$. A métrica SSIM é obtida pela seguinte equação.

$$
\operatorname{SSIM}(\mathrm{x}, \mathrm{y})=\frac{\left(2 \mu_{x} \mu_{y}+C_{1}\right)\left(2 \sigma_{x} \sigma_{y}+C_{2}\right)}{\left(\mu_{x}^{2}+\mu_{y}^{2}+C_{1}\right)\left(\sigma_{x}^{2}+\sigma_{y}^{2}+C_{2}\right)}
$$

- VQM (Video Quality Metric), em (XIAO, 2000) são descritos os passos desse modelo, que utiliza a transformada discreta de cosseno (DCT). Trabalhos anteriores apresentam o modelo qualidade de vídeo que também incorpora o DCT, mas o modelo apresentado considera dois tipos de matrizes, uma matriz chamada matriz de sensibilidade ao contraste para quadros estáticos e outro para quadros dinâmicos aplicados na mesma etapa para reduzir o processamento da função SCSF (Spatial Contrast Sensitivity Function). Na Figura 3.6, adaptada de (XIAO, 2000), podem ser observadas as principais etapas funcionais do modelo VQM.

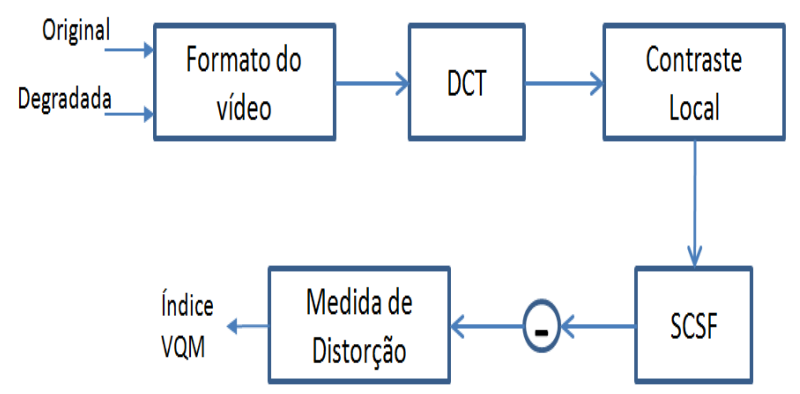

Figura 3.6: Diagrama de blocos da métrica VQM de (XIAO, 2000).

\subsubsection{Métodos Subjetivos de Qualidade de Vídeo}

Os métodos subjetivos de avaliação da qualidade de vídeo são baseados no julgamento de um observador. Esses métodos são descritos principalmente nas Recomendações ITU-R BT.500-8-13 e a Recomendação ITU-T P.910. Essa última recomendação descreve os métodos de avaliação subjetiva de vídeo que podem ser utilizadas em serviços multimídia. A descrição das condições e procedimentos 
para produzir um vídeo de referência é apresentada na Recomendação ITUT P.930 (ITU-T R. P.930, 1996).

Por outro lado, nos últimos anos surgiram trabalhos relacionados com a avaliação subjetiva de vídeo por meio da Internet, o que será tratado no final dessa seção.

1. Métodos descritos na Recomendação ITU-T P.910

- Métrica por Categorias Absolutas (ACR). O Método de Métrica por Categoria Absoluta, do inglês Absoluty Category Rating (ACR), é também chamado de método de um único estímulo. Nessa metodologia de teste a seqüência de vídeo é apresentada ao avaliador e cada cena é pontuada independentemente em uma escala de categorias. A mesma cena pode ser avaliada por várias pessoas simultaneamente em período de tempo menor que 10 segundos. Em relação aos outros métodos descritos em Rec. P.910 é a mais rápida de realizar. A Figura 3.7 ilustra como as seqüências de vídeo degradadas (VD) são observadas pelo avaliador na metodologia ACR.

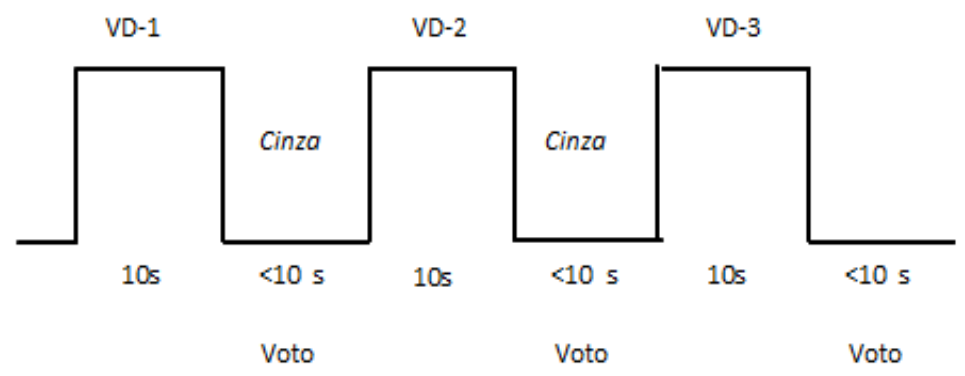

Figura 3.7: Formato de apresentação das seqüências de vídeos no método ACR.

A escala de avaliação mais utilizada nesses testes corresponde a cinco categorias, as quais são apresentadas na Tabela 3.1.

Tabela 3.1: ITU-T Escala ACR

\begin{tabular}{|c|c|}
\hline $\begin{array}{c}\text { Escala de } \\
\text { Pontuação }\end{array}$ & $\begin{array}{c}\text { Qualidade } \\
\text { Estimada }\end{array}$ \\
\hline 1 & Excelente \\
\hline 2 & Boa \\
\hline 3 & Regular \\
\hline 4 & Ruim \\
\hline 5 & Muito Ruim \\
\hline
\end{tabular}


No caso de requerer uma maior resolução nos resultados, o Anexo B.1 da recomendação P.910 apresenta uma escala de 9 ou 11 categorias. Adicionalmente, é necessário classificar o tipo de degradação nos vídeos, como: brilho, contraste, efeito mosquito, congelamento de imagem, sombras, entre outras. Também é possível solicitar ao usuário que responda a um questionário onde cada degradação mencionada seja avaliada em uma escala.

- Métrica por Categorias Absolutas com Referencia Oculta (ACR-HR): Neste método (do inglês Absolute category rating with hidden reference - ACR-HR) a seqüência de apresentação das cenas do vídeo é a mesma que é apresentada na Figura 3.7, a diferença está em que nessas seqüências de vídeo está incluída a seqüência do vídeo original (referência) para cada seqüência apresentada. O nome de referência oculta é devido a que o usuário não tem conhecimento de que a cena original está presente. A escala é a mesma utilizada na metodologia ACR.

A análise dos resultados é realizada a partir do parâmetro DMOS (Differential Mean Opinion Score), o qual é calculado a partir da diferença das pontuações das qualidades entre o vídeo original (referência escondida) e o vídeo degradado. Com o objetivo de utilizar a mesma escala do método ACR é definido o parâmetro DV (diferença de pontuação de vídeo) o qual é calculado por avaliador e por seqüência degradada de vídeo (VD) utilizada nos testes, como é indicado na seguinte equação:

$$
\mathrm{DV}(\mathrm{VD})=\mathrm{V}(\mathrm{VD})-\mathrm{V}(\mathrm{REF})+5
$$

Onde V é a pontuação na escala ACR que o avaliador outorga a cada uma das seqüências de vídeos.

- Métricas por Categorias de Degradação (DCR): Neste método DCR (do inglês Degradation Category Rating) as seqüências de vídeo são apresentadas em pares, onde a primeira seqüência apresentada sempre é a original (referência explicita - VR) e a segunda seqüência corresponde ao vídeo com alguma degradação (VD). Por esse motivo, esse método é chamado também de duplo estímulo. A Figura 3.8 apresenta a forma como as seqüências de vídeo são apresentadas aos avaliadores.

A Tabela 3.2 apresenta a escala de pontuação desse método.

- Comparação por pares (PC): No método PC (do inglês Pair com- 


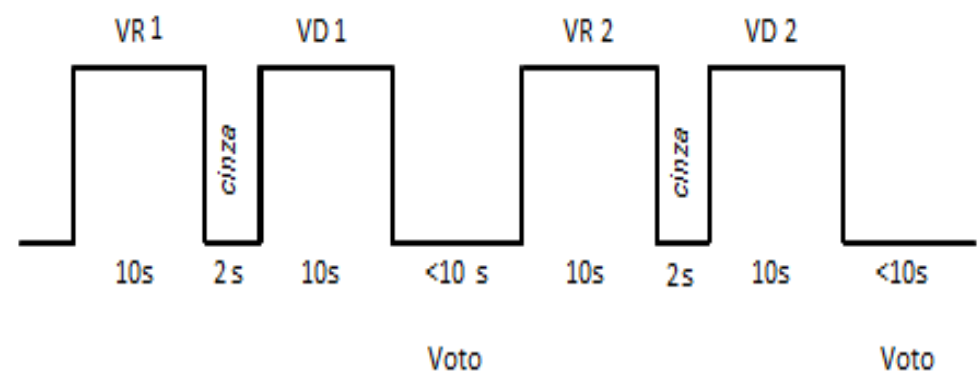

Figura 3.8: Formato de apresentação das seqüências de vídeos em DCR.

Tabela 3.2: ITU-T Escala DCR

\begin{tabular}{|c|c|}
\hline $\begin{array}{c}\text { Escala de } \\
\text { Pontuação }\end{array}$ & $\begin{array}{c}\text { Qualidade } \\
\text { Estimada }\end{array}$ \\
\hline 1 & Muito Incômodo \\
\hline 2 & Incômodo \\
\hline 3 & Ligeiramente Incômodo \\
\hline 4 & Perceptível, mas não Incômodo \\
\hline 5 & Imperceptível \\
\hline
\end{tabular}

parison) as mesmas seqüências de vídeo, mas cada uma com diferente tipos de degradação são apresentadas aos usuários em pares com uma pequena pausa de aproximadamente dois segundos. A Figura 3.9 mostra como são apresentadas essas seqüências de vídeo, onde as VD1a e VD1b, são a primeira seqüência de vídeo com dois tipos de degradações: a e b.

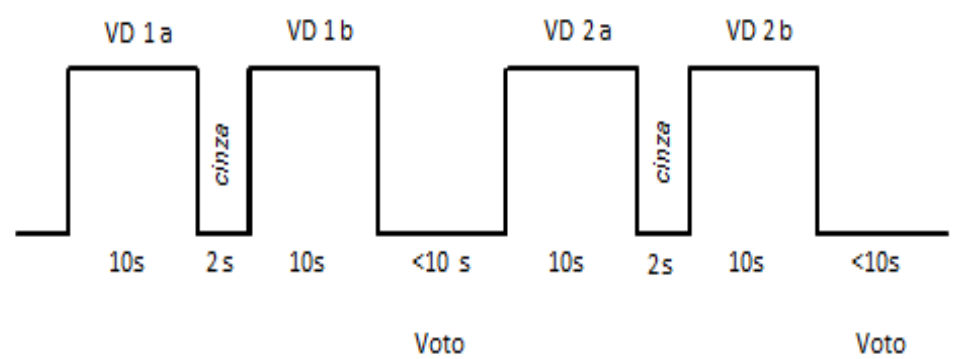

Figura 3.9: Formato de apresentação das seqüências de vídeos no método PC.

2. Métodos descritos na Recomendação ITU-R B.500

- Escala de degradação com duplo estímulo (DSIS): Este método (Double Stimulus Impairment Scale - DSIS) é similar ao método DCR, sendo que no DSIS as seqüências de vídeo podem ser apresentadas duas vezes. O método DSIS é adequado para avaliar degradações claramente visíveis, tais como artefatos causados por erros na transmissão. O 
teste consiste em assistir o sinal de vídeo original por uns segundos, e posteriormente o sinal de vídeo degradado pelo mesmo período de tempo. A escala de avaliação é a mesma que a descrita no método DCR (Tabela 3.2).

- Escala de qualidade contínua de duplo estímulo (DSCQS): O método DSCQS (Double-stimulus continuous quality-scale) é baseado na comparação de dois estímulos, as seqüências de vídeo original e degradado. Esse método é o adequado quando a qualidade dessas seqüências é semelhante por ser mais sensível a pequenas diferenças na qualidade de vídeo. Durantes os testes, os avaliadores não são informados sobre qual é a seqüência de vídeo original e qual é a seqüência de vídeo degradado. O formato da escala é continua como apresentada na Figura 3.10 .

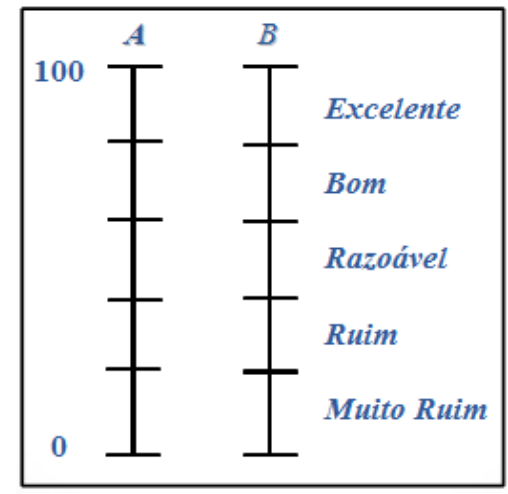

Figura 3.10: Escala de pontuação utilizada na metodologia DSCQS.

- Método de Estímulo Único (SS): Neste método (Single-stimulus - SS) somente uma seqüência de vídeo é apresentada aos avaliadores, os quais outorgam uma pontuação. Seguidamente são descritos as três variantes deste método.

- Método de avaliação por categoria adjetiva, do inglês Adjectival categorical judgment. Nesse tipo de testes os avaliadores outorgam a uma seqüência de vídeos um adjetivo, as alternativas da escala empregada são apresentadas de forma semântica, como as apresentadas na Tabela 3.1 ou Tabela 3.2.

- Método de avaliação por categoria numérica, do inglês Numerical categorical judgment. Nesse tipo de testes os avaliadores outorgam a uma seqüência de vídeos uma pontuação; a escala que utilizada é uma que possui 11 níveis numéricos (0-10)

- Método de avaliação sem uso de categoria, do inglês Non- 
categorical judgment methods. Esse tipo de teste pode ser realizado de duas formas: (a) em uma escala continua, onde os extremos dessa escala são os adjetivos da Tabela 3.1, essa escala pode ter adjetivos ou pontos intermediários para referência. (b) Em uma escala numérica, onde é avaliada uma característica específica do vídeo como o brilho da imagem.

- Avaliação de qualidade contínua de estímulo único (SSCQE): Nessa metodologia (Single stimulus continuous quality evaluation - SSCQE) de teste subjetivo, uma única seqüência de vídeo é apresentada ao avaliador. A principal diferença desse método com os outros é que o avaliador pode outorgar pontuações continuamente durante o vídeo, sendo a escala de avaliação de zero a cem. Outra diferença é que a duração das seqüências de vídeos não está limitada a 10 segundos, sendo que essas podem ser de uma maior duração, como é apresentado na Figura 3.11.

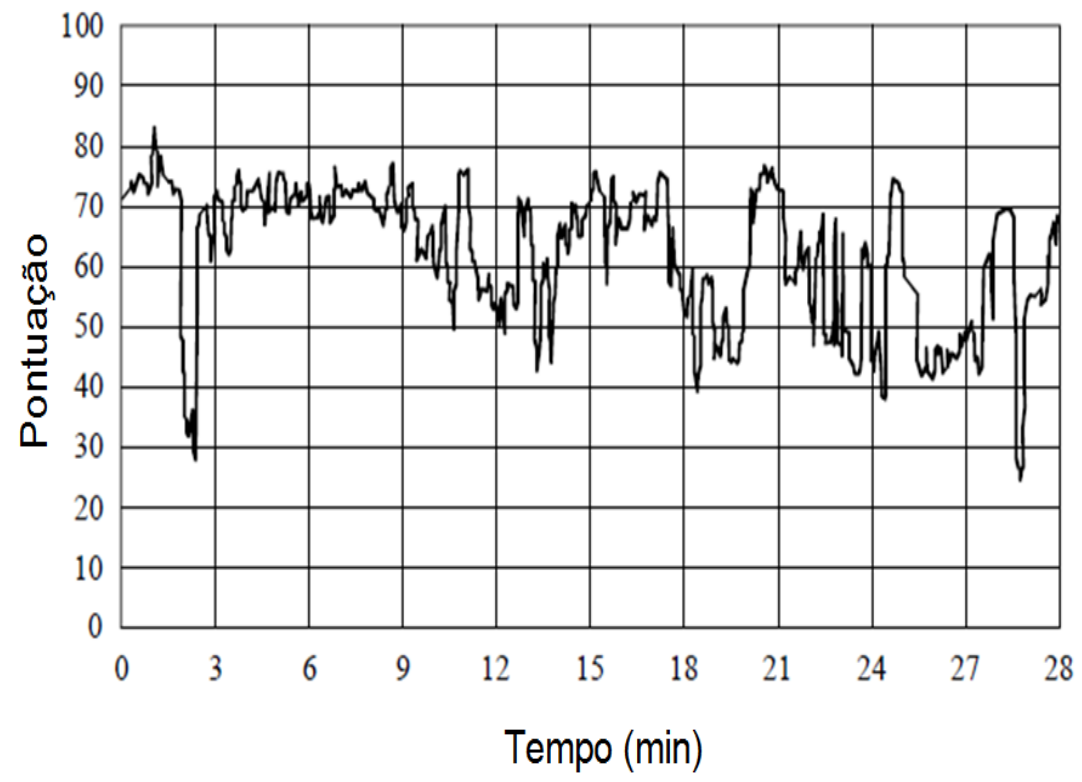

Figura 3.11: Resultados de um teste de avaliação de qualidade de vídeo utilizando-se a Metodologia SSCQE.

- Avaliação de qualidade contínua de duplo estímulo simultâneo (SDSCE): Este método (Simultaneous double stimulus for continuous evaluation - SDSCE) é de duplo estímulo pois utiliza uma sequência de vídeo de referência e a degradada. As seqüências de vídeo originais e degradadas (cenário testado) são apresentadas simultaneamente no mesmo monitor ou em dois monitores alinhados, sendo que o avaliador é advertido de qual é a seqüência de vídeo de referencia. 
Os usuários outorgam uma pontuação referente à fidelidade do vídeo testado, assim quando a fidelidade é perfeita é outorgada a máxima pontuação (numericamente equivalente a cem) e quando a fidelidade é nula corresponde ao mínimo valor (equivalente a zero).

3. Limitações dos Métodos Subjetivos atuais na avaliação do serviço de streaming de vídeo via TCP

Nas seções anteriores foram descritas as metodologias de testes subjetivos para avaliação de qualidade de vídeo pertencente às recomendações, ITU-R BT-500-13 e ITU-T P.910, essa última mais focada para serviços multimídia. O objetivo dessa seção é demonstrar por que essas metodologias não são apropriadas para avaliar o serviço de streaming de vídeo via TCP.

A Tabela 3.3 apresenta as principais características dessas metodologias (ITU), adicionando a metodologia SAMVIQ descrita em (BLIN, 2006) as quais são as mais citadas na literatura atual.

Tabela 3.3: Características das Metodologias de Testes Subjetivos

\begin{tabular}{|c|c|c|c|c|c|c|c|c|}
\hline & DSIS & DSCQS & SSCQE & SDSCE & SAMVIQ & ACR & DCR & PC \\
\hline Duração & $10 \mathrm{~s}$ & $10 \mathrm{~s}$ & $5 \mathrm{~min}$. & $10 \mathrm{~s}$ & $10 \mathrm{~s}$ & $10 \mathrm{~s}$ & $10 \mathrm{~s}$ & $10 \mathrm{~s}$ \\
\hline $\begin{array}{c}\text { Refer. } \\
\text { Explícita. }\end{array}$ & Sim & Não & Não & Não & Sim & Não & Sim & Não \\
\hline $\begin{array}{c}\text { Refer. não } \\
\text { Explícita }\end{array}$ & Não & Sim & Não & Não & Sim & Não & Não & Não \\
\hline $\begin{array}{c}\text { Estímulo } \\
\text { simultâneo }\end{array}$ & Não & Não & Não & Sim & Não & Não & Não & Não \\
\hline $\begin{array}{c}\text { Escala. cont. } \\
\text { de qualidade }\end{array}$ & Não & Não & Sim & Sim & Não & Não & Não & Não \\
\hline $\begin{array}{c}\text { Nro. mínimo } \\
\text { avaliadores }\end{array}$ & 15 & 15 & 15 & 15 & 15 & 15 & 15 & 15 \\
\hline
\end{tabular}

Todas essas metodologias, com exceção da SSCQE, consideram o tempo da seqüência do vídeo em torno de 10 segundos, por esse motivo elas estão mais orientadas em avaliar os efeitos de degradações espaciais nos quadros, sendo mais úteis em cenários onde o objetivo é avaliar o desempenho de um determinado codificador. Utilizando essas metodologias, os efeitos de degradações causadas pelas pausas não poderão ser corretamente avaliados, já que a duração de uma pausa é comparável com a duração do vídeo.

Por outro lado os vídeos disponíveis em serviços como o Youtube, são de uma maior duração, 10 segundos não correspondem a um cenário realístico. Todas essas metodologias, com exceção da SSCQE, consideram o tempo da seqüência do vídeo em torno de 10 segundos, por esse motivo elas estão mais orientadas em avaliar os efeitos de degradações espaciais nos quadros, sendo mais úteis em cenários onde o objetivo é avaliar o desempenho de 
um determinado codificador. Utilizando essas metodologias, os efeitos de degradações causadas pelas pausas não poderão ser corretamente avaliados, já que a duração de uma pausa é comparável com a duração do vídeo.

4. Avaliação Subjetiva de Qualidade de Vídeo através de Internet

A avaliação subjetiva de qualidade de vídeo é realizada em condições de laboratório, de forma presencial e seguindo recomendações específicas para cada tipo de avaliação, dessa forma, os testes requerem tempos longos para sua execução.

Nos últimos anos surge uma nova possibilidade de avaliação, a qual é baseada no conceito de crowdsourcing, que utiliza o julgamento de um público geral no lugar do julgamento de um público específico, sendo que o público participante pode estar disseminado por diferentes lugares geográficos. As tarefas nas quais o crowdsourcing pode ser utilizado correspondem a diferentes áreas, mas em geral, são tarefas onde os computadores não podem suprir a intervenção dos usuários.

Por outro lado é importante ressaltar a diferença entre os conceitos de outsourcing e crowdsourcing, no primeiro as tarefas são realizadas por um grupo específico de sujeitos, no segundo caso essas mesmas tarefas são realizadas por um grupo desconhecidos de usuários utilizando a rede Internet. A aplicação mais conhecida e importante de crowdsourcing é possivelmente a pesquisa utilizando questionários na Internet, e que são usados para diversos fins. Em (DUFFY et al., 2006) (SEM; JANKOWSI, 2006), os autores mostram que esse tipo de pesquisas tem algumas vantagens em relação às pesquisas presencias. Principalmente as pesquisas baseadas em crowdsourcing são mais eficientes em termos de tempo e custos, por outro lado os usuários (crowd) estão mais confortáveis para responder questionários. Porém, não é possível escolher perfis de usuários com características específicas para uma determinada pesquisa. Outra desvantagem é o grau de confiabilidade que podem ter as respostas dos usuários nas pesquisas, pela falta de um ambiente controlado.

Dessa forma, o conceito de crowdsourcing pode ser aplicado na avaliação subjetiva de vídeo, no qual um grupo grande de avaliadores anônimos conectados na internet avalia os diferentes vídeos e outorgam uma pontuação a cada vídeo assistido. Consideramos que (RIBEIRO; FLORENCIO; NASCIMENTO, 2011) (CHEN; LIN; WEI, 2009) (XU; HUANG; YAO, 2012) são os trabalhos de referências mais importantes encontrados na literatura 
atual sobre crowdsourcing, e sua aplicabilidade na avaliação de qualidade de imagem, voz e vídeo. O objetivo principal de utilizar essa metodologia é diminuir consideravelmente o tempo na realização dos testes subjetivos de avaliação de qualidade de vídeo, devido a que, essa é uma das principais dificuldades da execução de testes subjetivos presencias.

Os trabalhos atuais utilizam, na maioria dos casos, soluções denominadas como Mechanical Turk, onde os usuários realizam tarefas em troca de uma compensação econômica, sendo que na atualidade as ferramentas de maior aceitação são: Microworkers e Amazon MTurk.

\subsection{Adaptação dinâmica de streaming utili- zando o protocolo HTTP}

A solução DASH, do inglês Dynamic Adaptive Streaming over HTPP, é um novo padrão desenvolvido pela 3GPP e MPEG (STOCKHAMMER, 2011) (ISO 23009-1, 2012) (LOHMAR et al., 2011) com o objetivo de codificar arquivos de vídeo usando diferentes parâmetros de codificador. Como resultado, diferentes versões do mesmo vídeo são obtidas e armazenadas num servidor de vídeo, em que cada versão vídeo representa diferentes níveis de qualidade, pois cada versão possui uma resolução temporal ou espacial diferente. As diferentes versões do mesmo vídeo são compatíveis com dispositivos de diferentes resoluções.

O usuário que inicia uma sessão de streaming de vídeo, utilizando a solução DASH, tem a possibilidade de assistir uma determinada qualidade de vídeo, a qual dependerá das condições da rede. Por tanto, a solução DASH tem como objetivo melhorar a QoE do usuário, pois, quando as condições da rede o permitem o usuário consegue assistir maior resolução possível, e quando as redes não são favoráveis o usuário assiste um vídeo de menor resolução, porém o vídeo terá uma possibilidade menor de apresentar interrupções temporais (pausas).

No DASH os metadados são chamados de Descrição de Apresentação da Mídia, do inglês Multimedia Presentation Description (MPD). Cada versão de vídeo armazenados no servidor é dividida logicamente em segmentos de vídeo. Um segmento de vídeo pode ser representado como um arquivo de vídeo pequeno com o seu próprio MPD no cabeçalho do arquivo. O MPD mapeia a posição, no domínio do tempo, do segmento de vídeo para o tempo do vídeo completo. Assim, o usuário pode acessar um segmento de vídeo específico.

Na especificação técnica 26.247 da 3GPP (3GPP TS 26.247, 2011) são defini- 
das as especificações de interface entre o cliente e o servidor, assim como também do formato dos protocolos que podem ser enviados sobre o HTTP para habilitar o DASH. Nessa especificação técnica (3GPP TS 26.247, 2011) é descrito como um cliente, que suporta DASH, pode utilizar a informação para realizar um streaming de vídeo. O cliente deve ser capaz de mensurar e gerar um relatório de todas as métricas relacionadas com o QoE, as quais são especificadas no TS 26.247. Para efetuar um streaming de vídeo que suporte DASH, os clientes devem utilizar o HTTP GET ou HTTP partial GET para acessar a mídia oferecida no HTTP-URLs. Assim, se no servidor de vídeo se dispõe de várias qualidades do mesmo vídeo previamente gravadas, dependendo da qualidade da rede o terminal do usuário pode solicitar uma determinada qualidade de segmento de vídeo.

Uma descrição geral do sistema DASH é mostrada na Figura 3.12, na qual, quatro versões do mesmo vídeo, mas com diferentes resoluções espaciais $\left(V Q L_{A}\right.$, $V Q L_{B}, V Q L_{C}$ e $\left.V Q L_{D}\right)$ são armazenados no servidor de vídeo. Os segmentos de vídeo são representados pela letra $\mathrm{S}$, por exemplo, o primeiro segmento do $V Q L_{A}$ é SA1.

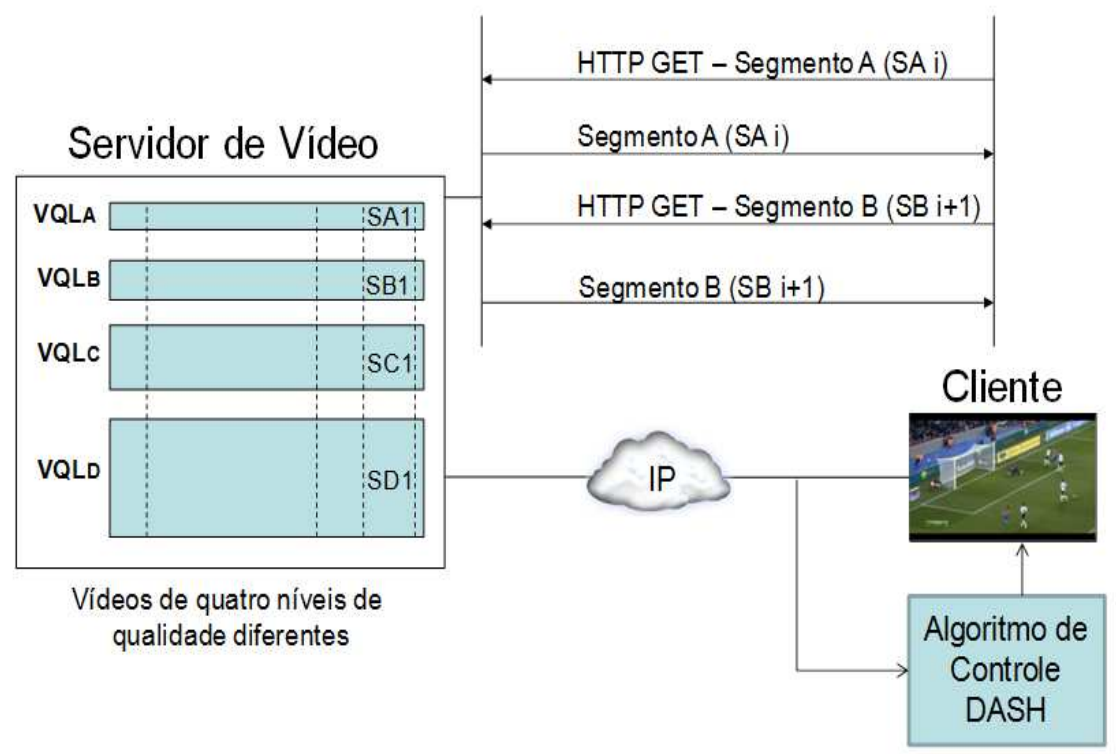

Figura 3.12: Descrição geral do Sistema de DASH.

Na Figura 3.12 pode ser observado um algoritmo de controle DASH no lado do cliente. Esse algoritmo utiliza diferentes parâmetros de rede como entradas, mais comumente a taxa de conexão de transferência no ponto do usuário, para determinar o nível de qualidade do próximo segmento de vídeo que será requerido ao servidor. Todas essas requisições são realizadas continuamente durante o streaming de vídeo sem qualquer ação do usuário. 
Os parâmetros, no qual o terminal do usuário que suporta DASH se baseia para tomar a decisão do nível de qualidade do vídeo, são os seguintes:

- Requisições e respostas das transações;

- Eventos de troca de requisição de uma nova resoluçõ;

- Carga de tráfego médio (Average throughput);

- Atraso inicial do player;

- Nível de carga do buffer;

- Lista de reprodução (desde que o envio de dados é iniciado pelo usuário até que é parado por uma ação do usuário, fim do vídeo ou uma falha permanente);

- Informação do MPD.

Nos últimos dois a três anos, alguns trabalhos propuseram diferentes algoritmos de controle de adaptação. Por exemplo, esses algoritmos são baseados em parâmetros, tais como, largura de banda disponível (REDI et al., 2010) (MOK; CHAN; CHANG, 2011) ou vazão (GOUACHE et al., 2011) (PU; ZOU; CHEN, 2011) (CICCO; MASCOLO; PALMISANO, 2011), o tempo de ida e volta (RTT), a taxa de bits média no download, o número da frequência das pausas durante o intervalo de tempo (PORTER; PENG, 2011) (MOK; CHAN; CHANG, 2011), que por sua vez estão relacionados com eventos de sobrecarrega no buffer (EVENSEN et al., 2011), e o atraso associado como a interatividade do usuário com o sistema (HUYSEGEMS et al., 2012). Além disso, em (PU; ZOU; CHEN, 2011) é estudada uma arquitetura para DASH em um cenário de uma rede de distribuição de conteúdo $(\mathrm{CDN})$.

Em (CRANLEY; PERRY; MURPHY, 2006) (FEAMSTER; BANSAL; BALAKRISHNAN, 2001) a percepção do usuário de se adaptar a qualidade do vídeo é estudado. Em (CRANLEY; PERRY; MURPHY, 2006), os cenários de teste diferentes de um melhoramento da qualidade são avaliados a fim de determinar a trajetória ótima de adaptação, mas a degradação do QoE do usuário não é medido quantitativamente, e assim, o algoritmo proposto não pode ser parte de um algoritmo de controle do DASH. Além disso, a localização temporal de eventos de comutação entre diferentes níveis de qualidade de vídeo não são considerados. 
Pode-se observar que o DASH não está associado a uma solução ou modelo de negocio, mas as informações que são contempladas no padrão, para que o dispositivo do usuário capture, permitirão predizer um nível de qualidade do serviço. Essa informação poderia ser utilizada em novos modelos de negocio no serviço de streaming de vídeo. Por outro lado, como já foi mencionado anteriormente, de uma forma geral, o DASH tem por objetivo melhorar a QoE do usuário final, sempre que as condições da rede o permitam. Porém, se a rede apresenta variações drásticas, e de uma forma constante, os algoritmos de controle do DASH que rodam no aparelho do usuário, realizaram requisições de diferentes resoluções de vídeo em um período de tempo curto. Assim, o usuário experimentará diversos eventos de comutação da resolução de vídeo, afetando negativamente a sua QoE. $\mathrm{Na}$ atualidade, os algoritmos de controle do DASH não levam em consideração os efeitos negativos que as altas frequências de mudanças de resolução de vídeo causam na QoE do usuário final. Nesse contexto, o presente trabalho, na seção 5.1, apresenta um estudo de caso, onde é proposto um parâmetro denominado de Fator de Degradação de Comutação (FDC), o qual controlará a frequência de eventos de comutações de resoluções. Assim, dependendo de um umbral, previamente definido, um evento de comutação será realizado ou não. O parâmetro FDC visa controlar a degradação da QoE do usuário, em situações onde a rede apresenta flutuações constantes de capacidade. 


\section{A Métrica eVsQM}

Nesta seção são descritos os componentes e a metodologia utilizada na determinação da métrica de avaliação de vídeo proposta, chamada de eVsQM. Na determinação dessa métrica foram levados em consideração alguns conceitos da cognição humana, que os métodos subjetivos de avaliação de qualidade de vídeo, mais citados na atualidade, não consideram e cujas limitações foram apresentadas na Tabela 3.3. Assim, nesta seção se apresentará as recomendações práticas da avaliação subjetiva utilizadas nos testes deste trabalho.

Em uma primeira fase, e baseado nos resultados experimentais obtidos nos testes subjetivos, a métrica VsQM é definida utilizando um modelo matemático. Visando a melhora da métrica VsQM, em uma segunda fase é considerado o tipo de conteúdo de vídeo avaliado, como um parâmetro adicional a ser considerado na determinação de uma métrica de qualidade de vídeo. Assim, utilizando o parâmetro de tipo de conteúdo de vídeo, a métrica eVsQM foi formulada.

Enfim, são apresentados os resultados do desempenho dessa métrica quando é avaliada por usuários remotos via a Internet, utilizando o método crowdsourcing descrito em 3.1.1.2. Nesses testes, vídeos com diferentes durações e diversos cenários de degradação foram utilizados.

\subsection{Recomendações Práticas na Avaliação Sub- jetiva de Qualidade do Streaming de Vídeo utilizando TCP}

Na realização de testes subjetivos, neste trabalho é considerada a variabilidade dos processos cognitivos das pessoas, assim os avaliadores possuem diferentes características como: graus de atenção, velocidade nos processamentos da informação, memória de curto prazo e memória de longo prazo, além dos conhecimentos anteriores. Nas seguintes linhas são apresentadas as considerações tomadas nos testes subjetivos presenciais, realizados neste trabalho: 
- Os testes de avaliação devem ser realizados em um ambiente similar ao uso real do serviço de streaming de vídeo. Nos testes considerou-se que o usuário faz o streaming dos vídeos na ordem de sua preferência, podendo assistir cada vídeo as vezes que ele considere necessário.

- As seqüências de vídeo devem ser maiores que 10 segundos para não perder o efeito de temporalidade das pausas. Na primeira fase deste trabalho foram utilizadas seqüências de 2 e 4 minutos tomando como referência que os vídeos mais acessados do YouTube tem uma duração média de 3 minutos.

- Considerando a variabilidade da atenção dos avaliadores consideramos que as instruções para realização dos testes devem ser específicas. Assim, no início dos testes o instrutor informa que as degradações dos vídeos se devem unicamente às pausas existentes, para que a atenção dos avaliadores seja direcionada a esse fator de degradação.

- As avaliações devem ser realizadas quando o usuário considerar que compreendeu as diferenças entre os vídeos, podendo mudar as pontuações se considerar necessário. Os avaliadores possuem diferentes velocidades no processamento das informações, não considerou-se um tempo limitado para dar a pontuação. Os avaliadores são convidados também a comentar cada um dos testes.

- Considerando a variabilidade na memória dos avaliadores, eles podem assistir aos vídeos o número de vezes que cada um deles considere necessário, considerando que é possível mudar a pontuação dos vídeos assistidos.

- Deve-se considerar a variabilidade da subjetividade dos avaliadores. Avaliadores com preferências explícitas no conteúdo do vídeo outorgam diferentes pontuações que os avaliadores que não os tem.

\subsection{Métrica VsQM para o serviço de Streaming de Vídeo sobre TCP}

Os testes subjetivos de vídeo foram realizados seguindo as considerações descritas no item anterior. No inicio foram realizados testes preliminares, nos quais foram avaliados três vídeos com pausas só no inicio e três só com pausas no final. Os resultados obtidos foram diferentes para os vídeos com pausas no inicio em relação aos vídeos com pausas no final. Assim, concluiu-se, que uma métrica para avaliar a qualidade de vídeo no serviço de streaming de vídeo tem que considerar 
a localização temporal de cada pausa no vídeo. Com base nesse critério, foi necessário construir uma base de dados de vídeos para utilizá-los como material de teste; assim, foram criados vídeos com pausas em diferentes instantes e com certa duração.

No presente trabalho, se introduz o conceito de segmentação temporal de vídeo, sendo definidos os seguintes segmentos:

(a) Segmento A, segmento inicial do vídeo,

(b) Segmento B, o primeiro segmento intermediário;

(c) Segmento C, segundo segmento intermediário;

(d) Segmento D, segmento final do vídeo.

A métrica VsQM proposta neste documento é determinada pelos parâmetros:

(a) Número de pausas;

(b) Duração das pausas;

(c) Peso do segmento temporal durante a qual as pausas ocorreram.

A Figura 4.1 ajuda na interpretação do significado da métrica proposta, onde o tempo de reprodução de vídeo era de $T_{D}$ segundos; nesse cenário foram considerados quatro segmentos de tempo, com seis pausas de duração diferente $(\Delta$ t) distribuídas aleatoriamente. O número de segmentos temporais pode ser incrementado, mas para calcular o peso individual de cada um dos segmentos, é necessário mais seqüências de vídeo de teste, razão pela qual foi restrito a quatro segmentos.

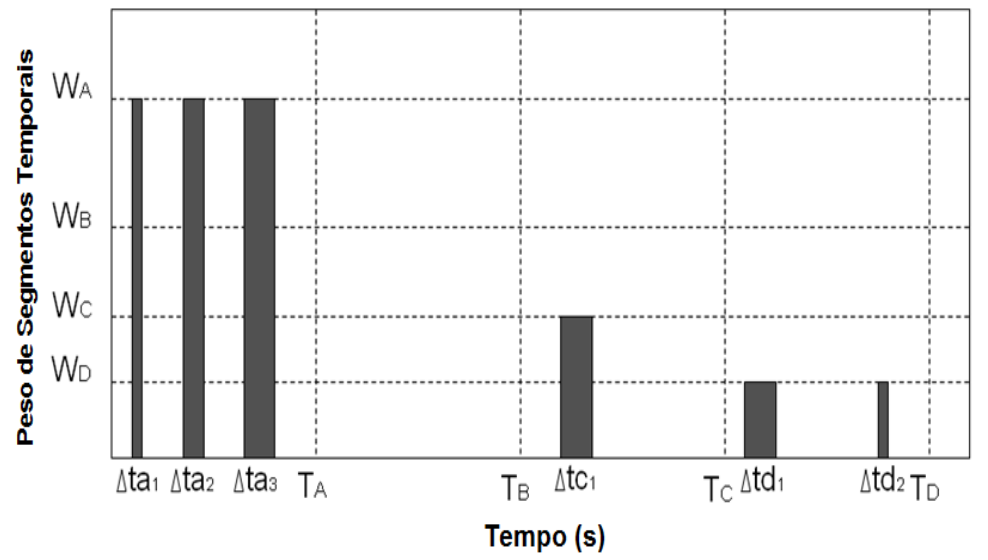

Figura 4.1: Parâmetros que compõem a métrica VsQM.

A métrica VsQM é definida pela equação (4.1): 


$$
V s Q M=\sum_{i=1}^{k} \frac{W_{i} * N_{i} * L_{i}}{T_{i}}
$$

Onde:

- $k$ é o número de segmentos temporais de um vídeo, este trabalho considera quatro segmentos para todos os testes.

- $T_{i}$ é o período de tempo, em segundos, de cada segmento;

- $N_{i}$ é o número de pausas em um segmento temporal $i$;

- $L_{i}$ é o comprimento médio de pausas, em segundos, que ocorre no mesmo segmento temporal. Assim, na Figura 4.1, para $i=A, L_{A}=$ $(\Delta t a 1+\Delta t a 2+\Delta t a 3) / 3$

- $W_{i}$ é um fator de peso, que representa o grau de degradação que cada segmento adiciona a degradação total do vídeo;

Com os resultados dos testes subjetivos será possível determinar cada um dos pesos $\left(W_{i}\right)$ de degradação que cada segmento temporal possui. Os pesos $\left(W_{A}\right.$, $W_{B}, W_{C}$ e $\left.W_{D}\right)$ determinarão uma função para mapear a métrica $V s Q M$ na escala MOS $\left(V s Q M_{M O S}\right)$ que vai desde 1 até 5 , na escala ACR apresentada na Tabela 3.1.

\subsubsection{Base de Dados dos Vídeos e Ambiente de Teste}

A métrica VsQM será determinada considerando os resultados dos testes subjetivos presenciais de vídeo, por essa razão nesses testes é necessário considerar vários vídeos com características diferentes para estabelecer a relação entre os pesos de degradação dos segmentos temporais e a QoE do usuário final.

Além do critério de localização temporal da pausa, e considerando que existem inúmeros estudos que indicam que o tipo de conteúdo de vídeo é um fator determinante na avaliação do QoE do usuário, foram considerados os tipos de vídeo: notícias (repórter falando), documentário (em relação a tecnologia) e esporte (futebol). A duração do vídeo foi estabelecida considerando que o comprimento médio da maioria dos vídeos vistos no YouTube tem a duração de 3 minutos, de modo que o comprimento dos vídeos utilizados nos testes subjetivos foram de 2 e 4 minutos. Além disso, os vídeos mais longos podem desencorajar o usuário 
Tabela 4.1: Características dos vídeos utilizados nos testes

\begin{tabular}{|c|c|c|c|}
\hline Parâmetro & Notícias & Documentário & Esporte \\
\hline Duração do vídeo (s) & 240 & 240 & 240 \\
\hline $\begin{array}{c}\text { Formato } \\
\text { Vídeo/áudio }\end{array}$ & H.264/AVC & H.264/AVC & H.264/AVC \\
\hline Resolução & $640 \times 360$ & $640 \times 360$ & $640 \times 360$ \\
\hline Taxas de frames (fps) & 25 & 29,97 & 29,97 \\
\hline
\end{tabular}

a ver todo o vídeo com uma atenção aceitável. As principais características dos três vídeos originais estão apresentadas na Tabela 4.1.

Como indicado na recomendação ITU-T P.910, os vídeos podem ser caracterizados usando os seguintes parâmetros: informação temporal (TI) e informação espacial (SI). O parâmetro SI define quão homogênea é a distribuição espacial de um quadro, e o parâmetro TI indica como varia, no plano de luminância, a posição de um pixel no domínio temporal; esses dois parâmetros são explicados com mais detalhe no Apêndice C. A Figura 4.2 apresenta os parâmetros TI e SI dos três vídeos originais sem pausas.

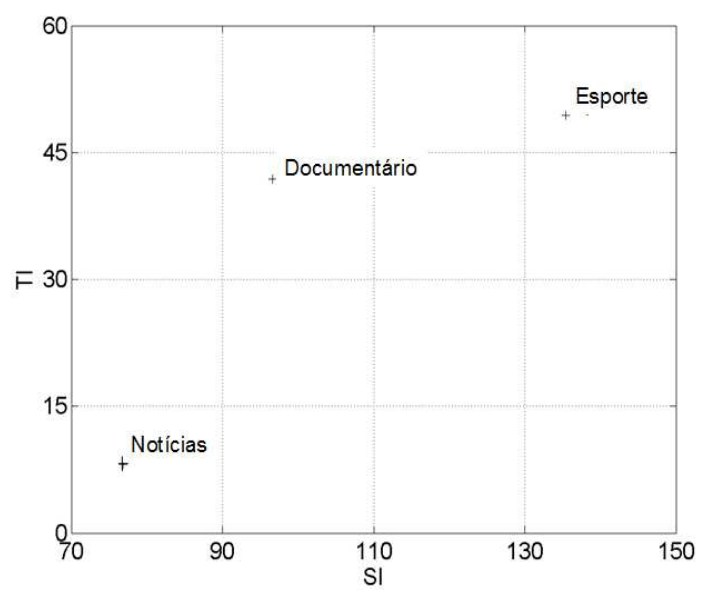

Figura 4.2: Parâmetros TI e SI dos arquivos de vídeos sem pausas.

Com todas essas considerações criou-se uma base de dados de vídeos degradados, que seguem os seguintes critérios: o tipo de conteúdo do vídeo, o comprimento de vídeo, o número de pausas, a localização temporal de cada pausa. Assim, para cada vídeo original, cada um com um determinado tipo de conteúdo, foram criados 20 vídeos degradados, aqui chamados de cenários a través da inserção de pausas em diferentes instantes, resultando 60 vídeos degradados.

Para um melhor entendimento a Figura 4.3 mostra como foi considerada a distribuição das pausas para a criação de um cenário. Assim, quatro pausas distribuídas de uma forma diferente no domínio do tempo causam diferentes impactos na QoE do avaliador. Essa figura servirá como referência para os temas 
que serão tratados nas próximas seções.

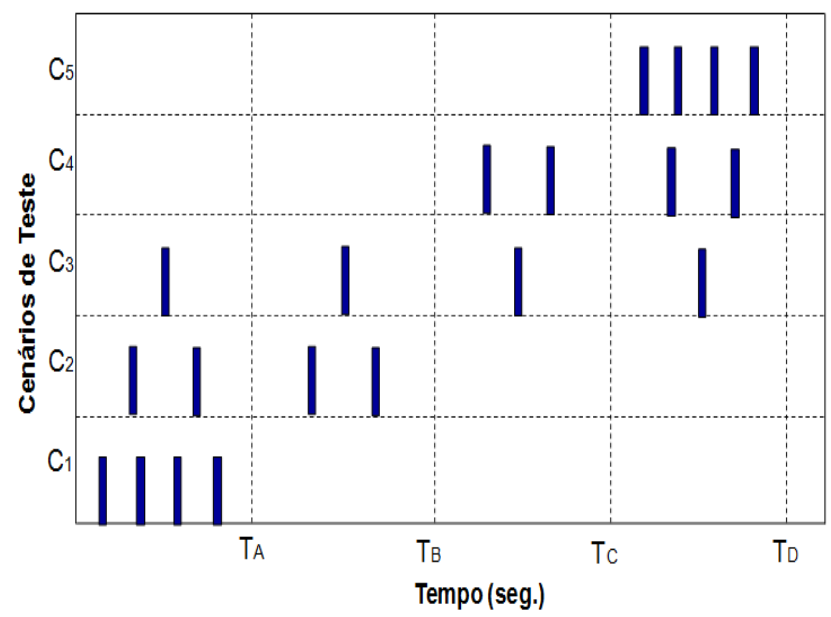

Figura 4.3: Exemplo de cenários de teste com diferente distribuição de pausas no domínio do tempo.

\subsubsection{Determinação do índice MOS por meio de testes subjetivos presenciais}

Os testes subjetivos presenciais foram realizados em dois ambientes apresentados na Figura 4.4, na sala do laboratório de processamento de sinais (LPS) da Engenharia Elétrica e na sala do Laboratório de Computação Gráfica da Faculdade de Arquitetura e Urbanismo, ambas na USP.

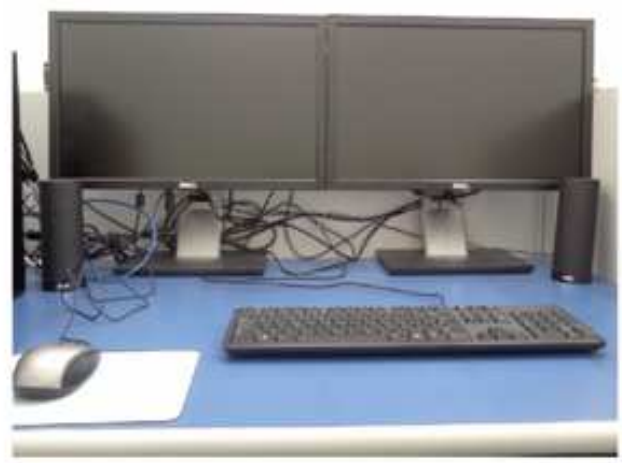

(a)

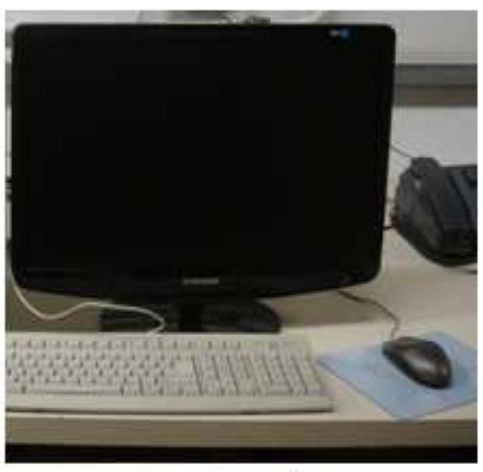

(b)

Figura 4.4: Ambientes de teste. (a) Sala do Laboratório de Processamento de Sinais - LPS. (b) Sala do Laboratório de Computação Gráfica da FAUUSP.

Os monitores tem um tamanho de visualização diagonal de 21.5 polegadas, resolução de tela de 1920x1080 pixels, tempo de resposta cinza a cinza de 8 ms, luminosidade de $250 \mathrm{~cd} / \mathrm{m} 2$, taxa de contraste dinâmico de 10000:1 e uma taxa 
de proporção Widescreen 16:9. O número total de avaliadores foi 96, todos eles informaram que não tem problemas de visão e tampouco experiência em testes de avaliação de qualidade de vídeo. Porém, todos os avaliadores já tinham utilizado o serviço de streaming de vídeo anteriormente, pelo menos uma vez. Na média, cada pessoa avaliou 10 cenários (vídeos degradados), sendo que 5 tinham uma duração de 4 minutos e os demais vídeos de 2 minutos. A avaliação foi feita nas mesmas condições para todos os observadores, considerando-se a distância de observação entre $50 \mathrm{~cm}$ a $60 \mathrm{~cm}$. Os testes foram realizados seguindo as recomendações apresentadas na seção 4.1, entre janeiro e abril de 2012.

Como resultado de testes subjetivos presenciais, obteve-se um índice de MOS para cada vídeo degradado avaliado (cenário de teste). Considerou-se apenas o valor MOS médio dos três tipos de vídeo que correspondem a um cenário, o que resulta em um vetor que denominamos vetor MOS de 20 componentes.

\subsubsection{Metodologia utilizada para determinar a métrica VsQM}

Usando a equação (4.1), e o vetor MOS obtido nos testes subjetivos, obtém-se um sistema linear de equações com três variáveis e 20 equações. Para resolver esse sistema de equações, é utilizado o método dos mínimos quadrados. Além disso, os valores VsQM foram transformados em valores na escala de 1 a 5 , correspondente à escala MOS e resultando nos valores de índices $V s Q M_{M O S}$ por meio da função exponencial, apresentada em (4.2). A função exponencial foi utilizada, pois teve um menor erro quadrático em relação a uma função linear, e porque a função exponencial é utilizada em trabalhos como (HOSSFELD et al., 2011) (AROUSSI; BOUABANA-TEBIBEL; MELLOUK, 2012), nos quais a QoE em serviços multimedia é modelada.

$$
V s Q M_{M O S}=C \times \exp \left(-\sum_{i=1}^{k} \frac{N_{i} \times L_{i} \times W_{i}}{T_{i}}\right)
$$

Onde C e uma constante de fator de escala a ser determinada. Portanto, para cada um dos cenários há uma relação entre $V s Q M_{M O S}$ e VsQM. Assim, por exemplo, em (4.3) é apresentada a relação corresponde a cenário 1 ( $\left.V s Q M_{M O S 1}\right)$ : 


$$
\begin{aligned}
V s Q M_{M O S 1} & =C * \exp \left(-\frac{W_{A} * N_{A} * L_{A}}{T_{A}}-\frac{W_{B} * N_{B} * L_{B}}{T_{B}}\right. \\
& \left.-\frac{W_{C} * N_{C} * L_{C}}{T_{C}}-\frac{W_{D} * N_{D} * L_{D}}{T_{D}}\right)
\end{aligned}
$$

Onde $\mathrm{C}$ é uma constante e $W_{X}$ é o peso do segmento temporal $X$ a serem determinados. Sendo que as variáveis $V s Q M_{M O S X}, N_{X}, T_{X}$ e $L_{X}$ são conhecidas. Em (4.4) é apresentada a equação, depois de considerar o logaritmo neperiano na equação (4.3).

$$
\begin{aligned}
\operatorname{Ln}\left(V s Q M_{M O S 1}\right) & =\operatorname{Ln}(C)-\frac{W_{A} * N_{A} * L_{A}}{T_{A}}-\frac{W_{B} * N_{B} * L_{B}}{T_{B}} \\
& -\frac{W_{C} * N_{C} * L_{C}}{T_{C}}-\frac{W_{D} * N_{D} * L_{D}}{T_{D}}
\end{aligned}
$$

Os valores do vetor MOS de 20 componentes obtido dos testes subjetivos são relacionados aos valores de $V s Q M_{M O S}$, já que esses valores modelam a QoE dos avaliadores. Utilizando os valores do vetor MOS e a equação (4.4), é obtido um sistema de equações lineares o qual é representado em (4.5).

$$
\left[\begin{array}{cccc}
1 & t_{1,2} & \ldots & t_{1,5} \\
1 & t_{2,2} & \ldots & t_{2,5} \\
\vdots & & & \vdots \\
1 & t_{20,2} & \ldots & t_{20,5}
\end{array}\right]\left[\begin{array}{c}
\operatorname{Ln}(C) \\
W_{A} \\
W_{B} \\
W_{C} \\
W_{D}
\end{array}\right]=\left[\begin{array}{c}
\operatorname{Ln}\left(V s Q M_{M O S-1}\right) \\
\operatorname{Ln}\left(V s Q M_{M O S-2}\right) \\
\vdots \\
\operatorname{Ln}\left(V s Q M_{M O S-20}\right)
\end{array}\right]
$$

O termo $t_{x} y$ representa a relação das variáveis $N y * L y / T y$ correspondentes ao segmento $y$ e ao cenário $x$. Assim, por exemplo, considerando o primeiro cenário, as variáveis $t_{1,2}$ a $t_{1,5}$ representam:

$t_{1,2}=-N_{A} \times L_{A} / T_{A} ; t_{1,3}=-N_{B} \times L_{B} / T_{B} ; t_{1,4}=-N_{C} \times L_{C} / T_{C} ; t_{1,5}=-N_{D} \times L_{D} / T_{D}$

\subsubsection{Resultados obtidos com a Métrica VsQM}

Utilizando o método de mínimos quadrados na equação (4.5), são obtidos os valores dos pesos de todos os segmentos temporais considerados: $W_{A}, W_{B}, W_{C}$ e 
$W_{D}$, os quais são apresentados na Figura 4.5 (RODRIGUEZ et al., 2012b).

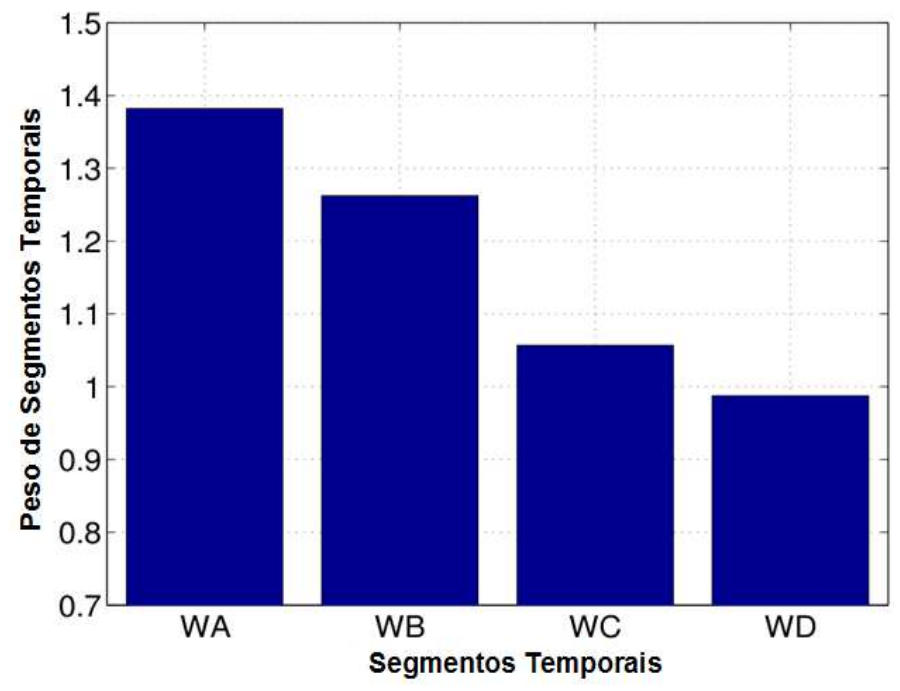

Figura 4.5: Peso dos segmentos temporais: $W_{A}, W_{B}, W_{C}$ e $W_{D}$ (RODRIGUEZ et al., 2012b).

Como representado nesta figura, é importante notar que o segmento inicial do vídeo é mais relevante, ou seja, tem um peso de degradação maior que os outros segmentos. Como conseqüência, as pausas no início do vídeo, tem um maior efeito negativo sobre a QoE do usuário final.

Esses resultados mostram que o conceito denominado como efeito de memória recente, não é aplicável no serviço de streaming de vídeo que tenha uma duração de dois ou quatro minutos. Isto poderia ser explicado por causa da natureza de degradação ser diferente. No caso de degradação da qualidade espacial não há perda total dos dados, o vídeo apresenta alguma degradação como imagem borrada (blurring) ou com movimentos espasmódicos (jerkiness), ou algum outro tipo de ruído, porém, a informação sempre está presente. No caso das pausas existe perda total de informação, a qual interrompe os processos de mecanismo cognitivo do ser humano.

Outro fator importante é que todos os avaliadores já tinham experiência no serviço de streaming de vídeo e, inconscientemente, eles aprenderam que quando existem cortes de informação (pausas) no início do vídeo, é muito provável que essas pausas também estejam presentes durante todo o vídeo. Como conseqüência, eles têm uma expectativa negativa a partir do início do vídeo.

A Figura 4.6 (a) apresenta a relação entre a métrica proposta VsQM na escala MOS (VsQM $M_{M O S}$ ) calculada usando a equação (4.2), e os valores MOS correspondentes aos testes subjetivos dos 20 cenários considerados. Para um melhor entendimento, a Figura 4.6 (b) mostra como se relaciona os valores obtidos 
para a métrica VsQM, VSQM $M_{M O S}$ e o MOS obtido na avaliação subjetiva do cenário de teste número 5 . Os resultados mostram que o modelo exponencial escolhido para modelar o $V S Q M_{M O S}$ é muito confiável, porque o erro máximo obtido entre $V s Q M_{M O S}$ e MOS é de 0,0129 na escala MOS de 5 pontuações.

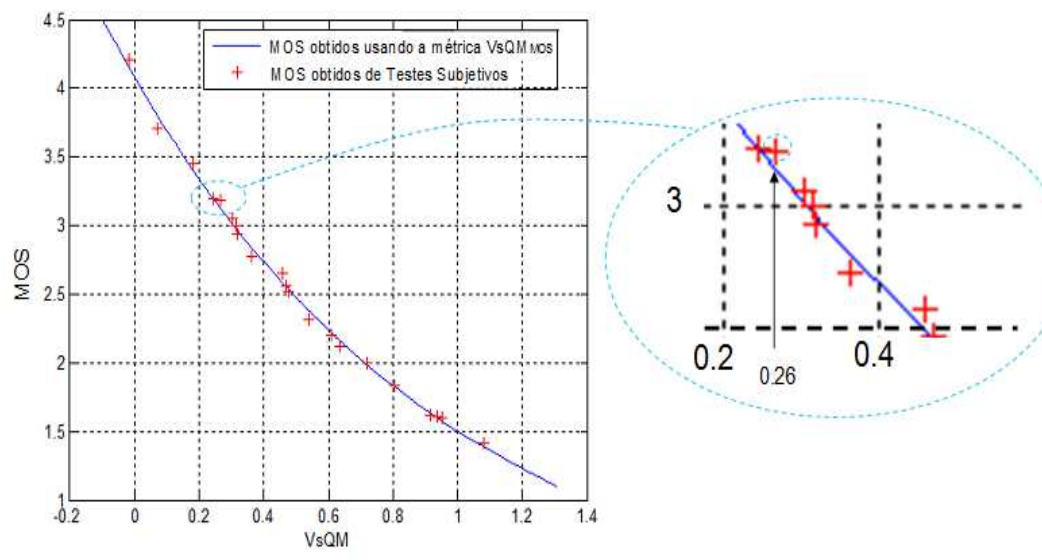

(a)

\begin{tabular}{|c|c|c|c|c|c|c|c|}
\hline Cenário & $\begin{array}{l}\text { Tamanho do } \\
\text { segmento do } \\
\text { vídeo (seg.) }\end{array}$ & $\begin{array}{c}\text { Localização } \\
\text { Temporal }\end{array}$ & $\begin{array}{l}\text { Número } \\
\text { de } \\
\text { pausas }\end{array}$ & $\begin{array}{l}\text { Pausa } \\
\text { (seg.) }\end{array}$ & VsQM & $\begin{array}{c}\text { VsQM- } \\
\text { MOS }\end{array}$ & $\begin{array}{c}\text { MOS } \\
\text { Subjetivo }\end{array}$ \\
\hline \multirow{4}{*}{ Cenário 5} & 60 & A & 0 & 0 & \multirow{4}{*}{0.26} & \multirow{4}{*}{3.179} & \multirow{4}{*}{3.19} \\
\hline & 60 & B & 0 & 0 & & & \\
\hline & 60 & C & 0 & 0 & & & \\
\hline & 60 & D & 4 & 4 & & & \\
\hline
\end{tabular}

(b)

Figura 4.6: Relação entre MOS, $V s Q M_{M O S}$ e VsQM: (a) Relação entre os índices MOS obtidos em testes subjetivos e $V s Q M_{M O S}$ para os 20 cenários avaliados (b) Exemplo para um cenário de teste (Cenário 5) que relaciona a métrica VsQM, $V s Q M_{M O S}$ e o MOS subjetivo.

Na Figura 4.7 é apresentada a relação entre o parâmetro de duração de pausa e o índice MOS obtido pela equação (4.2) para 5 cenários diferentes, onde a duração total do vídeo foi de 4 minutos. A diferença dos cenários está principalmente na distribuição das pausas no domínio do tempo, sendo que esses cenários correspondem aos apresentados na Figura 4.3.

A Figura 4.8 tem como principal objetivo ressaltar a importância de considerar o parâmetro peso de degradação do Segmento Temporal da Pausa (W) na métrica VsQM proposta. Essa figura apresenta quatro parâmetros: MOS (VsQM) - 2 min., que representa o valor de $V s Q M_{M O S}$ considerando o parâmetro W em um vídeo de 2 min. de duração; MOS (N-VsQM) - 2 min., que representa o valor de $V s Q M_{M O S}$ com W igual a 1; para os vídeo de 4 min. de duração é aplicada a mesma notação. Pode-se observar que dependendo da distribuição das pausas, no domínio do tempo, a QoE do usuário varia; por exemplo, no cenário 1, a diferença da métrica VsQM considerando o parâmetro W (VsQM - 2min) é 12\% 


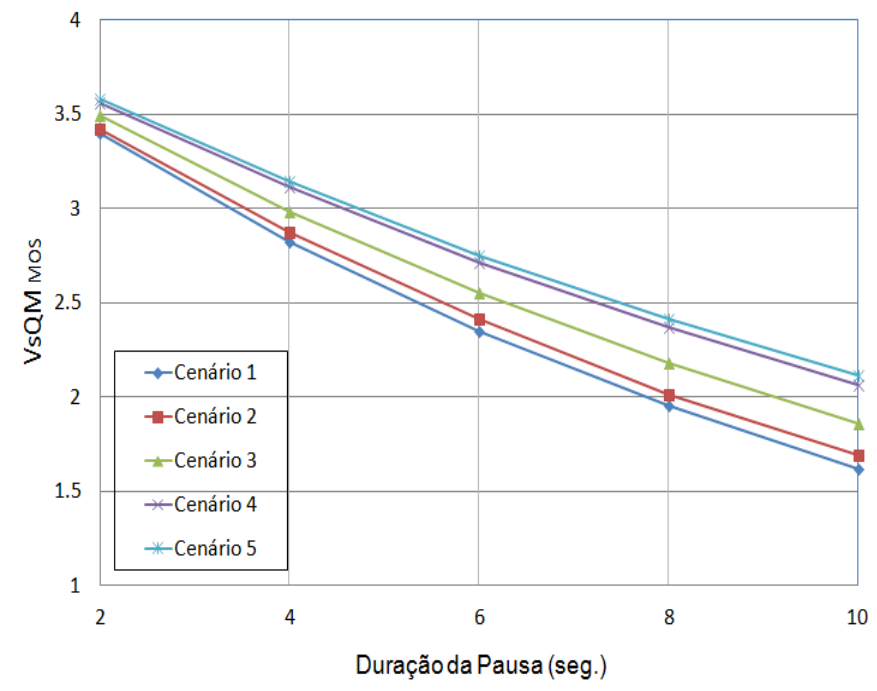

Figura 4.7: Relação entre o MOS obtido da métrica $V s Q M_{M O S}$ e a duração da pausa.

mais baixo que o valor obtido no mesmo cenário sem considerar o parâmetro W $(\mathrm{N}-\mathrm{VsQM}-2 \mathrm{~min})$.

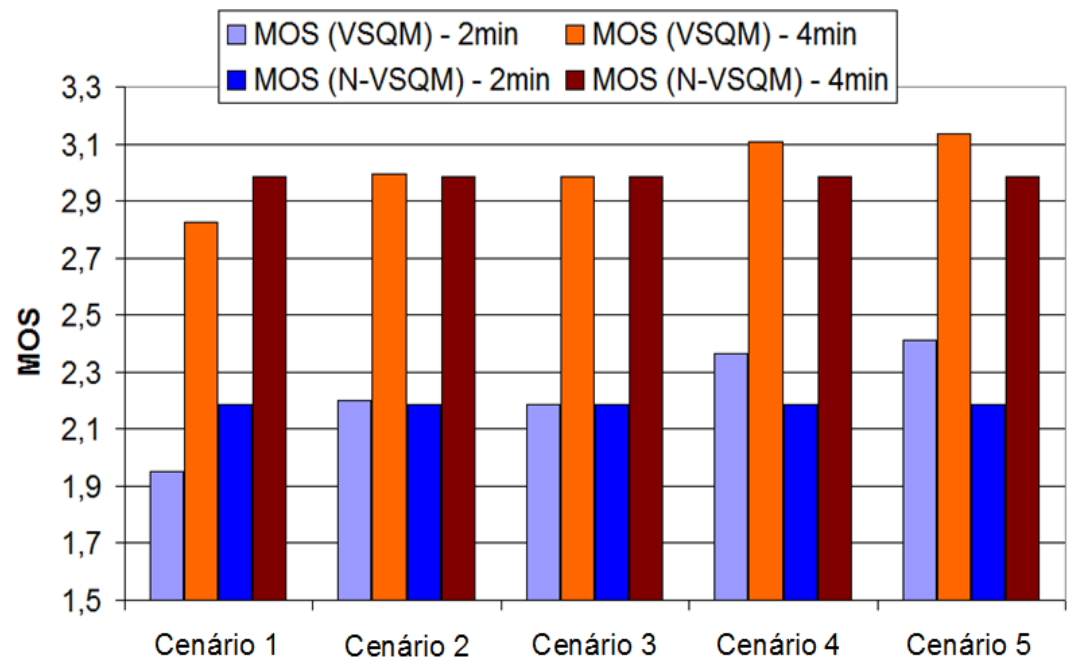

Figura 4.8: MOS obtidos considerando e sem considerar o parâmetro W, com seqüências de vídeo de 2 e 4 minutos.

Cabe esclarecer que nos casos, nos quais não se considera o parâmetro $\mathrm{W}$, o peso é único para todos os segmentos, é dizer não interessa a localização temporal da pausa. Assim, o MOS (VsQM) considera diferentes pesos de degradação para cada segmento temporal e MOS (N-VsQM) considera um peso único (um) para todos os segmentos, por isso todos os valores correspondentes a MOS (N-VsQM) para os vídeos de 4 minutos é o mesmo, da mesma forma para os vídeos de 2 minutos. Como mencionado anteriormente em (PORTER; PENG, 2011) foi definida a métrica denominada pause intensity, a qual não considera os pesos dos 
segmentos temporais, e que se for mapeada na escala MOS de cinco pontuações utilizando a função exponencial seria equivalente aos valores representados por (N-VsQM) na Figura 4.8. Assim, pode-se observar que o desempenho da métrica VsQM é superior da métrica pause intensity porque o VsQM utiliza o conceito de pesos de degradação para cada segmento temporal.

\subsection{Melhora da métrica VsQM considerando o tipo de conteúdo de vídeo}

Os resultados dos testes subjetivos mostraram que os valores MOS obtidos variam dependendo do tipo de conteúdo do vídeo testado, sempre considerando as mesmas degradações nos diferentes tipos de vídeos, ou seja, com o mesmo número de pausas e localizados nos mesmos instantes do tempo. Assim, se propõe incluir o tipo de conteúdo de vídeo como um novo parâmetro na determinação da métrica VsQM. A equação (4.7) apresenta a nova fórmula para determinar a métrica VsQM, que denominaremos de eVsQM (enhanced VsQM).

$$
e V s Q M=\sum_{i=1}^{k} \frac{N_{i} * L_{i} * W c t_{i}}{T_{i}}
$$

Onde:

- $k$ é o número de segmentos temporais de um vídeo, considerando-se quatro segmentos.

- $T_{i}$ é o período de tempo, em segundos, de cada segmento;

- $N_{i}$ é o número de pausas em um segmento temporal "i";

- $L_{i}$ é o comprimento médio de pausas, em segundos, que ocorre no mesmo segmento temporal.

- $W c t_{i}$ representa o peso de degradação dependente do tipo de conteúdo de vídeo para cada um dos segmentos temporais $i$.

Os valores de $W c t_{i}$ são determinados a partir dos resultados dos testes subjetivos, obtidos para cada tipo de conteúdo de vídeo, considerando os diferentes cenários de teste. Cada cenário de teste representa um vídeo degradado com quatro pausas localizadas em diferentes instantes ao longo do vídeo. Para um 
melhor esclarecimento, a Figura 4.9 apresenta um exemplo de três cenários $\left(C_{A}\right.$, $C_{B}$ e $\left.C_{C}\right)$ de teste.

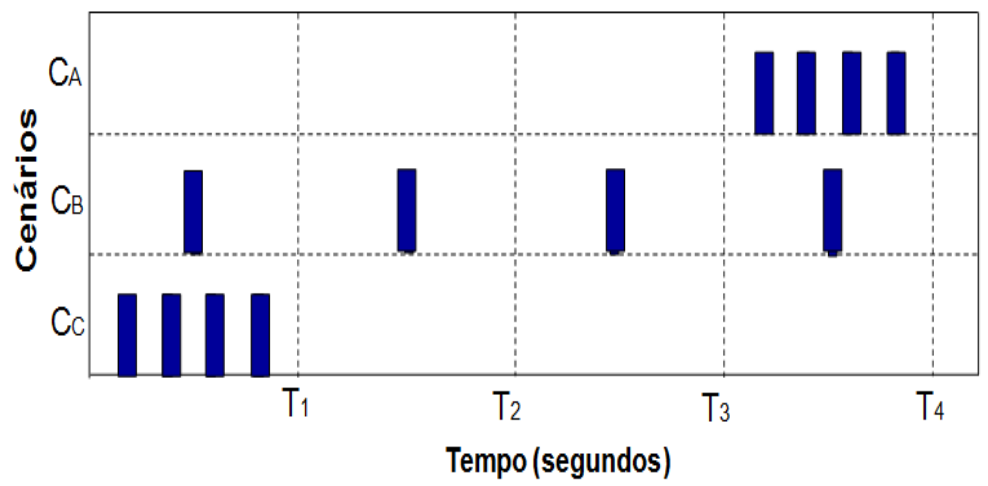

Figura 4.9: Distribuiçao temporal de pausas em um mesmo vídeo.

Os resultados dos testes subjetivos de avaliação de vídeo são apresentados na Tabela 4.2 .

Tabela 4.2: Resultados de testes subjetivos de qualidade de vídeo para cada tipo de conteúdo de vídeo

\begin{tabular}{|c|c|c|c|}
\hline Cenário & Esporte (MOS) & Documentário (MOS) & Notícias (MOS) \\
\hline Cenário 1 & 2,27 & 2,98 & 3,08 \\
\hline Cenário 2 & 2,72 & 3,17 & 3,25 \\
\hline Cenário 3 & 2,64 & 3,05 & 3,32 \\
\hline Cenário 4 & 2,66 & 3,09 & 3,08 \\
\hline Cenário 5 & 2,85 & 3,26 & 3,45 \\
\hline Cenário 6 & 1,43 & 2,66 & 2,85 \\
\hline Cenário 7 & 2,11 & 2,89 & 2,94 \\
\hline Cenário 8 & 1,90 & 2,82 & 2,95 \\
\hline Cenário 9 & 1,85 & 2,78 & 2,92 \\
\hline Cenário 10 & 1,15 & 2,28 & 2,58 \\
\hline Cenário 11 & 1,30 & 2,58 & 2,72 \\
\hline Cenário 12 & 1,31 & 2,42 & 2,64 \\
\hline Cenário 13 & 1,00 & 1,38 & 1,85 \\
\hline Cenário 14 & 1,00 & 1,74 & 2,12 \\
\hline Cenário 15 & 1,00 & 1,72 & 2,12 \\
\hline Cenário 16 & 1,00 & 1,68 & 2,12 \\
\hline Cenário 17 & 1,00 & 1,98 & 2,51 \\
\hline Cenário 18 & 3,52 & 3,84 & 3,76 \\
\hline Cenário 19 & 3,24 & 3,52 & 3,58 \\
\hline Cenário 20 & 2,94 & 3,24 & 3,42 \\
\hline
\end{tabular}

Com esses valores de índice MOS de cada tipo de conteúdo de vídeo e as informações de cada cenário (número de pausas e localização das pausas), formou-se um sistema de equações lineares, a partir do qual foram determinados os diferentes valores de $W c t_{i}$ utilizando a mesma metodologia empregada para determinar os pesos de degradação dos segmentos temporais na métrica VsQM, ou seja, utilizando um dos métodos de mínimos quadrados, especificamente o pseudo-inverso. 
Os valores obtidos de $W c t_{i}$ para cada tipo de conteúdo de vídeo são apresentados na Figura 4.10. Pode-se observar que os maiores pesos de degradação de qualidade de vídeo correspondem ao tipo de conteúdo de vídeo de esporte, e os menores correspondem aos vídeos de notícias. Adicionalmente, observa-se que os pesos de degradação dos dois primeiros segmentos temporais são maiores que dos dois últimos segmentos, acontecendo esse comportamento para todos os tipos de conteúdo de vídeo.

Cabe destacar, que se deve considerar que na aplicação de streaming de vídeo, o tipo de conteúdo do vídeo é armazenado e informado pelo servidor de vídeo ao cliente. Essa informação pode ser realizada adicionando um parâmetro no protocolo de descrição da seção multimídia ou estabelecendo um canal de comunicação socket (RODRIGUEZ; RAMIREZ, 2009) entre o servidor e o cliente.

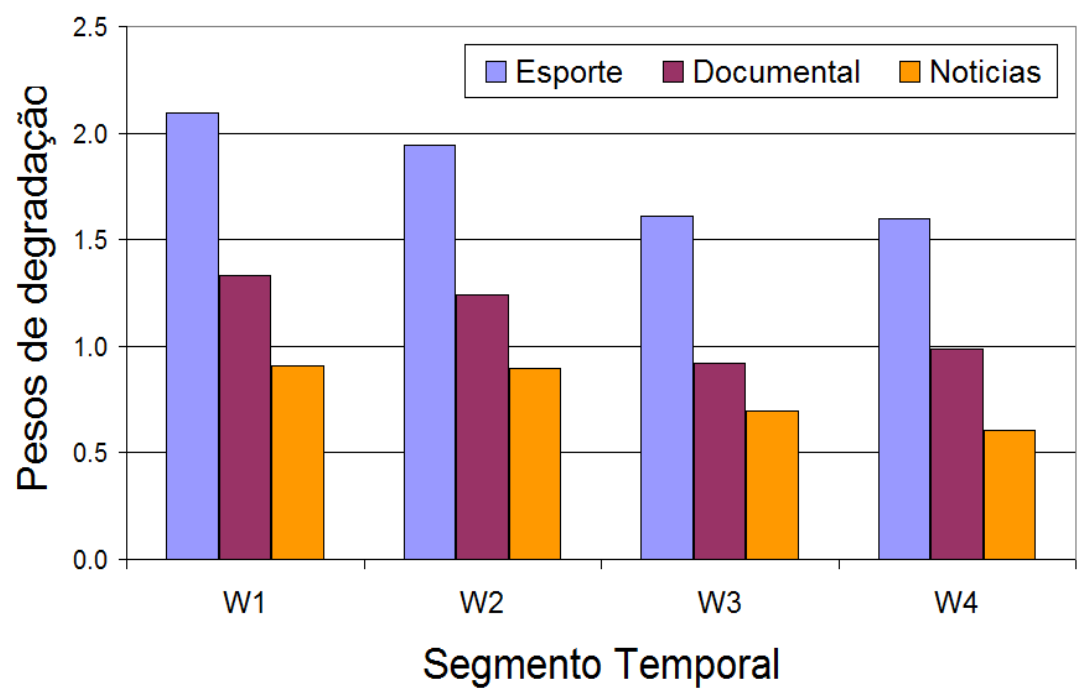

Figura 4.10: Peso de degradação de qualidade que cada segmento temporal adicionado à degradação total da qualidade do vídeo.

O algoritmo simplificado para a determinação da métrica eVSQM é apresentado na Figura 4.11. Neste trabalho somente são considerados três tipos de conteúdo de vídeo.

\subsubsection{Metodologia de Teste na Avaliação de Qualidade de vídeo utilizando Crowdsourcing}

Para validar os resultados da métrica eVsQM foram realizados testes subjetivos de avaliação, baseado no conceito de crowdsourcing, isto é, por meio de avaliadores remotos conectados na Internet. O objetivo principal de se utilizar essa metodologia é diminuir consideravelmente o tempo na realização dos testes, devido a que, essa é uma das principais dificuldades da execução de testes 


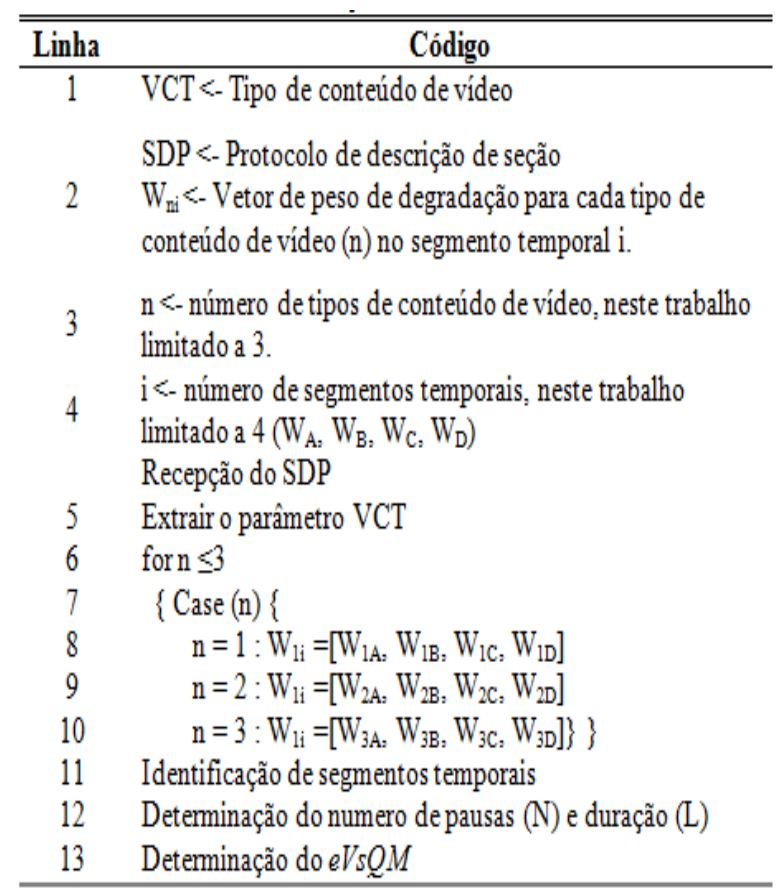

Figura 4.11: Algoritmo para determinação da métrica eVSQM no cliente.

subjetivos presencias.

Os trabalhos atuais utilizam, na maioria dos casos, soluções denominadas como Mechanical Turk, onde os usuários realizam tarefas em troca de uma compensação econômica, sendo que as ferramentas de maior aceitação são o Amazon MTurk e o Microworkers.

Para a realização dos testes utilizou-se a solução Microworkers, no qual foram apresentadas as instruções das tarefas a serem realizadas e a URL do portal construído.

A Figura 4.12 apresenta a interface gráfica do portal onde foram disponibilizados os vídeos utilizados como material de teste. Pode-se observar que, a escala de avaliação MOS é a escala ACR de 5 pontuações, apresentada na Tabela 3.1, sendo disponibilizado o vídeo original e os vídeos degradados.

Também, com o intuito de uma melhor análise dos resultados, se solicita ao avaliador algumas informações pessoais, tais como nome ou o identificador utilizado no Microworkers, gênero e preferência em conteúdo de vídeo. O conteúdo do portal é apresentado em três idiomas: espanhol, inglês e português. As pontuações e as informações dos avaliadores são enviadas a uma base de dados Mysql.

Adicionalmente, se solicita ao usuário, que responda a algumas perguntas referentes ao conteúdo visual de cada vídeo, com o objetivo de se certificar que o usuário assistiu a totalidade do vídeo, a fim de validar os resultados. Por 
exemplo, no vídeo correspondente ao conteúdo de esporte que trata sobre cenas de um jogo de futebol, pergunta-se ao avaliador quantos gols ocorreram em todo o vídeo. Essas perguntas são denominadas como perguntas de validação e são colocadas no site do Microworkers. No caso do usuário dar uma resposta errada, a ferramenta Microworkers não contabiliza essa avaliação, ou seja, o usuário não recebe a compensação econômica, e a mesma avaliação é realizada por outro usuário até que se consiga uma resposta correta.

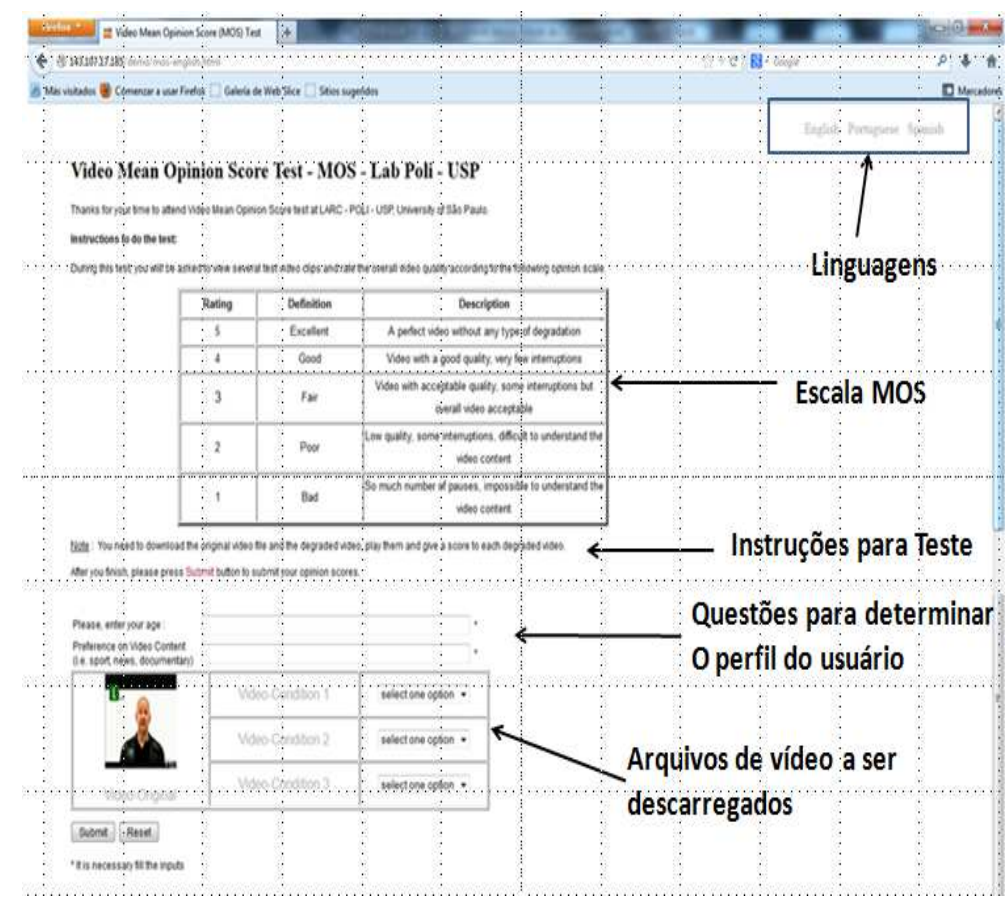

Figura 4.12: Framework - Interface do portal utilizado na Avaliação de Qualidade de Vídeo.

\subsubsection{Desempenho da métrica proposta eVsQM}

As regras do Microworker estabelecem que cada solicitação de trabalho, chamado de campanha, deve ser avaliada por pelo menos 30 avaliadores. Assim, para cada vídeo avaliado foram enviadas duas campanhas, conseguindo-se 60 pontuações MOS para cada vídeo.

Como descrito anteriormente, a métrica eVSQM foi modelada e definida a partir de teste presenciais, nos quais foram utilizados como material de teste, três tipos de conteúdos de vídeo: Esporte, Documentário e Noticias, com duração de 2 e 4 minutos e com pausas de 4 segundos.

A primeira análise realizada foi o estudo da confiabilidade dos resultados obtidos nos testes remotos em relação aos testes presenciais. Utilizaram-se três cenários de degradação de vídeo, de 4 minutos de duração, correspondentes aos 
cenários: 1, 3 e 5 da Figura 4.3. Os resultados dos testes remotos e presencias são apresentados na Tabela 4.3. Com esses resultados foram obtidos os coeficientes de correlação de Pearson $(\gamma=0,9821)$ e Spearman $(\rho=0,9833)$, os quais são bastante próximos.

Tabela 4.3: Resultados de testes com avaliadores remotos e presenciais

\begin{tabular}{|c|c|c|c|c|}
\hline Tipo de teste & & Cenário 1 & Cenário 3 & Cenário 5 \\
\hline \multirow{2}{*}{ Esporte } & Presencial & 2,27 & 2,64 & 2,85 \\
& Remoto & 2,61 & 2,87 & 2,95 \\
\hline \multirow{2}{*}{ Documentário } & Presencial & 2,98 & 3,05 & 3,26 \\
& Remoto & 3,25 & 3,31 & 3,39 \\
\hline \multirow{2}{*}{ Notícias } & Presencial & 3,08 & 3,32 & 3,45 \\
& Remoto & 3,26 & 3,49 & 3,66 \\
\hline
\end{tabular}

Para os testes de validação, utilizando o método de crowdsourcing, foi utilizado como material de testes os mesmos tipos de conteúdos de vídeo utilizados nos testes presenciais, mas com degradações diferentes. Cada cenário de teste representa um vídeo com uma duração de 5, 8 ou 11 minutos, nos qual foi inserido pausas em diferentes localizações no domínio do tempo e com durações de 2, 6 e 9 segundos.

A Tabela 4.4 apresenta os resultados obtidos pelas métricas eVSQM $M_{M O S}$, $V s Q M_{M O S}$ e nos testes de usuários remotos (MOS/Crowd), considerando um vídeo de 5 minutos e com três diferentes cenários de degradação ( $\mathrm{Ca}, \mathrm{Cb}$ e $\mathrm{Cc}$ ) para os conteúdos de vídeo de esporte (Esp), documentário (Doc) e noticias (Not). Pode-se observar que, a métrica $V s Q M_{M O S}$, por ter os mesmos pesos de degradação para os três tipos de conteúdo apresentou os mesmos valores. Assim, a métrica $V s Q M_{M O S}$ apresenta uma pontuação superior para os vídeos de esporte e uma pontuação inferior para os vídeos de notícias. A Figura 4.13 apresenta a relação MOS/Crowd vs. eVSQM $M_{M O S}$ e a relação MOS/Crwod vs. V $s Q M_{M O S}$. Os valores de correlação de Pearson obtidos são: $\rho 1$ (eVsQM, Crowd) $=0,94$ e $\rho 2(\mathrm{VsQM}$, Crowd $)=0,58$.

Tabela 4.4: Resultados obtidos pelas métricas $e V S Q M_{M O S}, V s Q M_{M O S}$ e nos testes de usuários remotos (MOS/Crowd) com vídeos de 5 minutos de duração

\begin{tabular}{|c|c|c|c|}
\hline Cenário & MOS/ eVsQM & MOS/ VsQM & MOS/ Crowd \\
\hline Esporte - Ca & 2,262 & 2,798 & 2,471 \\
\hline Esporte - Cb & 1,53 & 2,164 & 1,65 \\
\hline Esporte - Cc & 1,866 & 2,499 & 1,996 \\
\hline Documentário - Ca & 2,972 & 2,798 & 3,25 \\
\hline Documentário - Cb & 2,295 & 2,164 & 2,642 \\
\hline Documentário - Cc & 2,693 & 2,499 & 2,471 \\
\hline Noticias - Ca & 3,313 & 2,798 & 3,41 \\
\hline Noticias - Cb & 2,764 & 2,164 & 2,54 \\
\hline Noticias - Cc & 3,122 & 2,499 & 3,042 \\
\hline
\end{tabular}




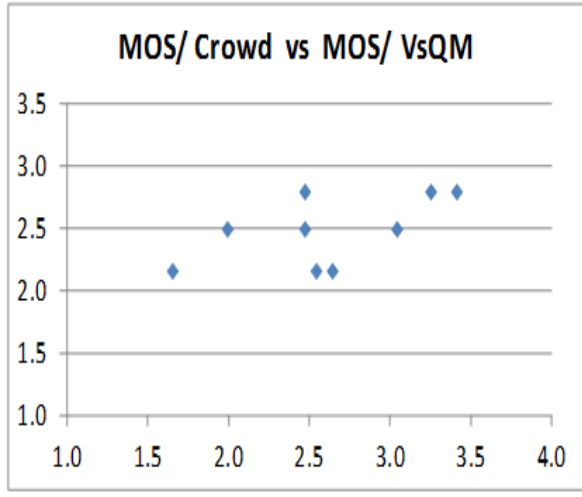

(a)

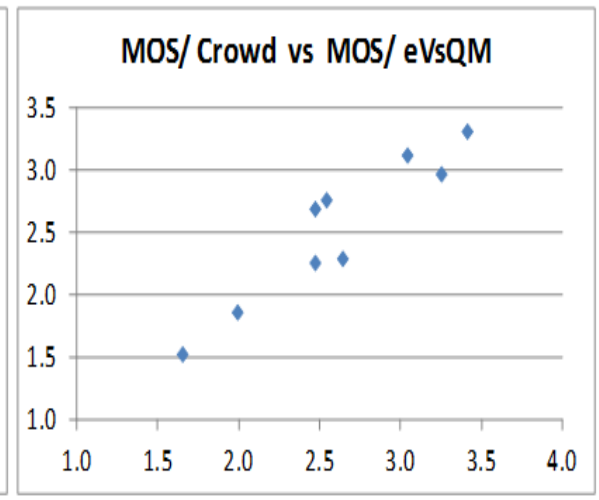

(b)

Figura 4.13: Relação dos resultados obtidos para vídeos de 5 minutos de duração. (a) Relação da métrica $V S Q M_{M O S}$ com (MOS/Crowd). (b) Relação da métrica $e V s Q M_{M O S}$ com (MOS/Crowd)

Considerando os dois primeiros cenários ( $\mathrm{Ca}$ e $\mathrm{Cb}$ ), para os três conteúdos de vídeos, mas com uma duração de vídeo de oito minutos, obtiveram-se os resultados apresentados na Tabela 4.5. A Figura 4.14 apresenta as relações MOS/Crowd vs. $e V S Q M_{M O S}$ e MOS/Crwod vs. $V s Q M_{M O S}$. Nessa figura os valores de correlação de Pearson foram: $\rho 1(\mathrm{eVsQM}$, Crowd $)=0,94$ e $\rho 2(\mathrm{VsQM}$, Crowd $)=0,58$.

Tabela 4.5: Resultados obtidos pelas métricas $e V S Q M_{M O S}, V s Q M_{M O S}$ e nos testes de usuários remotos (MOS/Crowd) com vídeos de 8 minutos de duração

\begin{tabular}{|c|c|c|c|}
\hline Cenário & MOS/ eVsQM & MOS/ VsQM & MOS/ Crowd \\
\hline Esporte - Ca & 2,810 & 3,224 & 2,91 \\
\hline Esporte - Cb & 2,201 & 2,745 & 2,432 \\
\hline Documentário - Ca & 3,400 & 3,224 & 3,293 \\
\hline Documentário - Cb & 2,893 & 2,745 & 2,994 \\
\hline Noticias - Ca & 3,642 & 3,224 & 3,520 \\
\hline Noticias - Cb & 3,252 & 2,745 & 3,051 \\
\hline
\end{tabular}

A Tabela 4.6 apresenta os resultados ao avaliar o cenário "Ca" utilizando um vídeo de 11 minutos. Pode-se observar que, em relação às duas figuras anteriores obtiveram-se valores maiores de índice MOS, pois o número e a duração das pausas são as mesmas, mas estão distribuídas em um tempo maior, ocasionando um menor desconforto no usuário.

Tabela 4.6: Resultados obtidos pelas métricas $e V S Q M_{M O S}, V s Q M_{M O S}$ e nos testes de usuários remotos (MOS/Crowd) com vídeos de 11 minutos de duração

\begin{tabular}{|c|c|c|c|}
\hline Cenário & MOS/ eVsQM & MOS/ VsQM & MOS/ Crowd \\
\hline Esporte - Ca & 3,102 & 3,438 & 3,262 \\
\hline Documentário - Ca & 3,614 & 3,438 & 3,381 \\
\hline Noticias - Ca & 3,803 & 3,438 & 4,025 \\
\hline
\end{tabular}

Em seguida, algumas considerações finais sobre os resultados obtidos pelas 


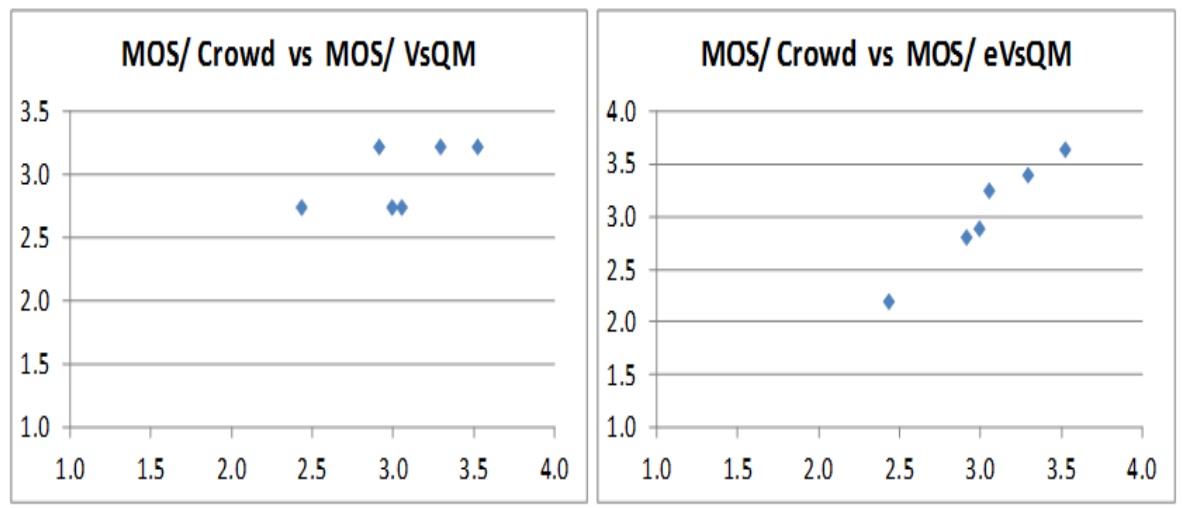

(a)

(b)

Figura 4.14: Relação dos resultados obtidos para vídeos de 8 minutos de duração. (a) Relação da métrica $V S Q M_{M O S}$ com (MOS/Crowd). (b) Relação da métrica $e V s Q M_{M O S}$ com (MOS/Crowd)

métricas VsQM e eVsQM:

- Os resultados dos testes experimentais demonstraram que o peso de degradação que acontece em cada segmento temporal depende do tipo de conteúdo de vídeo, como apresentado na Tabela 4.2. Nos testes foram utilizados três tipos de conteúdo de vídeo: esporte, documentário e notícias. Assim, o vídeo relacionado a esporte apresentou o maior peso de degradação, e o de notícias apresentou o menor valor.

- Também se observa que as pausas que acontecem na parte inicial do vídeo, denominadas como primeiro segmento temporal tem um maior peso de degradação na qualidade total do vídeo em relação aos outros segmentos temporais. Por outro lado, as pausas que acontecem no final do vídeo, denominadas como quarto segmento temporal tiveram o menor peso de degradação. É importante destacar que, esse comportamento foi observado nos três tipos de conteúdo de vídeo, como pode ser observado na Figura 4.10 .

- A partir dos resultados e com o intuito de melhorar a exatidão da métrica VsQM foi incluído, na determinação dessa métrica, um parâmetro relacionado ao tipo de conteúdo do vídeo. Denominando-se a essa métrica de eVsQM.

- O desempenho da métrica eVSQM foi avaliado em diferentes cenários de degradação, ou seja, utilizando vídeos com diferentes localizações e durações de pausas. A avaliação subjetiva de qualidade de vídeo foi realizada por meio de usuários remotos conectados à Internet. 
- Os resultados apresentados nas Tabelas 4.4, 4.5 e 4.6 demonstram que a métrica eVsQM teve uma melhor correlação com os resultados dos testes subjetivos com usuários remotos se comparada com a métrica VsQM. Assim, dependendo do cenário de degradação do vídeo analisado, a métrica eVsQM atingiu valores de correlação de Pearson de 0,94 a 0,98.

- No seguinte capítulo, se apresentará um caso de estudo no qual a QoE do usuário do serviço de streaming de vídeo, utilizando a solução DASH, é afetada por fatores diferentes às pausas. Assim, a métrica eVsQM é utilizada como um fator da QoE global do usuário. 


\section{$5 \quad$ Estudo de Caso}

Nesta seção é apresentado um estudo de caso, o qual trata sobre os efeitos que as mudanças de resolução de vídeo têm sobre a QoE do usuário que assiste um streaming de vídeo utilizando a solução DASH. Como apresentado no Capítulo 4, as pausas que acontecem durante uma transmissão de streaming de vídeo degradam a QoE do usuário, da mesma forma, se estudará como as mudanças frequentes de resolução de vídeo degradam a QoE do usuário e como determinar a QoE global do usuário quando estes dois fatores de degradação estão presentes durante a transmissão do vídeo.

\subsection{Efeitos das mudanças de resolução de vídeo na QoE}

Um serviço de streaming de vídeo utilizando uma solução DASH tem por objetivo melhorar a QoE do usuário. No entanto, os resultados experimentais obtidos neste trabalho, mostraram que, se dois eventos de comutação entre duas resoluções de vídeo acontecem em um período menor do que 14 segundos, a QoE do usuário começa a diminuir. Para eventos de comutação entre vídeos de diferente resolução, que ocorrem em períodos maiores que 16 segundos, a atenção visual humana parece ser menos afetada, portanto a QoE do usuário quase não decrementa. Esse fato destaca a importância de que os algoritmos DASH precisam considerar o comportamento da QoE do usuário, e devem controlar o número de eventos de comutação.

O sistema visual humano (HVS, do inglês Human Visual System) emprega o mecanismo de atenção visual para limitar o processamento de informações que são necessárias para tarefas visuais e o comportamento humano (SUN; FISHER, 2003), uma vez que o sistema visual trabalha com uma quantidade enorme de informações. Para lidar com essa enorme quantidade de entradas visuais, uma seleção, envolvendo o movimento dos olhos, é necessário para alocar recursos de processamento para algumas partes do nosso campo visual (MEUR et al., 
2006). O HVS envolve diferentes tipos de movimentos oculares. Um desses, é o movimento rápido dos olhos, permitindo saltar de uma área para outra, ambos os olhos movem-se juntos na mesma direção e sob controle voluntário. A finalidade desses movimentos é trazer imagens de áreas particulares, do campo visual para a fóvea, a qual é a região central da retina do olho humano, a fim de melhorar a nossa atenção seletiva. O último passo corresponde à fixação, com uma duração de cerca de 200 a 300 ms. Esse movimento rápido dos olhos é, portanto, um importante instrumento da atenção visual seletiva (MEUR et al., 2006).

No mundo da Internet, o vídeo é uma das formas mais comuns para capturar uma informação visual (KUCEROVA; POLEC; TARCSIOVA, 2012). No entanto, se há várias mudanças na qualidade de vídeo durante uma sessão de streaming de vídeo, a atenção visual pode ser afetada negativamente. Portanto, altas frequências de comutação de diferentes resoluções de vídeo devem ser evitadas porque o HVS se adaptará a um nível de resolução depois de alguns segundos. Nesse processo, movimentos oculares precisam ser realizados repetidas vezes se houver várias mudanças de qualidade contínua. Isso pode ser mais evidente quando o evento de comutação ocorre entre vídeos com diferenças marcadas na resolução.

Nesse contexto, este estudo de caso propõe primeiramente analisar quais são efeitos que as mudanças de resolução têm sobre a QoE do usuário que assiste um streaming de vídeo com a solução DASH. Assim, serão identificados os principais problemas que atuais algoritmos de controle do DASH apresentam. Em seguida será proposto um parâmetro que controle as frequências das comutações de resolução. Esse parâmetro é denominado de Fator de Degradação de Comutação (FDC).

Nos testes de avaliação de qualidade de vídeo, o ambiente de teste experimental para a realização de testes subjetivos precisa ser isolado de estímulos externos, tais como ruído visual ou sonoro que possa interferir na atenção dos avaliadores. Neste trabalho a escala utilizada foi a escala MOS de 5 pontos descrito na recomendação ITU-T P.910, mostrada na Tabela 3.1.

\subsubsection{Problemas dos atuais algoritmos de controle do DASH}

Como já foi mencionado, os algoritmos de controle de qualidade de adaptação DASH tentam melhorar a QoE dos usuários oferecendo diferentes versões de qualidade (resolução) do mesmo vídeo. A comutação entre as diferentes versões de 
vídeo depende das condições da rede. Nesse contexto, se as condições da rede mudam com freqüência, haverá vários eventos de comutação. Como conseqüência, a atenção dos usuários é afetada e, portanto, a QoE do usuário é afetada negativamente. Para se ter uma melhor compreensão de como os atuais algoritmos DASH podem ser melhorados, foram identificados os seguintes problemas desses algoritmos.

\subsubsection{Frequência de eventos de comutação de qualidade de vídeo}

Considerando as condições das redes e o status do buffer, os algoritmos DASH podem realizar basicamente duas ações, um acréscimo - switch-up (SU) ou um decréscimo - switch-down (SD) de resolução de vídeo. A primeira ocorre quando a largura de banda permite que o cliente solicite uma maior resolução ao servidor. Por outro lado, o decréscimo switch-down ocorre quando a largura de banda não está disponível e é necessário realizar um decréscimo na resolução do vídeo, para evitar interrupções na transmissão de vídeo.

A Figura 5.1 apresenta um cenário, denominado Cenário 1, com vários eventos de comutação de nível de qualidade de vídeo (VQL, do inglês Video Quality Level). Nessa figura, há somente dois VQL, nos quais o $V Q L_{A}$ e o $V Q L_{B}$ representam a maior e a menor resolução de vídeo, respectivamente.

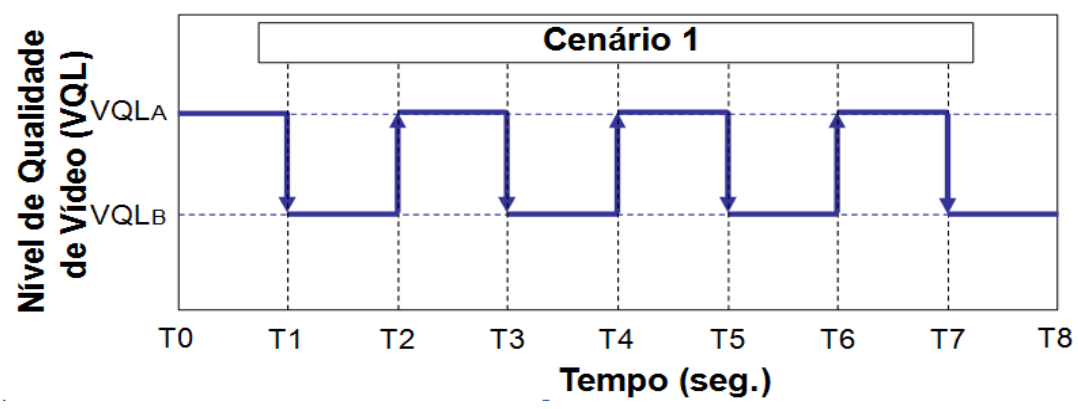

Figura 5.1: Um exemplo de eventos de comutação de resolução de vídeo com o algoritmo de controle de qualidade DASH, que não considera a frequência de eventos de comutação.

Como representado na Figura 5.1, existem oito intervalos de tempo (ex., o primeiro intervalo de tempo de instante T0 até o instante T1), cada intervalo com $t$ segundos de duração, durante cada intervalo, um nível de qualidade de vídeo é transmitido. Para fins de exemplo, um período T pode ser definido como (5.1).

$$
T=4 \times t
$$


A duração do período $T$ poderá depender da duração de cada um dos segmentos de vídeo. Neste caso, a duração do período $T$ é de quatro vezes o intervalo de tempo, mas essa é apenas para fins de exemplo, e ajuda a explicar as Tabelas 5.1 e 5.3. Além disso, $N_{S}$ e $F_{S}$ representam o número de eventos de comutação VQL e sua frequência, respectivamente. Assim, a $F_{S}$ é definida por (5.2).

$$
F_{s}=\frac{N_{s}}{t}
$$

A Tabela 5.1 explica o comportamento do cenário A apresentando: o parâmetro $F_{s}$; o estado do buffer e da rede é representado como Bom (B), Igual (I) ou Ruim (R); a saída do algoritmo DASH é expressa como SU ou SD. O estado da rede e do buffer pode ser complementado com outros parâmetros da camada de aplicação utilizados como entradas nos algoritmos DASH. Para calcular os valores de $F_{s}$ para os instantes T0 a T4, se assume que nenhum evento de comutação VQL ocorreu antes de T0.

Tabela 5.1: Eventos de comutação de qualidade no cenário 1, utilizando um algoritmo DASH sem considerar a frequência de eventos de comutação

\begin{tabular}{|c|c|c|c|c|c|c|c|c|}
\hline $\begin{array}{c}\text { Parâmetro/ } \\
\text { Tempo }\end{array}$ & T0 & T1 & T2 & T3 & T4 & T5 & T6 & T7 \\
\hline $\begin{array}{c}\text { Eventos de comutação } \\
\text { de frequência (Fs) }\end{array}$ & 0 & 0 & $1 / 4$ & $1 / 2$ & $3 / 4$ & 1 & 1 & 1 \\
\hline $\begin{array}{c}\text { Estados da rede } \\
\text { e de buffer) }\end{array}$ & $\mathrm{I}$ & $\mathrm{R}$ & $\mathrm{B}$ & $\mathrm{R}$ & $\mathrm{B}$ & $\mathrm{R}$ & $\mathrm{B}$ & $\mathrm{R}$ \\
\hline $\begin{array}{c}\text { Saída do alg. } \\
\text { DASH }\end{array}$ & - & $\mathrm{SD}$ & $\mathrm{SU}$ & $\mathrm{SD}$ & $\mathrm{SU}$ & $\mathrm{SD}$ & $\mathrm{SU}$ & $\mathrm{SD}$ \\
\hline
\end{tabular}

Como podem ser observados na Tabela 5.1, os eventos de comutação entre as VQLs foram realizadas em todos os instantes de tempo, porque os algoritmos atuais do DASH consideram apenas os parâmetros da rede e/ou os parâmetros da camada de aplicação.

A fim de evitar os vários eventos de comutação VQL, uma regra simples é definida. O algoritmo dessa regra é apresentado na Figura 5.2. Esse algoritmo inclui o parâmetro Fs como um fator de decisão para realizar um evento de comutação.

É importante notar que o valor limiar de FS é igual a 1/2 e serve apenas para propósitos deste exemplo.

A Figura 5.3 apresenta o novo comportamento de Cenário 1, chamado de Cenário 2, após a aplicação do algoritmo definido na Figura 5.2. Como esperado, 


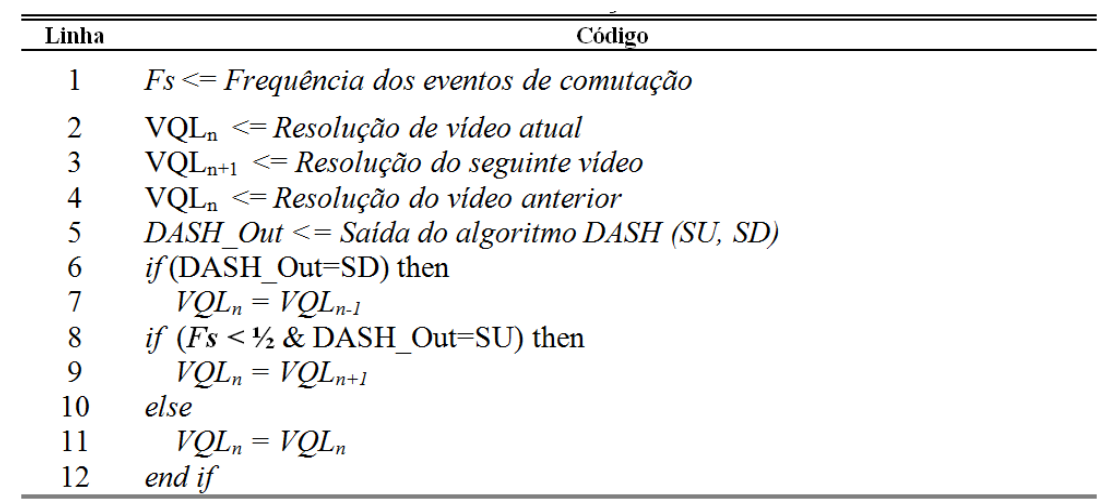

Figura 5.2: Frequência de eventos de comutação como um fator de decisão para realizar um evento de comutação.

o número de eventos de comutação de VQL foi reduzido porque o algoritmo DASH é complementado com o parâmetro de FS. Neste trabalho, a solução proposta levará em consideração o FS como parte do algoritmo DASH.

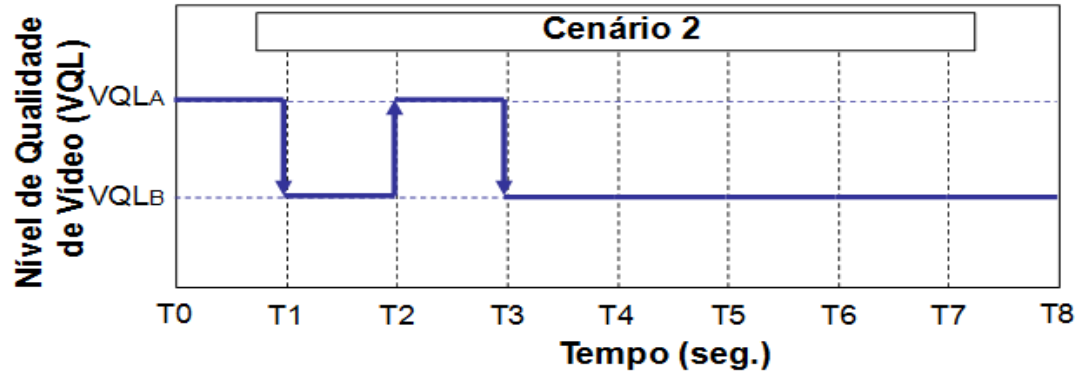

Figura 5.3: Um exemplo de eventos de comutação de qualidade de vídeo com um algoritmo de controle de qualidade DASH que considera a freqüência de eventos de comutação.

Tabela 5.2 explica o comportamento do cenário 2. Pode-se observar a que os eventos SD são basicamente regulados pelos parâmetros de rede/aplicação, por exemplo, os eventos SD em T1 e T3. Em T5 e T7, um SD não é executado porque na existe uma resolução menor de vídeo.

Tabela 5.2: Eventos de comutação de qualidade de vídeo no cenário 2, utilizando um algoritmo DASH considerando a frequência de eventos de comutação

\begin{tabular}{|c|c|c|c|c|c|c|c|c|}
\hline $\begin{array}{c}\text { Parâmetro/ } \\
\text { Tempo }\end{array}$ & T0 & T1 & T2 & T3 & T4 & T5 & T6 & T7 \\
\hline $\begin{array}{c}\text { Frequência de eventos } \\
\text { de comutação (Fs) }\end{array}$ & 0 & 0 & $1 / 4$ & $1 / 2$ & $3 / 4$ & $3 / 4$ & $1 / 2$ & $1 / 4$ \\
\hline $\begin{array}{c}\text { Estados da rede } \\
\text { e de buffer }\end{array}$ & $\mathrm{I}$ & $\mathrm{R}$ & $\mathrm{B}$ & $\mathrm{R}$ & $\mathrm{B}$ & $\mathrm{R}$ & $\mathrm{B}$ & $\mathrm{R}$ \\
\hline $\begin{array}{c}\text { Algoritmo } \\
\text { DASH com Fs }\end{array}$ & - & $\mathrm{SD}$ & $\mathrm{SU}$ & $\mathrm{SD}$ & - & - & - & - \\
\hline
\end{tabular}




\subsubsection{Pesos de Degradação de diferentes eventos de comutação de nível de qualidade de vídeo}

Em um cenário DASH, diferentes versões do mesmo vídeo estão disponíveis no servidor de vídeo e, portanto, diferentes tipos de eventos de comutação podem ser executados.

A Figura 5.4 apresenta o Cenário 3, no qual existem diferentes tipos de eventos de comutação. Nesta figura, existe um total de cinco VQLs, onde $V Q L_{A}$ e $V Q L_{E}$ representam o maior e o menor nível de qualidade de vídeo, respectivamente. Assim, cada tipo de comutação é realizado entre diferentes VQLs.

Além disso, cada tipo de comutação pode perturbar a atenção do usuário de diferentes maneiras. Portanto, é necessário investigar como os algoritmos DASH podem considerar esse cenário, por exemplo, diferentes pesos de degradação da qualidade precisam ser relacionados a cada tipo de evento de comutação.

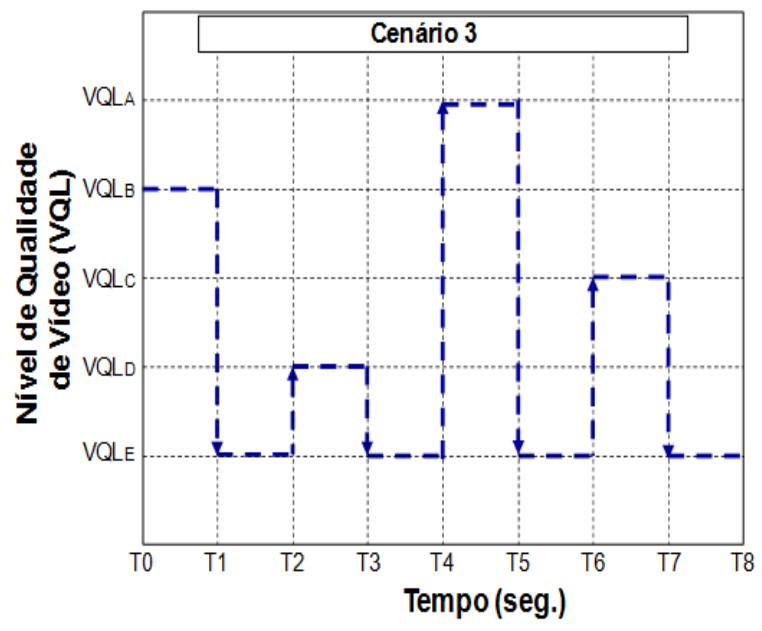

Figura 5.4: Diferentes tipos de comutação utilizando cinco níveis de qualidade do mesmo vídeo.

\subsubsection{Localização Temporal de eventos de comutação do nível de qualidade de vídeo}

Dependendo da localização temporal dos eventos de comutação, a QoE dos usuários podem ser afetadas de diferentes formas. Os algoritmos DASH atuais não consideram esse fato, e dão o mesmo peso de degradação para eventos de comutação que ocorrem do início ou no final do vídeo, tal como apresentado na Figura 5.5. 


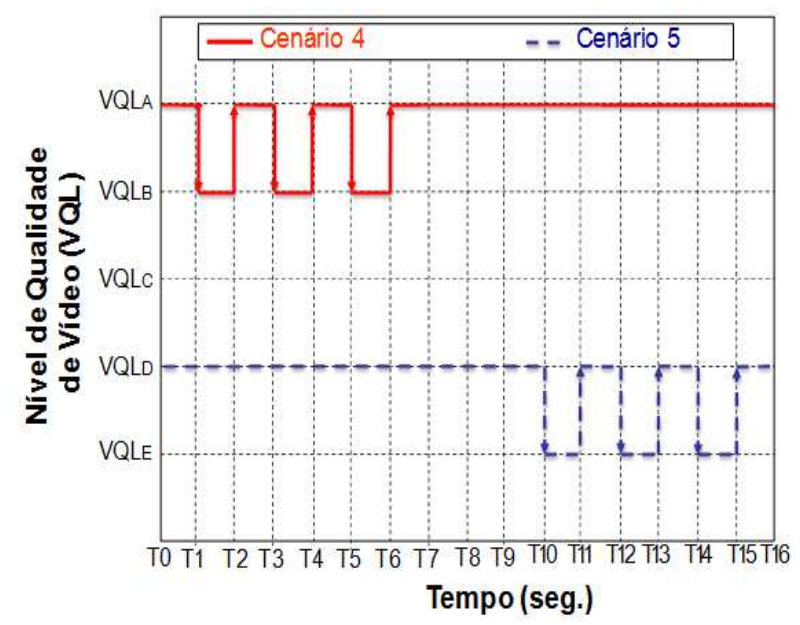

Figura 5.5: Eventos de comutação de resoluções de vídeo localizados em diferentes segmentos temporais.

\subsubsection{Proposta do fator de degradação por mudanças de resoluções}

Os resultados dos testes subjetivos preliminares de avaliação da qualidade de vídeo demonstraram que a QoE dos usuários é afetada pela frequência de mudanças de resolução de vídeo. A medição da degradação da QoE do usuário não é uma tarefa fácil, considerando os diferentes fatores de degradação durante uma sessão DASH. A fim de resolver esse problema, testes subjetivos precisam ser conduzidos. O objetivo destes testes é modelar a degradação da QoE dos usuários durante um ou mais eventos de comutação de VQL em uma sessão DASH.

Nesta seção, o fator de degradação de comutação (FDC) é apresentado. O parâmetro FDC pretende melhorar os algoritmos DASH, tendo em conta os três problemas indicados na seção anterior. Assim, o FDC considera a frequência, tipo e localização temporal de eventos de comutação de VQLs.

Neste trabalho, o número de versões disponíveis do mesmo vídeo está limitado a cinco, eles são, $V_{A}, V_{B}, V_{C}, V_{D}$ e $V_{E}$. Onde $V_{A}$ e $V_{E}$ representam o maior e o menor VQL, respectivamente. Além disso, a mudança entre dois vídeos com resolução espacial diferente e a mesma resolução temporal é chamado de Comutação de Resolução Espacial (SRS, do inglês, Spatial Resolution Switching). A Comutação de Resolução Temporal (TRS, do inglês, Temporal Resolution Switching) acontece quando a mudança entre VQL é realizada entre dois vídeos com a mesma resolução espacial, mas com diferente resolução temporal. Esses dois tipos de comutação de VQL e suas combinações foram utilizados neste trabalho.

Cada tipo de comutação de VQL pode afetar a global QoE do usuário de uma 
forma diferente. Assim, cada tipo de comutação de VQL poderia ter um fator de degradação diferente. Neste trabalho, esse fator é chamado de peso do tipo de comutação (WST, do inglês, Weight of Switching Type). A Tabela 5.3 apresenta os cinco tipos de comutação de VQL utilizadas nos testes. O número de versões de vídeo pode ser aumentado, mas o número de tipos de comutação de VQL será aumentado significativamente. Assim, para calcular o peso de todos os tipos de comutação, seriam necessários mais testes de avaliação da qualidade de vídeo.

Tabela 5.3: Casos de comutação de nível de resolução de vídeo

\begin{tabular}{|c|c|c|c|}
\hline $\begin{array}{c}\text { Resolução de } \\
\text { Vídeo (VQL) }\end{array}$ & $\begin{array}{c}\text { Características do } \\
\text { Vídeo }\end{array}$ & $\begin{array}{c}\text { Evento de comutação } \\
\text { entre VQLs }\end{array}$ & $\begin{array}{c}\text { Tipo de } \\
\text { Comutação VQL }\end{array}$ \\
\hline$V_{A}$ & (SR1,TR1) & $V_{A}<-->V_{B}$ & TRS $\left(V_{A B}\right)$ \\
\hline$V_{B}$ & (SR1,TR2) & $V_{B}<-->V_{C}$ & TRS \& SRS $\left(V_{B C}\right)$ \\
\hline$V_{C}$ & (SR2,TR1) & $V_{B}<-->V_{D}$ & SRS $\left(V_{B D}\right)$ \\
\hline$V_{D}$ & (SR2,TR2) & $V_{C}<-->V_{D}$ & TRS $\left(V_{C D}\right)$ \\
\hline$V_{E}$ & (SR3,TR2) & $V_{A}<-->V_{E}$ & TRS \& SRS $\left(V_{A E}\right)$ \\
\hline
\end{tabular}

Como afirmado anteriormente, a comutação de eventos ocorridos no início, no meio ou no fim do vídeo pode ter diferentes efeitos na QoE dos usuários. Portanto, três segmentos temporais são considerados em cada vídeo usado como material de teste. Os pesos dos segmentos temporais no início, no meio ou no fim do vídeo são nomeados WTS1 (do inglês, Weight of Temporal Segment) WTS2 e WTS3, respectivamente.

Considerando todos os aspectos acima sinalados, o parâmetro FDC é definido por (5.3).

$$
F D C=\sum_{j=1}^{n} \frac{\sum_{i=1}^{m} N_{i j} * W S T_{i} * W T S_{j}}{T}
$$

Onde:

- $m$ é o número de diferentes tipos de comutação VQL, este trabalho considerou cinco tipos de comutação;

- $n$ é o número de diferentes segmentos temporais, neste trabalho três segmentos foram considerados;

- $N_{i j}$ é o número de eventos de comutação VQL do tipo i, durante o segmento temporal j;

- $W S T_{i}$ é um fator de peso que representa o grau de degradação que cada resolução de vídeo de comutação do tipo $i$ adiciona para a degradação total 
do vídeo;

- $W T S_{j}$ é um fator de peso que representa o grau de degradação que o segmento temporal, $j$, acrescenta a degradação total do vídeo;

- $T$ é o período de tempo, em segundos, em que o vídeo é reproduzido.

Com os resultados dos ensaios de avaliação subjetiva da qualidade de vídeo, foi possível determinar o peso relacionado com o grau de degradação em que cada tipo de comutação de VQL e segmento temporal causaram na degradação total do vídeo. Para melhor compreensão, os valores FDC são mapeados com valores de índice MOS em uma escala de 5 pontos. Ambos, os modelos exponenciais e lineares foram avaliados, e a função exponencial atingiu o erro máximo mais baixo igual a 0,0829 na escala MOS de 5 pontos. Assim, utilizando o modelo exponencial, FDC na escala MOS é denotado como $F D C_{M O S}$, e é apresentado em (5.4).

$$
F D C_{M O S}=C \times \exp \left(\frac{-F D C}{\beta}\right)
$$

Em que $\beta$ é o fator de velocidade de decaimento da função exponencial. A fim de calcular o WST e os parâmetros WTS, foram realizados testes subjetivos em duas fases. Na primeira fase, 18 cenários de teste foram usados para determinar apenas os fatores WST. Isso significa que somente um segmento temporal $(\mathrm{n}=$ 1) foi considerada com um peso (WTS) igual a 1. Uma vez que os cinco fatores WST foram obtidos, em uma segunda fase, 12 diferentes cenários foram avaliados para obter os fatores WTS. Os comprimentos de vídeo usados na primeira e na segunda fase foram de 1 e 3 minutos, respectivamente. Em cada cenário de teste foram inseridos diferentes números de eventos de comutação de VQL e diferentes tipos de comutação.

Dos testes subjetivos resultaram diferentes índices MOS para cada cenário avaliado e esses valores serão utilizados para modelar o FDC. A relação entre um valor de MOS e o $F D C_{M O S}$, para o mesmo cenário $x$, é apresentado em (5.5).

$$
F D C_{M O S-x}=M O S_{V m e a n-x}-M O S_{x}
$$

O MOSVmean-x corresponde a média aritmética dos valores de índices MOS obtidos para cada VQL que foi inserida no cenário $x$, por exemplo, se no cenário 
$x$, a $V Q L_{A}, V Q L_{B}$ e $V Q L_{C}$ foram inseridas, $M O S_{V m e a n-x}$ representa a média dos índices MOS obtidos quando cada VQL que foi avaliada individualmente. Por outro lado, MOSx representa o índice MOS único obtido no cenário de "x".

Considerando a primeira fase dos testes e as equações de (5.3) a (5.5), a seguinte relação corresponde ao cenário 1 da primeira fase $\left(F D C_{M O S-1}\right)$ :

$$
\begin{aligned}
\operatorname{Ln}\left(F D C_{M O S-1}\right) & =\operatorname{Ln}(C)-\left(N_{1}^{(1)} * W S T_{A B}-N_{2}^{(1)} * W S T_{B C}-N_{3}^{(1)}\right. \\
& \left.* W S T_{B D}-N_{4}^{(1)} * W S T_{C D}-N_{5}^{(1)} * W S T_{A E}\right) /(T * \beta)
\end{aligned}
$$

Usando (5.6), um sistema linear com duas variáveis e 18 equações foi obtido. Onde, C é uma constante e WSTx é o peso do tipo de comutação da VQL $x$, a qual será determinado. Além disso, as variáveis $F D C_{M O S-X}, N_{X}$ e $T_{X}$ são conhecidos para cada cenário. Considerando os 18 cenários de teste e (5.6), o seguinte sistema linear de equações foi obtido:

$$
\left[\begin{array}{cccc}
1 & t_{1,1} & \ldots & t_{1,5} \\
1 & t_{2,1} & \ldots & t_{2,5} \\
\vdots & & & \vdots \\
1 & t_{18,1} & \ldots & t_{18,5}
\end{array}\right]\left[\begin{array}{c}
\operatorname{Ln}(C) \\
W S T_{A B} \\
W S T_{B C} \\
W S T_{B D} \\
W S T_{C D} \\
W S T_{A E}
\end{array}\right]=\left[\begin{array}{c}
\operatorname{Ln}\left(F D C_{M O S-1}\right) \\
\operatorname{Ln}\left(F D C_{M O S-2}\right) \\
\vdots \\
\operatorname{Ln}\left(F D C_{M O S-18}\right)
\end{array}\right]
$$

Onde:

$$
t_{k, i}=\frac{N_{i}^{(k)}}{T * \beta}
$$

Em que $N_{i}^{(k)}$ é o número de eventos de comutação de VQL do tipo $i$ no cenário $k(\mathrm{k}=1,2, \ldots 18)$. Se as seguintes relações são consideradas: 


$$
\left[\begin{array}{cccc}
1 & t_{1,1} & \ldots & t_{1,5} \\
1 & t_{2,1} & \ldots & t_{2,5} \\
\vdots & & & \vdots \\
1 & t_{18,1} & \ldots & t_{18,5}
\end{array}\right]=A ;\left[\begin{array}{c}
\operatorname{Ln}(C) \\
W S T_{A B} \\
W S T_{B C} \\
W S T_{B D} \\
W S T_{C D} \\
W S T_{A E}
\end{array}\right]=w ;\left[\begin{array}{c}
\operatorname{Ln}\left(F D C_{M O S-1}\right) \\
\operatorname{Ln}\left(F D C_{M O S-2}\right) \\
\vdots \\
\operatorname{Ln}\left(F D C_{M O S-18}\right)
\end{array}\right]=b
$$

As variáveis no vetor $\mathrm{w}$ pode ser calculadas utilizando o método de mínimo quadrado, especificamente, pseudo-inverso, como mostrado em (5.10):

$$
w=\left(A^{T} A\right)^{-} 1 * A^{T} b
$$

Assim, obtiveram-se os valores da constante C e os cinco WST utilizados nos 18 cenários. Na segunda fase, os cinco valores WST e o valor C obtido na primeira fase foram considerados. Utilizando as equações (5.3) a (5.5), o primeiro cenário da segunda fase é representado pela seguinte relação:

$$
\begin{aligned}
\operatorname{Ln}\left(F D C_{M O S-1}\right) & =\operatorname{Ln}(C)-\sum_{j=1}^{3}\left(N_{1} j^{(1)} * W S T_{A B}-N_{2} j^{(1)} * W S T_{B C}-N_{3} j^{(1)}\right. \\
& \left.* W S T_{B D}-N_{4} j^{(1)} * W S T_{C D}-N_{5} j^{(1)} * W S T_{A E}\right) * W T S_{j} /(T * \beta)
\end{aligned}
$$

Na fase 2, 12 cenários foram testados e, portanto, 12 valores MOS foram obtidos. Com os resultados obtidos em (5.10) e usando (5.11) um sistema linear de 12 equações foi obtido, o qual é apresentado em (5.12).

$$
\left[\begin{array}{ccc}
t_{1,1} & t_{1,2} & t_{1,3} \\
t_{2,1} & t_{2,2} & t_{2,3} \\
\vdots & & \vdots \\
t_{12,1} & t_{12,2} & t_{12,3}
\end{array}\right]\left[\begin{array}{l}
W T S_{1} \\
W T S_{2} \\
W T S_{3}
\end{array}\right]=\left[\begin{array}{c}
\operatorname{Ln}\left(F D C_{M O S-1}\right) \\
\operatorname{Ln}\left(F D C_{M O S-2}\right) \\
\vdots \\
\operatorname{Ln}\left(F D C_{M O S-12}\right)
\end{array}\right]
$$

Onde: 


$$
\begin{aligned}
t_{k *, j} & =N_{1 j}^{k *} * W S T_{A B}+N_{1 j}^{(k *)} * W S T_{B C}+N_{1} j^{(k *)} \\
& \left.* W S T_{B D}+N_{1} j^{(k *)} * W S T_{C D}+N_{1} j^{(k *)} * W S T_{A E}\right) /(T * \beta)
\end{aligned}
$$

Onde, $k *$ representa um cenário da segunda fase $\left(\mathrm{k}^{*}=1,2, \ldots 12\right)$ e $j$ é o segmento temporal $(\mathrm{j}=1,2,3)$ de cada cenário. E, WTS1, WTS2 e WTS3 representam os pesos dos segmentos temporais no início, no meio ou no final do vídeo. Como podem ser observadas, as representações das equações (5.7) e (5.12) são semelhantes. Então, os três pesos dos segmentos temporais (WTS) apresentados em (5.12) podem ser obtidos utilizando (5.10).

\subsubsection{Metodologia e Cenário de Teste}

O cenário experimental utilizado nos testes é mostrado na Figura 5.6. Esse cenário foi isolado e nenhum outro serviço é executado nos computadores. O emulador de rede utilizado é implementado com a ferramenta Open Source NETem, e a sua função é controlar a largura de banda disponível entre cliente e servidor. O servidor de vídeo é um Linux com um Servidor Web Apache versão 2.2.21.

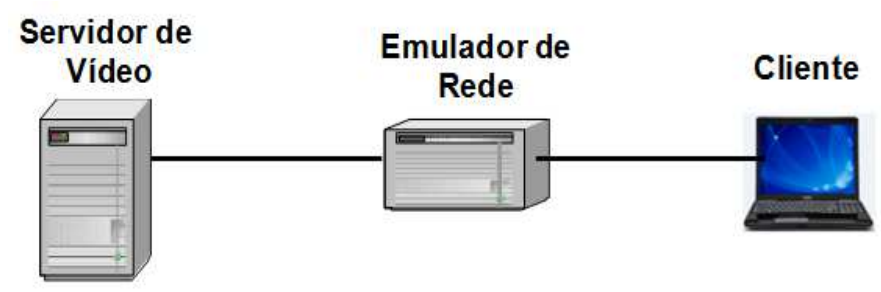

Figura 5.6: Cenário de teste.

O comprimento total de vídeo foi de 1 e 3 minutos, em todos os vídeos usados como material de teste. O codec de vídeo utilizado foi o Advanced Video Codec H.264/AVC com diferentes características de codificação obtendo 5 VQLs apresentados na Tabela 5.4.

Tabela 5.4: Características dos vídeos usados como material de teste

\begin{tabular}{|c|c|c|}
\hline $\begin{array}{c}\text { Resolução de } \\
\text { Vídeo (VQL) }\end{array}$ & $\begin{array}{c}\text { Resolução } \\
\text { Temporal (fps) }\end{array}$ & $\begin{array}{c}\text { Resolução Espacial } \\
\text { (width x height) }\end{array}$ \\
\hline$V_{A}$ & 25 & $854 \times 480$ \\
\hline$V_{B}$ & 20 & $854 \times 480$ \\
\hline$V_{C}$ & 25 & $640 \times 360$ \\
\hline$V_{D}$ & 20 & $640 \times 360$ \\
\hline$V_{E}$ & 20 & $180 \times 320$ \\
\hline
\end{tabular}

Um algoritmo de controle DASH é implementado com base na OSMF (Open 
Source Media Framework) em que o parâmetro FDC foi incluído. O fluxograma do algoritmo é apresentado na Figura 5.7.

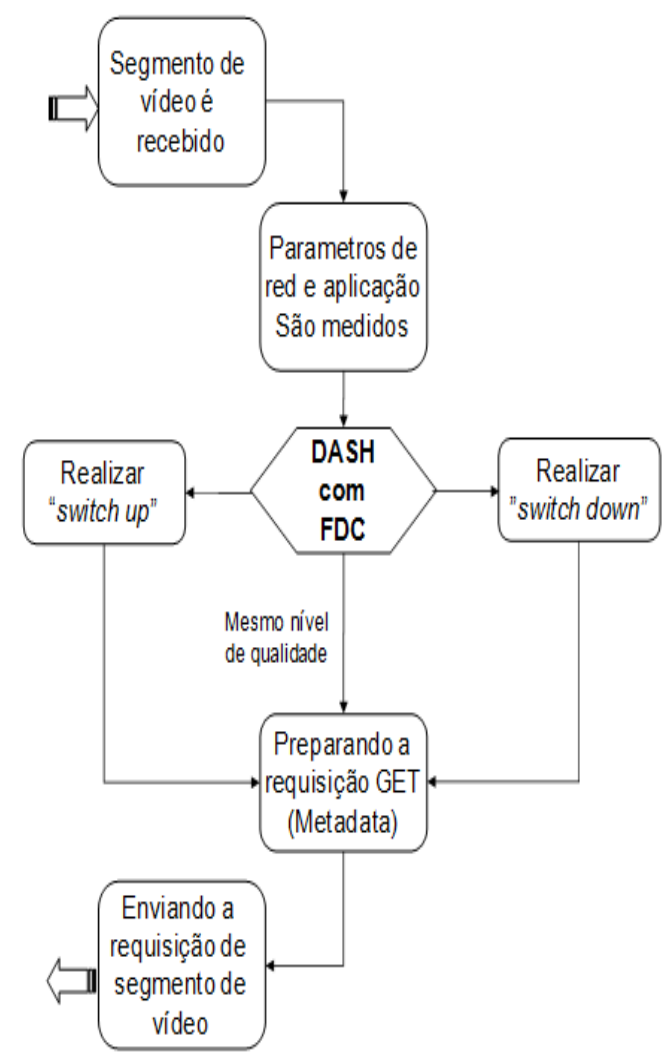

Figura 5.7: Fluxograma do algoritmo de controle de adaptação DASH, que inclui o parâmetro FDC proposto.

No cenário de teste, foram emuladas mudanças drásticas na largura de banda disponível. Assim, vários cenários de teste foram criados, nos quais foram inseridos diferentes números de eventos de comutação de VQL e diferentes tipos de comutação. Além disso, a localização temporal de cada evento de comutação foi considerada.

A fim de avaliar o desempenho de um algoritmo de controle DASH que considera o parâmetro FDC, os mesmos cenários de teste foram avaliados utilizando e sem utilizar o parâmetro FDC. Esses resultados são apresentados na seguinte subseção.

\subsubsection{Resultados}

Cada vídeo utilizado como material de teste teve, pelo menos, quinze pontuações e o número total de avaliadores foi de 72. Além disso, nenhum deles apresentou problemas na visão e tampouco tinha experiência na avaliação de testes de qualidade de vídeo. A Figura 5.8 apresenta os resultados obtidos a partir 
de (5.9), utilizando-se três valores de $\beta$, em relação ao peso dos cinco tipos de comutação de VQL considerados na primeira fase do trabalho.

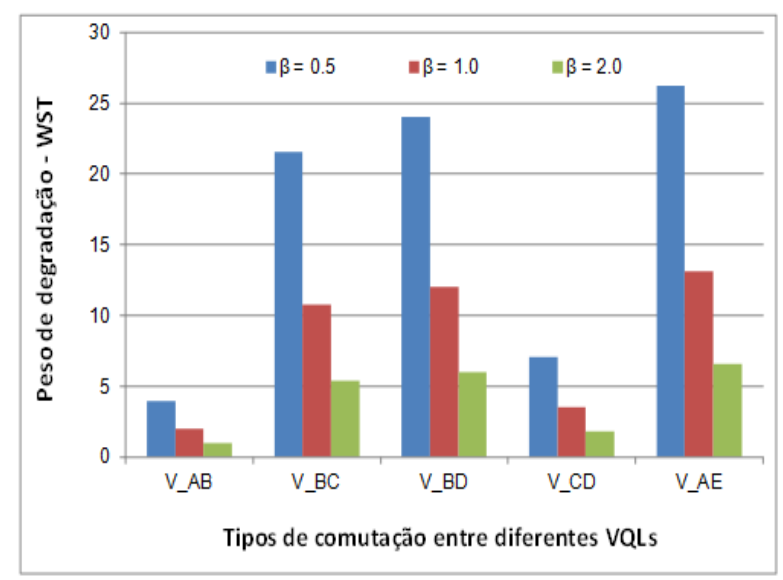

Figura 5.8: Degradação de peso dos cinco tipos diferentes de comutação de VQL.

Na segunda fase de testes subjetivos, os pesos de degradação dos três segmentos temporais foram obtidos utilizando (5.12). Os resultados são mostrados na Figura 5.9.

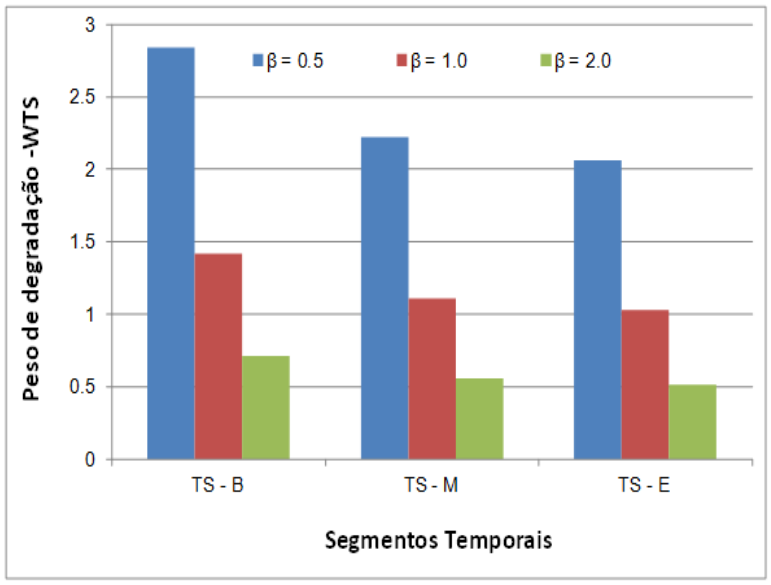

Figura 5.9: O peso de degradação dos segmentos temporais, em que TS-B, TS-M TS-E representam o segmento temporal, no início, meio e final do vídeo, respectivamente.

Como pode ser observado na Figura 5.8 e na Figura 5.9, o fator $\beta$ trabalha como um fator de escala, mas a relação entre os parâmetros é a mesma para cada valor $\beta$ considerado.

Na Figura 5.10 mostram-se os resultados de ambos os testes subjetivos e os valores MOS objetivos obtidos por (5.12) para os 18 cenários considerados na primeira fase. O coeficiente de correlação de Pearson entre os valores subjetivos e 
objetivos MOS é 0,94. Os cenários que apresentaram os índices menores de MOS correspondem a cenários donde a comutação de VQL foi do tipo espacial.

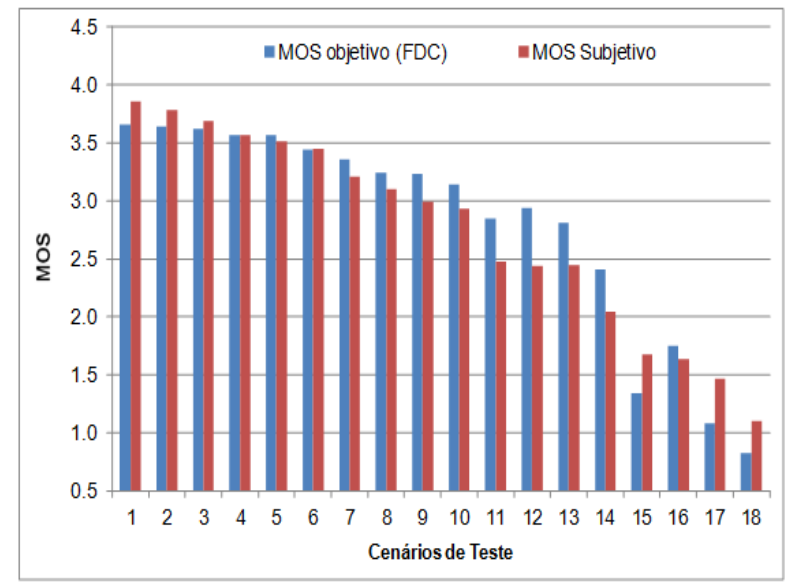

Figura 5.10: MOS subjetivo e objetivo de cenários com diferentes tipos de comutação entre VQLs.

A fim de demonstrar a importância de se considerar o segmento temporal, a Figura 5.11 apresenta como as mesmas degradações (comutações) localizadas em diferentes instantes degradam a QoE do usuário de diferentes formas. Quatro cenários são apresentados, cada um com três variantes denominados de A, B e C que representam o segmento temporal, inicial, intermédio e final, respectivamente. Assim, o cenário A têm eventos de comutação VQL apenas no segmento temporal inicial, e a mesma regra ocorre para cenários B e C. Os eventos de comutação VQL no primeiro segmento temporal possuem o maior efeito negativo sobre a QoE do usuário e, dependendo do cenário teste, a QoE pode ser drasticamente reduzida.

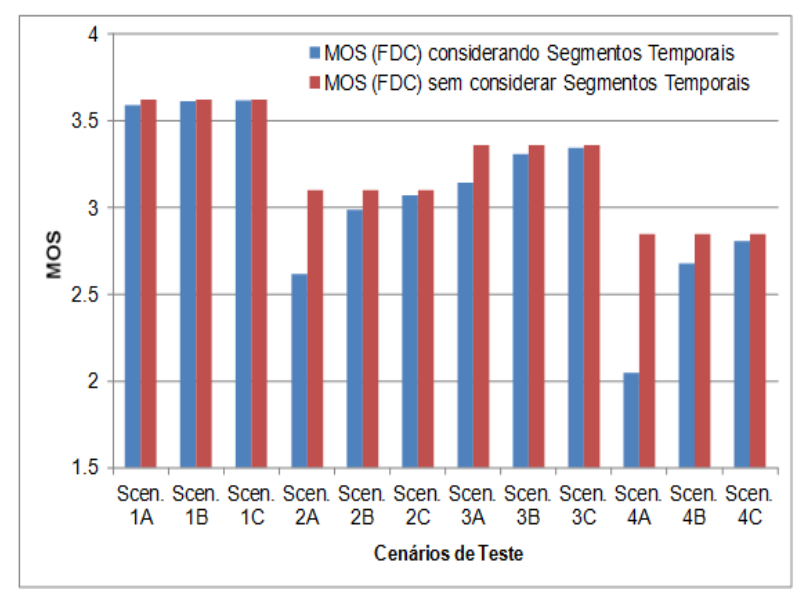

Figura 5.11: Valores MOS Objetivo de cenários com eventos de comutação VQL localizados nos diferentes segmentos temporais (A, B, C representam o segmento temporal, inicial, intermediária e final, respectivamente). 
Finalmente, a Figura 5.12 mostra a importância de usar o parâmetro FDC como um fator de decisão em um algoritmo de controle de adaptação DASH. O valor $F D C_{M O S}$ utilizado como limiar foi de 0,6 , e o valor $\beta$ foi 1,0. Foram utilizados cinco cenários, cada um foi avaliado usando tanto um algoritmo DASH, com e sem FDC. Dependendo do cenário teste, a diferença no desempenho em uma escala MOS pode ser grande. Por exemplo, o Cenário 5 teve o maior número de eventos de comutação VQL e os tipos de comutação mais degradantes, porque a largura de banda foi drasticamente alterada várias vezes. Por outro lado, o Cenário 1 apresentou o menor número de eventos de comutação. Nesses cinco cenários, o comprimento de vídeo foi de 3 minutos.

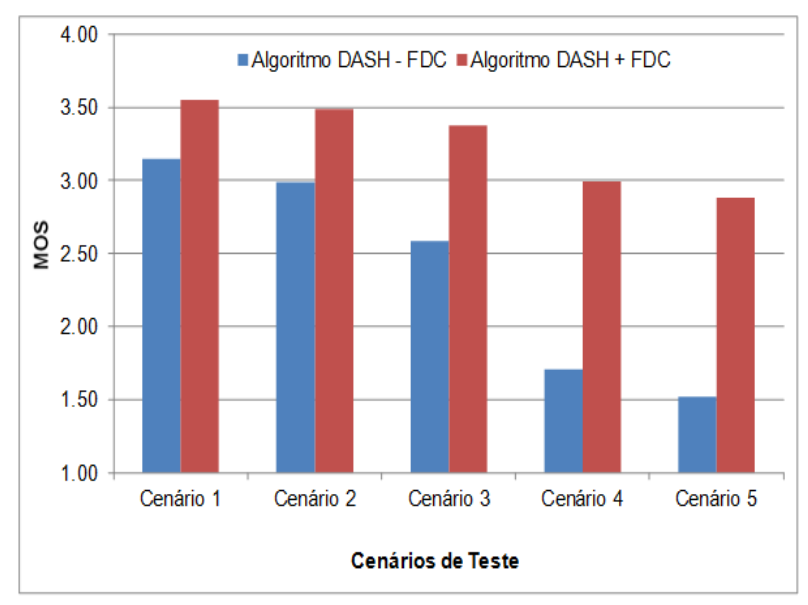

Figura 5.12: Comparação de desempenho baseada em valores MOS entre algoritmos DASH que considera ou não o parâmetro FDC.

\subsection{Efeito global das mudanças de resolução de vídeo e das pausas na QoE do usuário}

Quando a capacidade da rede diminui, durante um streaming de vídeo que utiliza a solução DASH, se transmite uma menor resolução do mesmo vídeo armazenado no servidor. Porém, se a capacidade da rede continua diminuindo e não permite a transmissão continua do vídeo de menor qualidade em termos da resolução, acontecerão congelamentos da imagem do vídeo, ou pausas, no momento em que o buffer do player não possua nenhuma informação. Neste cenário, a QoE do usuário se decrementará pelos fatores de degradação correspondentes às mudanças continuas de resolução de vídeo e às pausas acontecidas durante a transmissão. A Figura 5.13 apresenta o cenário 6, no qual existem três comutações de VQL até chegar ao mínimo VQL $\left(V Q L_{E}\right)$; neste ponto, se a capacidade da rede não suporta a transmissão do $V Q L_{E}$ acontecerão pausas durante a trans- 
missão do vídeo. Pode-se observar que durante os instantes de tempo T0 e T8, a QoE do usuário se decrementa pelos dois fatores: eventos de comutação entre VQLs e as pausas.

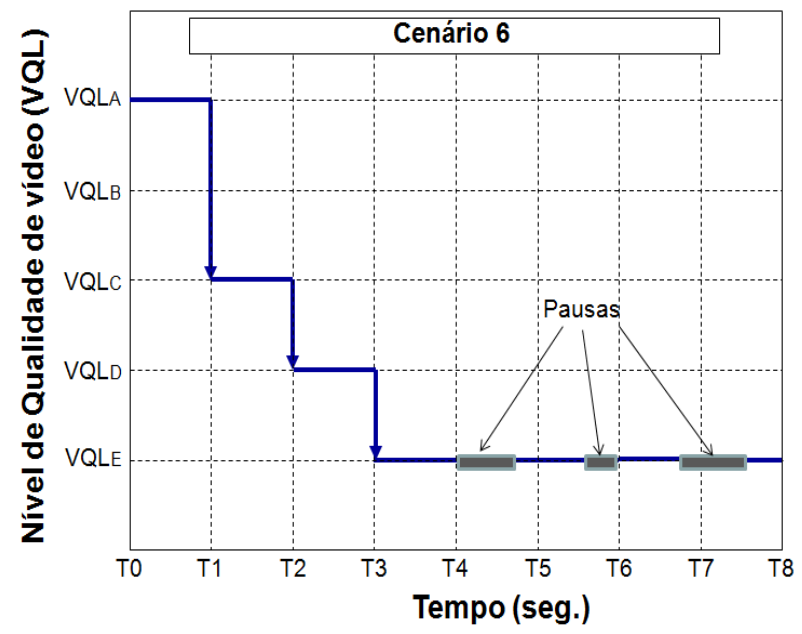

Figura 5.13: Eventos de comutação de qualidade de vídeo e pausas durante um congestionamento crítico na rede.

A equação (5.4) determina a degradação da QoE do usuário pelos efetos das comutações entre VQLs, e a equação (4.7) estima a QoE do usuário depois de decrementar as degradações correspondentes às pausas. Assim, a QoE global de um usuário de streaming de vídeo que utiliza a solução DASH, que denominaremos como $Q o E_{M O S}$, e que corresponde ao cenário apresentado na Figura 5.13, pode ser determinada pela seguinte equação:

$$
Q_{o} E_{M O S}=e V s Q M_{M O S}-F D C_{M O S}
$$

\subsection{Considerações finais}

Neste estudo de caso, alguns problemas técnicos nos algoritmos de controle de qualidade de soluções DASH foram formulados tendo em conta a QoE do usuário; com isso foram realizados, testes subjetivos para avaliar a QoE.

Em primeiro lugar, foram estudados os efeitos da freqüência de eventos de comutação VQL possuem sobre a QoE do usuário. Os resultados dos testes subjetivos mostraram que a mudança de frequência de eventos desempenha um papel importante na determinação da QoE do usuário porque os eventos de comutação perturbam a atenção do usuário durante uma sessão de streaming de vídeo. $\mathrm{O}$ HVS adapta-se a um nível de resolução específico, após alguns segundos, e se o 
vídeo muda de resolução continuamente, ocorre uma diminuição da atenção visual do usuário.

Em segundo lugar, os diferentes tipos de comutação de VQL foram avaliados. Os resultados mostraram que os eventos de comutação entre vídeos com resolução temporal diferente tem um efeito negativo muito menor sobre a QoE do usuário em relação aos eventos de comutação entre vídeos com resolução espacial diferente. Isso pode ser explicado porque durante os eventos de comutação de resolução espacial, diversos movimentos oculares são necessários a fim de fixar a nova posição espacial da região saliente, que é o foco da atenção do usuário.

Como terceiro ponto, os resultados demonstraram a relevância de se considerar a localização temporal dos eventos de comutação VQL em um modelo matemático para quantificar a degradação da QoE do usuário. Os usuários têm uma expectativa negativa a partir do início do vídeo, porque eles inconscientemente sabem que, se houver problemas no início do vídeo, também ocorrerá ao longo do vídeo.

Considerando essas abordagens, um novo parâmetro FDC a ser incluído em um algoritmo de controle de qualidade DASH foi determinado. O FDC trabalha como um limiar que indica o nível máximo permitido de degradação para realizar um evento de comutação de VQL. A fim de facilitar a escolha desse parâmetro, o FDC foi mapeado na escala MOS de 5 pontos obtendo um parâmetro denominado $F D C_{M O S}$. Os resultados experimentais demonstraram que a utilização do parâmetro FDC em algoritmos DASH ajuda a melhorar a QoE global do usuário. Essa melhoria é muito acentuada quando ocorrem muitos eventos de comutação de VQL durante o streaming de vídeo. É importante notar que esses resultados são baseados em testes realizados com vídeos de duração de 3 minutos.

Finalmente, quando a rede apresenta um decremento drástico de capacidade, a QoE global do usuário pode ser afetada pelas pausas e pelos eventos de comutação entre diferentes VQLs. Esta QoE global, QoE $E_{M O S}$, pode ser determinada pela equação (5.14). 


\section{Conclusões}

Neste trabalho foi descrita uma proposta de métrica de avaliação de qualidade de vídeo no serviço de streaming de vídeo que utiliza o TCP como protocolo de transporte. Na primeira etapa do trabalho, essa métrica foi denominada como VsQM, e foi determinada por um modelo matemático que utilizou parâmetros da aplicação de streaming de vídeo e os resultados de testes subjetivos de avaliação de qualidade de vídeo. Assim, a métrica VsQM esteve baseada principalmente no número de pausas, sua duração e a localização temporal dessas durante a transmissão do vídeo assistido. Também, com o intuito de facilitar o uso da métrica VsQM, a escala de valores dessa foram mapeados à escala MOS de 5 pontos da Metodologia ACR descrita na Tabela 3.1.

Da literatura atual, a métrica pause intensity (PORTER; PENG, 2011) é a mais relacionada com o trabalho atual. O desempenho da métrica VsQM foi comparada com a métrica pause intensity de uma forma indireta, pois considerouse uma função exponencial para mapear o pause intensity na escala MOS de cinco pontuações utilizada pela métrica VsQM, como apresentado na Figura 4.8. A métrica VsQM por considerar segmentos temporais teve um melhor desempenho, pois foi baseado nos resultados de testes subjetivos, nos que se utilizaram vídeos con pausas localizadas em diferentes instantes.

Deve-se salientar que na realização dos testes subjetivos foi empregada uma metodologia definida neste trabalho, e que difere das metodologias de avaliação de vídeo descritas na ITU-T, principalmente pelo fato de que a pausa é o fator de degradação nos vídeos, precisando-se como material de teste vídeos de maior duração.

Em uma segunda fase do trabalho, o desempenho da métrica foi melhorado utilizando o tipo de conteúdo do vídeo com um parâmetro adicional na determinação da métrica. Assim, a nova métrica foi chamada de eVsQM, e apresentou uma melhora significativa na exatidão considerando a alta correlação com os resultados dos testes subjetivos realizados, como apresentado nas Tabelas 4.4, 4.5 e 4.6. A avaliação subjetiva de qualidade de vídeo, nessa segunda fase do traba- 
lho, foi realizada utilizando o método de crowdsourcing, no qual usuários remotos conectados na Internet e cadastrados na plataforma Microworkers avaliaram os vídeos. Os resultados obtidos pelos usuários remotos, foram semelhantes com os resultados dos testes subjetivos realizados presencialmente, como apresentado na Tabela 4.3, dando um alto grau de confiabilidade ao método de crowdsourcing. Resultado similares foram obtidos em (XU; HUANG; YAO, 2012) (RIBEIRO; FLORENCIO; NASCIMENTO, 2011).

É importante destacar que os vídeos utilizados como material de teste, utilizando o método de crowdsourcing, tiveram diferentes durações, o que demonstrou o alto grau de desempenho da métrica eVsQM em diferentes cenários de teste.

Por outro lado, foi estudado o desempenho da solução DASH em situações onde a rede tem muitas variações na largura de banda disponível no ponto do usuário final. Como os algoritmos DASH mudam a resolução do vídeo transmitido dependendo principalmente da largura de banda que dispõe o usuário final, em cenários onde a capacidade da rede é muito flutuante, esses algoritmos realizam comutações entre diferentes resoluções de vídeo constantemente. A frequência alta de eventos de comutação afetarão a QoE do usuário. Nesse contexto, no presente trabalho foi definido um parâmetro denominado FDC que depende do numero e tipos de comutações entre diferentes qualidades de vídeo. A função desse parâmetro é atuar como um limiar de degradação de qualidade, ou seja, não permite comutações entre qualidade de vídeos se a comutação degradará a QoE do usuário em uma quantidade maior a $x$ na escala MOS de 5 pontuações. Para isto, é definido o parâmetro $F D C_{M O S}$, o qual representa o valor limiar na escala MOS. Os resultados experimentais demonstraram que a utilização do parâmetro FDC melhora o desempenho de um algoritmo de controle do DASH. Essa melhora é bem significativa quando a rede apresenta variações de capacidade da largura de banda frequentemente. Finalmente, foi estimada a QoE do usuário, em um cenário no qual existem eventos de comutação de VQL e pausas, ou seja, a QoE é degradada por esses dois fatores.

\subsection{Contribuições}

A principal contribuição deste trabalho foi a proposta de uma métrica de avaliação de qualidade de vídeo no serviço de streaming de vídeo que utiliza o TCP como protocolo de transporte. No modelo matemático utilizado, representado na equação (4.7), levaram-se em consideração aspectos do sistema cognitivo humano, como por exemplo, o fato de saber o efeito de degradação na QoE do usuário em 
relação as pausas que acontecem na parte inicial, intermediária ou final do vídeo. Assim, considerou-se um parâmetro referente à localização das pausas no domínio do tempo.

Os testes subjetivos de avaliação de vídeo foram realizados utilizando uma metodologia proposta neste trabalho. As metodologias de avaliação de vídeo definidas nas recomendações da ITU-T são mais focadas em degradações espaciais; para esse tipo de degradação uma duração de vídeo de dez segundos pode ser suficiente para estimar o índice MOS, mas para um vídeo que possui pausas a duração do vídeo a ser avaliado deve ser maior.

Utilizando a solução DASH, foi apresentado um parâmetro denominado FDC, o qual tem com o objetivo melhorar o desempenho dos algoritmos de controle de qualidade dos algoritmos DASH. Resultados experimentais demonstraram com clareza que em cenários de mudanças frequentes de largura de banda, o FDC melhorou substancialmente o desempenho do DASH, ou seja, a QoE do usuário não foi severamente afetada. Cabe destacar, que na literatura atual não foi encontrada nenhuma proposta semelhante.

\subsection{Limitações}

A métrica eVsQM foi avaliada com durações de vídeos de 3 até 11 minutos. Vídeos com durações maiores não foram avaliados por restrições de tempo na realização de testes subjetivos. No entanto, deve-se mencionar que vídeos de curta duração, com um valor médio de três minutos, são os mais acessados em serviços de streaming de vídeo como o Youtube.

Na determinação do parâmetro FDC foi utilizado um número restrito de cinco resoluções de qualidade de vídeo. Aplicações comerciais de streaming de vídeo podem ter mais que cinco versões de resolução do mesmo vídeo e conseguintemente diferentes tipos de comutações.

\subsection{Trabalhos Futuros}

O parâmetro FDC utilizado nas soluções DASH pode ser generalizado para possibilitar o uso dele em aplicações reais de streaming de vídeo. Utilizando os resultados já obtidos, pretende-se elaborar um algoritmo que considere as resoluções de vídeos a serem comutados, estabelecendo uma relação entre eles. Assim, será possível determinar pesos fixos de degradação dependentes do valor 
da relação entre as resoluções e não de valores específicos de resolução.

\subsection{Produção Cientifica}

No desenvolvimento dessa tese foram publicados trabalhos em revistas, e eventos nacionais e internacionais, os quais são listados a seguir na ordem cronológica de publicação:

- RODRÍGUEZ, D. Z.; ROSA, R. L.; BRESSAN, G. Video Quality Assessment in Video Streaming Services Considering User Preference for Video Content. In: 2013 32th IEEE International Conference on Consumer Electronics (ICCE), Las Vegas, US, Jan. 2014.

- RODRÍGUEZ, D. Z.; ROSA, R. L.; BRESSAN, G. A billing system model for voice call service in cellular networks based on voice quality. In: 2013 IEEE 17th International Symposium on Consumer Electronics (ISCE), 2013, Hsinchu City. 2013 IEEE International Symposium on Consumer Electronics (ISCE), 2013. p. 89.

- ROdrÍGUEZ, D. Z.; ROSA, R. L.; BRESSAN, G. A Business Model for Video Transmission Services using Dynamic Adaptation Streaming over HTTP. In: AICT 2013, The Ninth Advanced International Conference on Telecommunications, 2013, Rome. AICT 2013, 2013. p. 60-70.

- RODRÍGUEZ, D. Z.; BRESSAN, G. Improving the Minimization Drive Tests using Voice Quality Index. In: International Workshop on Telecommunications, 2013, Minas Gerais. IWT 2013. Minas Gerais: INATEL, 2013. v. 1. p. 10-13.

- RODRÍGUEZ, D. Z.; ROSA, R. L.; BRESSAN, G. Predicting the Quality Level of a VoIP Communication through Intelligent Learning Techniques. In: ICDS 2013, The Seventh International Conference on Digital Society, 2013, Nice. ICDS 2013, 2013. p. 42-47.

- RODRIGUEZ, D. Z.; ABRAHÃO, J. I.; COAQUIRA, D. B; ROSA, R. L.; BRESSAN, G. Quality metric to assess video streaming service over TCP considering temporal location of pauses. IEEE Transactions on Consumer Electronics, v. 58, p. 985-992, 2012. 
- RODRÍGUEZ, D. Z.; BRESSAN, G. Video Quality Assessments on Digital TV and Video Streaming services using Objective Metrics. IEEE Latin America Transactions, v. 10, p. 1184-1189, 2012.

- ROdRiguez, D. Z.; ABRAhÃO, J. I.; COAQUiRA, D. B; ROSA, R. L.; BRESSAN, G. Video quality subjective assessment considering cognitive criteria and user preferences on video content. In: the 18th Brazilian symposium, 2012, São Paulo/SP. Proceedings of the 18th Brazilian symposium on Multimedia and the web - WebMedia '12. New York: ACM Press, 2012. p. $269-272$

- RODRIGUEZ, D. Z. ; BRESSAN, G. Video Quality Assessment on Digital TV and Video Streaming services using Objective Metrics. In: I2TS, 2011, Florianopolis. I2TS Conference.

Os seguintes artigos foram realizados durante o período do programa de doutorado e foi na modalidade de co-autor:

- ROSA, R. L.; RODRÍGUEZ, D. Z.; BRESSAN, G. SentiMeter-Br: A new social web analysis metric to discover consumers' sentiment. In: 2013 IEEE 17th International Symposium on Consumer Electronics (ISCE), 2013, Hsinchu City. 2013 IEEE International Symposium on Consumer Electronics (ISCE), 2013. p. 153.

- ROSA, R. L.; RODRÍGUEZ, D. Z.; BRESSAN, G. SentiMeter-Br: A Social Web Analysis Tool to Discover Consumers' Sentiment. In: 2013 14th IEEE International Conference on Mobile Data Management (MDM), 2013, Milan. 2013 IEEE 14th International Conference on Mobile Data Management, 2013. p. 122 .

- ROSA, R. L.; RODRÍGUEZ, D. Z.; BRESSAN, G. SSentiMeter-Br: Facebook and Twitter Analysis Tool to Discover Consumers' Sentiment. In: AICT 2013, The Ninth Advanced International Conference on Telecommunications, 2013, Rome. AICT 2013, 2013. p. 60-65.

- PIVARO, F. G.; RODRÍGUEZ, D. Z.; BRESSAN, G. Avaliação da Qualidade de uma Comunicação VoIP em uma rede WLAN real com diferentes Modelos de Desvanecimento. In: XXIX Simpósio Brasileiro de Telecomunicações, 2011. XXIX Simpósio Brasileiro de Telecomunicações SBrT, 2011. 
- ROSA, R. L.; RODRÍGUEZ, D. Z.; DE SOUSA JUNIOR, V. A.; BRESSAN, G. Recommendation system based on user profile extracted from an IMS network with emphasis on social network and digital TV. In: the 6th Latin America Networking Conference, 2011, Quito. Proceedings of the 6th Latin America Networking Conference on - LANC '11. New York: ACM Press. p. 40.

- SOUSA, J. M; RODRIGUEZ, D. Z. ; PIVARO, F. G.; BRESSAN, G. Avaliação do Índice de Qualidade de Voz em Redes Móveis Celulares Baseada na Percepção dos Usuários. In: XXIX Simposio Brasileiro de Telecomunicações, 2011, Curitiba. XXIX Simposio Brasileiro de Telecomunicações, 2011. 


\section{Referências}

3GPP TS 26.247. Progressive Download and Dynamic Adaptive Streaming over HTTP (3GP-DASH). [S.l.], dez. 2011. Disponível em: <http://www.3gpp.org/ftp/specs/html-info/26247.htm>.

ABRAHAO, J. Introdução a Ergonomia da pratica á teoria. [S.l.]: Blucher, 2009.

AlVAREZ, L.; COELHO, L. Percepção e Imagem, Trabalho de disciplina: O Simbolico no discurso visuala. [S.1.]: PUC/Rio, 2006.

AMAZON. Mechanical Turk. September 2013. Disponível em: 〈https: //www.mturk.com/mturk/welcome).

ANDERSON, J. Cognitive Phiscology and its implications. [S.1.]: Worth Publishers, 2000.

AROUSSI, S.; BOUABANA-TEBIBEL, T.; MELLOUK, A. Empirical qoe/qos correlation model based on multiple parameters for vod flows. p. 1963-1968, 2012 .

BAUER, B.; PATRICK, A. S. A Human Factors Extension to the Seven-Layer OSI Reference Model. January 2004. Disponível em: 〈\{http: //www.andrewpatrick.ca/OSI/10layer.html\}).

BLIN, J. New quality evaluation method suited to multimedia context: Samviq. Proceedings of the Second International Workshop on Video Processing and Quality Metrics, January 2006.

BOUTEN, N. et al. Qoe in multimedia services transmission. In: . [S.l.: s.n.], 2008. p. 233-240.

CALYAM, P. et al. Impact of router queuing disciplines on multimedia QoE in IPTV deployments. Proceedings of International Workshop on Quality of Multimedia Experience QoMEx 2009, p. 92-97, 2009.

CERMAK, G. W. Subjective video quality as a function of bit rate, frame rate, packet loss, and codec. Proceedings of International Workshop on Quality of Multimedia Experience QoMEx 2009, p. 41-46, 2009.

CHEN, Z.; LIN, C.; WEI, X. Enabling on-demand internet video streaming services to multi-terminal users in large scale. IEEE Trans. Consumer Electronics, v. 55, n. 4, p. 1988-1996, 2009.

CICCO, L. D.; MASCOLO, S.; PALMISANO, V. Feedback control for adaptive live video streaming. In: Proceedings of the Second Annual ACM Conference on Multimedia Systems. New York, NY, USA: ACM, 2011. (MMSys 11), p. 145-156. ISBN 978-1-4503-0518-1. 
CISCO. Visual Networking Index. June 2012. Disponível em: 〈\{http: //www.cisco.com/en/US/solutions/collateral/ns341/ns525/ns537/ns705】V/ ns827/VNIHyperconnectivity/WP.html $\}\rangle$.

CRANLEY, N.; PERRY, P.; MURPHY, L. User perception of adapting video quality. International Journal of Man-Machine Studies, v. 64, n. 8, p. 637-647, 2006.

DAVIES, E. Machine Vision: Theory, Algorithms, Practicalities. [S.l.]: Elsevier, 2005.

DIVINO, R.; FAIGLE, A. A. Distinções entre Memória de Curto Prazo e Memória de Longo Prazo. October 2004. Disponível em: 〈\{http: //www.ic.unicamp.br/wainer/cursos/906/trabalhos/curto-longo.pdf $\}\rangle$.

DUFFY, B. et al. Comparing data from online and face-to-face surveys. International Journal of Market Research, v. 47, n. 6, p. 615-640, 2006.

Ericsson. AVC and HEVC: The future of Encoding. June 2012.

EVENSEN, K. et al. Improving the performance of quality-adaptive video streaming over multiple heterogeneous access networks. In: Proceedings of the Second Annual ACM Conference on Multimedia Systems. New York, NY, USA: ACM, 2011. (MMSys 11), p. 57-68. ISBN 978-1-4503-0518-1.

FEAMSTER, N.; BANSAL, D.; BALAKRISHNAN, H. On the interactions between layered quality adaptation and congestion control for streaming video. In: 11th International Packet Video Workshop. Kyongju, Korea: [s.n.], 2001.

GARCIA, M.-N.; RAAKE, A. Parametric packet-layer video quality model for iptv. In: ISSPA. [S.1.]: IEEE, 2010. p. 349-352. ISBN 978-1-4244-7165-2.

GARCIA, M.-N.; RAAKE, A.; LIST, P. Towards content-related features for parametric video quality prediction of iptv services. In: . [S.l.]: IEEE, 2008. p. 757-760. ISBN 1-4244-1484-9.

GINGER, S.; GINGER, A. uma terapia do contato. [S.l.]: Summus, 1995.

GLEITMAN, H.; FRIDLUnD, A.; REISBERG, D. Psychology. [S.l.]: W. W. Norton \& Co. New York, 2004.

GOUACHE, S. et al. Distributed \& adaptive http streaming. In: IEEE International Conference on Multimedia and Expo (ICME). [S.l.: s.n.], 2011. p. $1-6$.

GUYTON, A. C. Tratado de Fisiologia Médica. [S.l.]: Guanabara Koogan, 1997.

HAM, K. G.; KIM, H. J.; CHOI, S. G. User preference based selection method to provide personalized multimedia service with service quality. In: 14th International Conference on Advanced Communication Technology. [S.l.: s.n.], 2012. p. 623-627.

HARMAN, G. The Intrinsic Quality of Experience. Philosophical perspective JSTOR, 1990. 
HOSSFELD, T. et al. The memory effect and its implications on web qoe modeling. p. 103-110, 2011.

HUYSEGEMS, R. et al. Session reconstruction for http adaptive streaming: Laying the foundation for network-based qoe monitoring. In: IWQoS. [S.l.]: IEEE, 2012. p. 1-9. ISBN 978-1-4673-1296-7.

ISO 23009-1. Information Technology - Dynamic adaptive streaming over HTTP (DASH). May 2012. Disponível em:〈www.itu.int/rec/T-REC-G.723.1/en〉.

ITU-T 1540. Internet protocol data communication service - IP packet transfer and availability performance parameters. Disponível em: 〈http: //www.itu.int/rec/T-REC-Y.1540〉.

ITU-T H.264. H.264: Advanced video coding for generic audiovisual services. Disponível em:〈http://www.itu.int/rec/recommendation.asp?T-REC-H.264〉.

ITU-T R. 500-13. Methodology for the subjective assessment of the quality of television pictures. January 2012. Disponível em: 〈www.itu.int/rec/R-REC-BT. $500 / \mathrm{en}\rangle$.

ITU-T R. J.143. User requirements for objective perceptual video quality measurements in digital cable television. May 2000. Disponível em: $\langle$ http://www.itu.int/rec/T-REC-J.143-200005-I .

ITU-T R. P.910. Subjective video quality assessment methods for multimedia applications. Geneva, Switzerland, abr. 2008.

ITU-T R. P.930. Principles of a reference impairment system for video. Geneva, Switzerland, ago. 1996.

JAGADISH, S.; MANIVASAKAN, R. Analysis of jitter control algorithms in QoS networks. Second Asian Himalayas International Conference on Internet, p. 1-5, 2011.

JAIN, R. Quality of experience. IEEE Multimedia, 2004.

JOSKOWICZ, J. et al. A mathematical model for evaluating the perceptual quality of video. In: MAUTHE, A. et al. (Ed.). FMN. [S.l.]: Springer, 2009. v. 5630, p. 164-175. ISBN 978-3-642-02471-9.

KIM, H.-J. et al. The qoe evaluation method through the qos-qoe correlation model. In: KIM, J. et al. (Ed.). NCM (2). [S.1.]: IEEE Computer Society, 2008. p. 719-725. ISBN 978-0-7695-3322-3.

KORHONEN, J.; YOU, J. Improving objective video quality assessment with content analysis. In: . [S.l.]: Proceedings of 5th Intenational Workshop on Video Processing and Quality Metrics for Consumer Electronics, 2010.

KOUMARAS, H. et al. Quantified pqos assessment based on fast estimation of the spatial and temporal activity level. Multimedia Tools Appl., v. 34, n. 3, p. 355-374, 2007.

KUCEROVA, J.; POLEC, J.; TARCSIOVA, D. Video quality assessment using visual attention approach for sign language. World Academy of Science, Engineering and Technology, v. 6, n. 5, p. 180 - 186, 2012. ISSN 1307-6892. 
KUROSE, J. F.; ROSS, K. W. Redes de Computadores e a Internet - Uma nova abordagem. São Paulo, Addison Wesley, vol. 1, p. 303, 2004.

LAGHARI, K. U. et al. Qoe aware service delivery in distributed environment. In: Advanced Information Networking and Applications (WAINA), 2011 IEEE Workshops of International Conference on. [S.l.]: IEEE, 2011. p. 837-842. ISBN 978-1-61284-829-7.

LOHMAR, T. et al. Dynamic adaptive http streaming of live content. 2013 IEEE 14th International Symposium on A World of Wireless, Mobile and Multimedia Networks (WoWMoM), IEEE Computer Society, Los Alamitos, CA, USA, v. 0, p. 1-8, 2011.

LU, Y. et al. Assessing the quality of experience of sopcast. In: International Journal of Internet Protocol Technology. [S.l.: s.n.], 2009. p. 11-23.

MEUR, O. L. et al. A coherent computational approach to model bottom-up visual attention. IEEE Transactions on Pattern Analysis and Machine Intelligence, IEEE Computer Society, Los Alamitos, CA, USA, v. 28, n. 5, p. 802-817, 2006. ISSN 0162-8828.

MICROWORKERS. Crowdsourcing-Microworker. September 2013. Disponível em: 〈http://microworkers.com $\rangle$.

MOK, R. K. P.; CHAN, E. W. W.; CHANG, R. K. C. Measuring the quality of experience of http video streaming. In: AGOULMINE, N. et al. (Ed.). Integrated Network Management. [S.1.]: IEEE, 2011. p. 485-492. ISBN 978-1-4244-9221-3.

NEWELL, A.; SIMON, H. Human Problem Solving. [S.l.]: Oxford, England: Prentice-Hall, 1972.

NISHIDA, S. M. Sentido da Visão. In: . Apostila do Curso de Fisiologia, 2012. Disponível em: 〈http://www.ibb.unesp.br $\rangle$.

NYMAN, G. et al. What do users really perceive: probing the subjective image quality. In: . [S.l.: s.n.], 2006. v. 6059, p. 605902-605902.

NYMAN RADUN, L.; VUORI. From image fidelity to subjective quality: a hybrid qualitative/quantitative methodology for measuring subjective image quality for different image contents. IFIP/IEEE International Symposium on Integrated Network Management (IM), p. 1817-1820, 2005.

OATLEY, K.; JENKINS, J. Understanding emotions. [S.l.]: Oxford :Blackwell publishing, 2003.

ORTEGA, A.; RAMCHANDRAN, K. Rate-Distortion Methods for Image and Video Compression. IEEE Signal Processing Magazine, p. 23-50, 2008.

PARK, H.-J.; HAR, D.-H. Subjective image quality assessment based on objective image quality measurement factors. In: . [S.l.]: IEEE Trans. Consumer Electron., 2011. p. 1176-1184.

PORTER, T.; PENG, X.-H. An objective approach to measuring video playback quality in lossy networks using tcp. IEEE Communications Letters, v. 15, n. 1, p. $76-78,2011$. 
PRATT, W. K. Digital Image Processing (2Nd Ed.). New York, NY, USA: John Wiley \& Sons, Inc., 2001. ISBN 0-471-85766-1.

PU, W.; ZOU, Z.; CHEN, C. W. Dynamic adaptive streaming over http from multiple content distribution servers. In: GLOBECOM. [S.l.: s.n.], 2011. p. 1-5.

RAAKE, A. et al. T-v-model: Parameter-based prediction of iptv quality. In: ICASSP. [S.l.]: IEEE, 2008. p. 1149-1152. ISBN 1-4244-1484-9.

REDI, J. et al. Comparing subjective image quality measurement methods for the creation of public databases. In: . [S.l.: s.n.], 2010. v. 7529, p. 752903-752903-11.

RIBEIRO, F. P.; FLORENCIO, D. A. F.; NASCIMENTO, V. H. Crowdsourcing subjective image quality evaluation. In: MACQ, B.; SCHELKENS, P. (Ed.). ICIP. [S.1.]: IEEE, 2011. p. 3097-3100. ISBN 978-1-4577-1304-0.

RODRIGUEZ, D. Z. et al. Video quality subjective assessment considering cognitive criteria and user preferences on video content. In: Proceedings of the 18th Brazilian Symposium on Multimedia and the Web. New York, NY, USA: ACM, 2012. (WebMedia 12), p. 269-272. ISBN 978-1-4503-1706-1.

RODRIGUEZ, D. Z. et al. Quality metric to assess video streaming service over tcp considering temporal location of pauses. In: . [S.l.]: IEEE Transactions on Consumer Electronics, 2012. p. 985-992.

RODRIGUEZ, D. Z.; BRESSAN, G. Avaliação de qualidade de vídeo nos serviços de streaming e tv digital utilizando métricas objetivas. In: . [S.l.]: Revista IEEE America Latina, 2012. p. 10.

RODRIGUEZ, D. Z.; RAMIREZ, M. A. Voip quality improvement with a ratedetermination algorithm. In: International Workshop on Telecommunications. [S.l.: s.n.], 2009. (IWT 09).

SCARAZATTO, P. Conceitos Fundamentais (Visão). October 2012. Disponível em: 〈http://www.usp.br/fau/cursos/graduacao/arqurbanismo/disciplinas/ aut0213\\/MaterialdeApoio/02.ConceitosFundamentais(visao).pdf $\rangle$.

SEM, M.; JANKOWSI, N. Conducting online surveys. March 2006. 435-456 p.

Siller and Woods. Qoe in multimedia services transmission. In: . [S.l.: s.n.], 2003. v. 7, p. $74-76$.

SILVA, G.; BRADSHAW. Attention-memory interactions in scene perception. In: . [S.l.: s.n.], 2006. v. 19, p. 9-19.

STERNBERG, R. Psicologia Cognitiva. 2000.

STOCKHAMMER, T. Dynamic adaptive streaming over http -: Standards and design principles. In: Proceedings of the Second Annual ACM Conference on Multimedia Systems. New York, NY, USA: ACM, 2011. (MMSys 11), p. 133-144. ISBN 978-1-4503-0518-1.

SUN, Y.; FISHER, R. B. Object-based visual attention for computer vision. Artif. Intell., v. 146, n. 1, p. 77-123, 2003. 
TAKAHASHI, A.; HANDS, D.; BARRIAC, V. Standardization activities in the itu for a qoe assessment of iptv. Communications Magazine, IEEE, v. 46, n. 2, p. 78-84, mar. 2008.

WANG, Z. University of texas. IEEE Signal Processing Letters, 2001.

WANG, Z.; BOVIK, A. C. A universal image quality index. IEEE Signal Processing Letters, v. 9, p. 81-84, December 2002.

WANG, Z.; BOVIK, A. C. Why is image quality assessment so difficult? In: in Proc. IEEE Int. Conf. Acoust., Speech, and Signal Processing. [S.l.: s.n.], 2002. p. 3313-3316.

WANG, Z. et al. Image quality assessment: From error visibility to structural similarity. IEEE TRANSACTIONS ON IMAGE PROCESSING, v. 13, n. 4, p. 600-612, 2004.

WIEGAND, T. et al. Overview of the h.264/avc video coding standard. Circuits and Systems for Video Technology, IEEE Transactions on, IEEE, v. 13, n. 7, p. 560-576, jul. 2003. ISSN 1051-8215.

XIAO, F. DCT-based Video Quality Evaluation. 2000.

XU, Q.; HUANG, Q.; YAO, Y. Online crowdsourcing subjective image quality assessment. In: Proceedings of the 20th ACM International Conference on Multimedia. New York, NY, USA: ACM, 2012. (MM 12), p. 359-368. ISBN 978-1-4503-1089-5.

YAMAGISHI, K.; HAYASHI, T. Parametric packet-layer model for monitoring video quality of iptv services. In: ICC. [S.l.]: IEEE, 2008. p. 110-114.

ZAPATER, M. N.; BRESSAN, G. A proposed approach for quality of experience assurance of iptv. In: ICDS. [S.l.]: IEEE Computer Society, 2007. p. 25. ISBN 978-0-7695-2760-4. 


\section{Apêndice A - Sistema Visual Humano}

O olho humano é o órgão responsável pela visão do ser humano e em cada visão, os olhos provêem megabits de informação, a uma taxa que provavelmente exceda os 10 Mbps. No entanto, a maioria dessa informação é redundante e é comprimida pelos vários níveis do córtex visual do cérebro humano, interpretando-se abstratamente uma pequena fração da informação recebida (DAVIES, 2005).

\section{A.1 Anatomia do Olho Humano}

O olho humano tem a forma de globo, pelo que se denomina de globo ocular. A Figura A.1 de (NISHIDA, 2012) ilustra a secção lateral da anatomia do olho humano, apresentando-se as principais estruturas funcionais que o compõem.

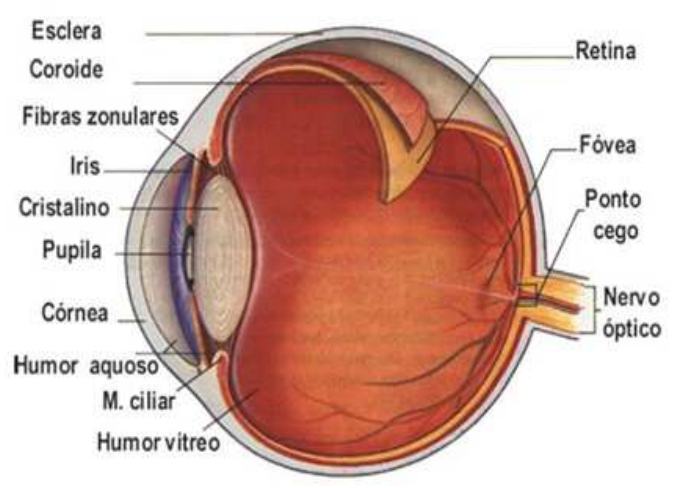

Figura A.1: Estruturas funcionais do olho humano (NISHIDA, 2012).

Em seguida são descritas brevemente as principais estruturas do olho humano (NISHIDA, 2012):

- Pupila: é uma abertura intra-ocular que permite a entrada de luz para o interior do globo ocular em direção a retina.

- Íris: permite estabelecer a cor dos olhos devido à pigmentação que contém. A íris é formada por músculos lisos e fibras radiadas e circulares, cuja contração e relaxamento controlam a abertura da pupila. Assim, a íris regula 
a entrada de luz pela pupila, cujo diâmetro pode ser variado graças à ação antagônica de dois músculos lisos: o músculo esfíncter da pupila causa redução do diâmetro pupilar (miose) e o músculo dilatador da pupila causa um aumento (midríase). Assim, esse diâmetro pode variar de $2 \mathrm{~mm}$ a 8 $\mathrm{mm}$, aproximadamente.

- Córnea: é a parte anterior transparente e protetora do olho, sendo uma superfície transparente e curva de tecido conjuntivo que funciona como uma lente de grande capacidade de refração e que filtra os raios UV. São as lágrimas (secreção lacrimal) que mantêm a córnea úmida e saudável.

- Cristalino: O cristalino se localiza entre a íris e o humor vítreo É uma lente gelatinosa, elástica e convergente que focaliza a luz que entra no olho, formando imagens na retina. A distância focal do cristalino é modificada por movimentos de um anel de músculos, os músculos ciliares, permitindo ajustar a visão para objetos próximos ou distantes. Isso se chama de acomodação do olho à distância do objeto (GLEITMAN; FRIDLUND; REISBERG, 2004). A convergência correta do cristalino faz com que a imagem de um objeto que é formada na retina, fique nítida e bem definida (ALVAREZ; COELHO, 2006). Com o envelhecimento, o cristalino pode perder sua transparência, causando uma visão opaca que é chamada de catarata, cujo tratamento consiste na sua remoção cirúrgica e na colocação de uma lente artificial em seu lugar.

- Músculo Ciliar: O processo de acomodação feita pelo cristalino é realizado pelo músculo ciliar, que o circunda, por meio de pequenos ligamentos ciliares.

- Retina: É a camada mais interna do olho humano, seguida pela coróide e pela esclera. A retina desempenha uma importante função na visão, pois é na retina que se encontram as células conhecidas como fotorreceptoras, e que recebem a imagem a ser transmitida ao cérebro que formará a imagem da visão. Essas células são de dois tipos: cones, para detecção de cores, a maioria localizados na fóvea; e bastonetes que são os principais receptores para baixos níveis de luz.

- Fóvea Central: Está localizada no fundo da retina, com uma dimensão de $3 \mathrm{~mm}$ de largura por $2 \mathrm{~mm}$ de altura. A fóvea é de suma importância para a visão devido ao fato da acuidade visual obtida nessa região ser de $100 \%$. Fora da fóvea a acuidade visual perde gradativamente a eficiência, à medida 
que a concentração de cones diminui. Basicamente a fóvea é composta de três tipos de cones: um para a cor verde, outro para a amarela e outro para a vermelha.

- Coróide: Trata-se de uma membrana conjuntiva, localizada entre a esclerótica e a retina. A coróide é entrecortada de vasos sangüíneos, numa verdadeira trama de pequenas veias que envolvem o globo ocular, tornando a câmara posterior em um local escuro, condição primordial para uma boa visão.

- Esclera: É também conhecida como esclerótica, sendo um tecido conjuntivo rígido e branco que continua a córnea. A esclerótica e a córnea dão a forma esférica ao olho.

- Nervo óptico: fibras nervosas que transportam as informações visuais para o cérebro, próximo à glândula pituitária.

- Ponto cego: Está situado no fundo da retina ao lado da fóvea e é o ponto que liga a retina ao nervo óptico, essa região da retina não possui células fotorreceptoras pelo que está desprovida de visão. Uma vez que não existem células para detectar a luz nessa região, uma parte do campo de visão não é percebida. O cérebro preenche esse ponto com informações sobre imagens ao redor e com informações percebidas pelo outro olho, dessa forma o ponto cego normalmente não é percebido.

- Humor vítreo: O espaço entre o cristalino e a retina é ocupado por um sustância totalmente transparente denominado humor vítreo ou corpo vítreo, contendo fibras sub-microscópicas e ácido hialurônico, que preenche internamente o globo ocular, fazendo com que tome a forma aproximada de uma esfera, com a protuberância da córnea.

- Humor aquoso: é o líquido incolor, constituído por água (98\%) e sais dissolvidos $(2 \%)$ - predominantemente cloreto de sódio - que preenche as câmaras oculares entre a córnea e o cristalino. Esse fluído determina a pressão intraocular que em condições normais é menor que $22 \mathrm{mmHg}$.

\section{A.2 Funcionamento do Olho Humano}

O funcionamento do olho humano é análogo a câmara fotográfica. As estruturas anteriores do olho: córnea, o humor aquoso e o cristalino são transparentes e permitem a entrada da luz atuando como uma lente, sendo o cristalino que refrata 
os raios luminosos que passam através dele (GUYTON, 1997). O Iris atua como o diafragma da câmera fotográfica. A luz passa por um grande espaço no interior do olho, chamado de cavidade vítrea. A luz é focada na retina que é uma fina camada de tecido que recobre a parede posterior interna do olho. A retina atua como o filme fotográfico da câmara, quando a luz focada atinge a retina é possível obter uma fotografia. A Figura A.2 adaptada de (SCARAZATTO, 2012) ilustra graficamente a comparação entre o funcionamento do olho humano e a câmera fotográfica, e como o cérebro pode retificar a imagem captada pela retina.

Na percepção visual, a luz do ambiente entra através da córnea e é projetada ao interior do olho sendo captado pela retina, esse estímulo físico é transformado num estímulo neural (GLEITMAN; FRIDLUND; REISBERG, 2004). Esses sinais são enviados através do nervo óptico ao cérebro para que sejam processados e as imagens sejam formadas.

A conversão da luz em sinais elétricos é realizada na retina por células neurais especializadas, os fotorreceptores (cones e bastonetes). Os cones são responsáveis pela visão diurna (fotóptica) e estão envolvidos no processamento visual dos detalhes, concentrando-se na região central da retina. Os bastonetes são os mediadores da visão noturna (escotóptica). Esses dois tipos de neurônios estabelecem um complexo sistema de conexões com outras células da retina, propiciando condições para que se possam detectar contrastes mínimos, rápidas alterações na intensidade luminosa, detalhes espaciais finos e diferentes tonalidades de cor.

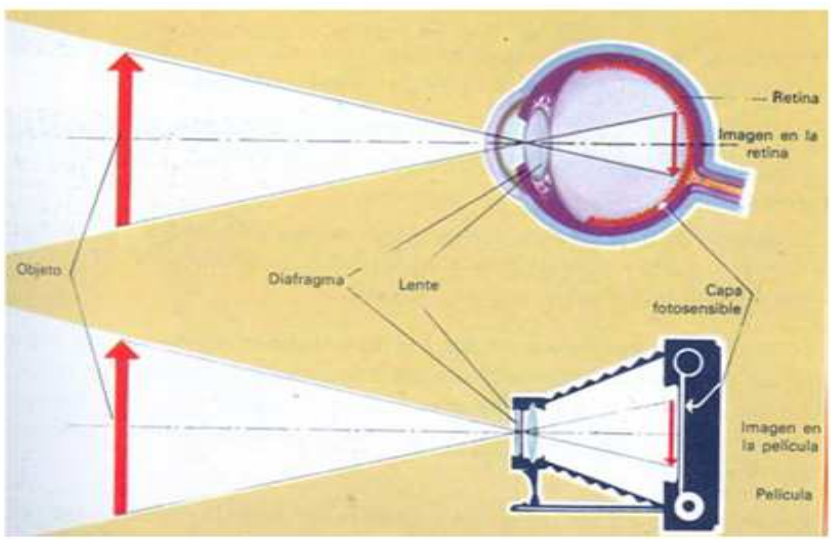

(a)

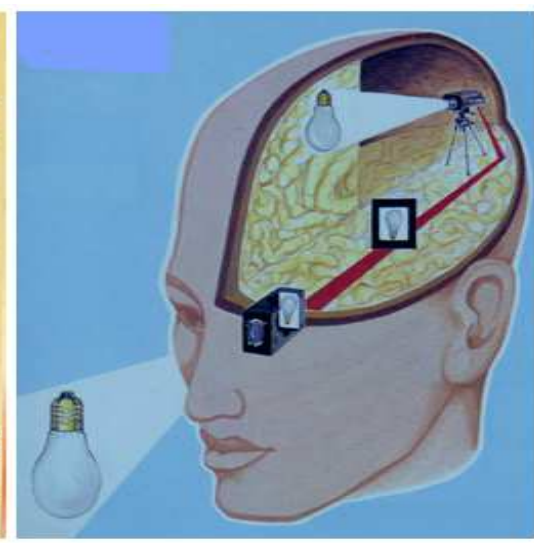

(b)

Figura A.2: Funcionamento de olho humano: (a) Esquema ilustrativo que compara o funcionamento de uma câmera fotográfica ao olho humano. (b) Diagrama que apresenta como o cérebro retifica a imagem capturada pela retina. Adaptada de (SCARAZATTO, 2012).

A Figura A.3 de Nishida, apresenta como as informações ópticas são transmitidas ao córtex visual do cérebro, destacando-se que essas informações não são 
utilizadas unicamente para a percepção visual (Tálamo), as informações óticas servem também para outras funções como: ritmos biológicos (núcleo supraquiasmático), a acomodação visual (área pré-tectal), reflexos oculares (colículo superior).

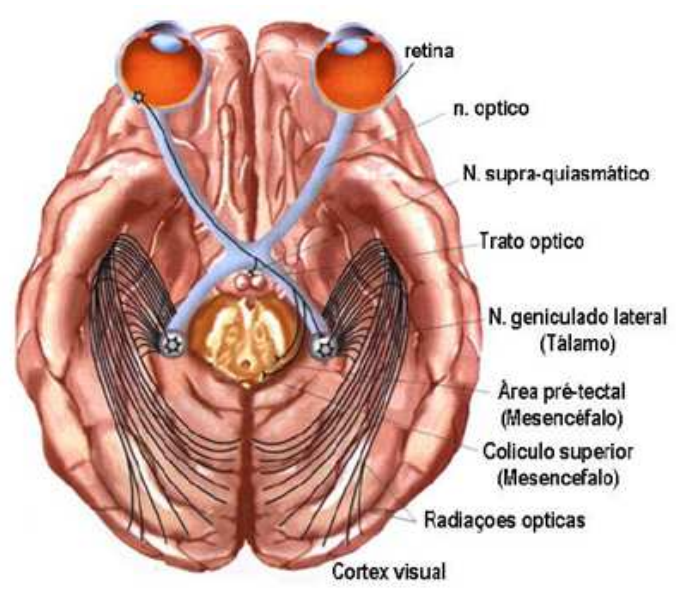

Figura A.3: Transmissão das informações ópticas ao cérebro (NISHIDA, 2012).

O campo visual de um olho é a extensão do ambiente externo que pode ser observada, se a cabeça permanecer em uma posição fixa. No ser humano o campo visual abrange cerca de 150 graus e os campos de ambos os olhos se sobrepõem em cerca de 120 graus. A sobreposição dos dois campos na retina proporciona a experiência tri-dimensional do ambiente (relevo e profundidade). Esse campo visual do olho humano é representado na Figura A.4.

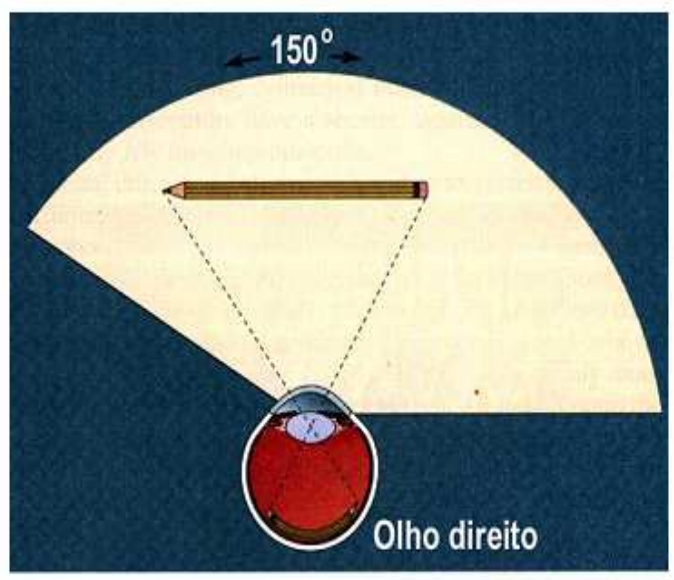

Figura A.4: Campo visual do olho humano (NISHIDA, 2012). 


\section{Apêndice B - Avaliação da qualidade de TV digital com diferentes modelos de desvanecimento}

Neste Apêndice é apresentado um estudo de caso para avaliar a qualidade de um video no recepotor utilizando o serviço de TV Digital. Esse estudo foi desenvolvido em parceria com o laboratorio de telecomunicações da Nokia Brasil.

Antes de apresentar o cenário de teste implementado, brevemente descreveremos as características do canal de radio-frequencias e do desvanecimento.

\section{B.1 Canal de Radiofreqüência e Desvanecimen- tos}

Em sistemas de comunicação sem fio, existem três elementos principais: transmissor $(\mathrm{Tx})$, receptor $(\mathrm{Rx})$ e canal de rádio de frequencia. Esse último devido às suas características intrínsecas apresenta distúrbios na comunicação sem fio. Algumas desses distúrbios são: atenuação, ruído, multipercurso e desvanecimento, entre outros.

Em uma comunicação LAN sem fio (WLAN), o sinal enviado a partir do Tx à $\mathrm{Rx}$ atravessa muitos obstáculos físicos e é refletida em várias direções. Esses sinais diferentes chegam ao Rx com diferentes atrasos e fases, resultando em um sinal composto que depende da freqüência e localização de Rx. Essa situação muda rapidamente quando Rx está em movimento. Esse fenômeno é chamado de propagação multipercurso. A fim de simular o que acontece no canal de rádio e testar o comportamento de sistemas e equipamentos de rádio, foram criados os modelos de canal. As principais características de um modelo são: distribuição estatística de amplitude, o espectro Doppler, a quantidade de multipercurso, fase e atraso de cada multipercurso. Esse conjunto de características, mais a velocidade de avançe do $\mathrm{Tx} / \mathrm{Rx}$, (na maioria dos casos, só do receptor) determina o desvanecimento de que o sinal RF sofre. 
Vários modelos de canal foram definidos para emular todos os tipos de ambientes, tais como transporte urbano, rural. Exemplos desses modelos são: Constante (Constante x), Clássico (Clássico x), urbanos típicos (TU x), rural (RA $\mathrm{x})$, veícular ( $\mathrm{VH} \mathrm{x})$, onde a variável $\mathrm{x}$ indica a velocidade de deslocamento do Rx. Neste trabalho vários modelos com diferentes velocidades foram testados e somente são apresentados aqueles que tiveram o maior impacto na qualidade da comunicação.

\section{B.2 Cenário de Teste e Resultados}

O cenário usado para testes de avaliação da qualidade em serviços digitais de TV, seguindo a norma Integrated Service Digital Broadcasting-Terrestrial (ISDBT), é mostrado na Figura B.1.

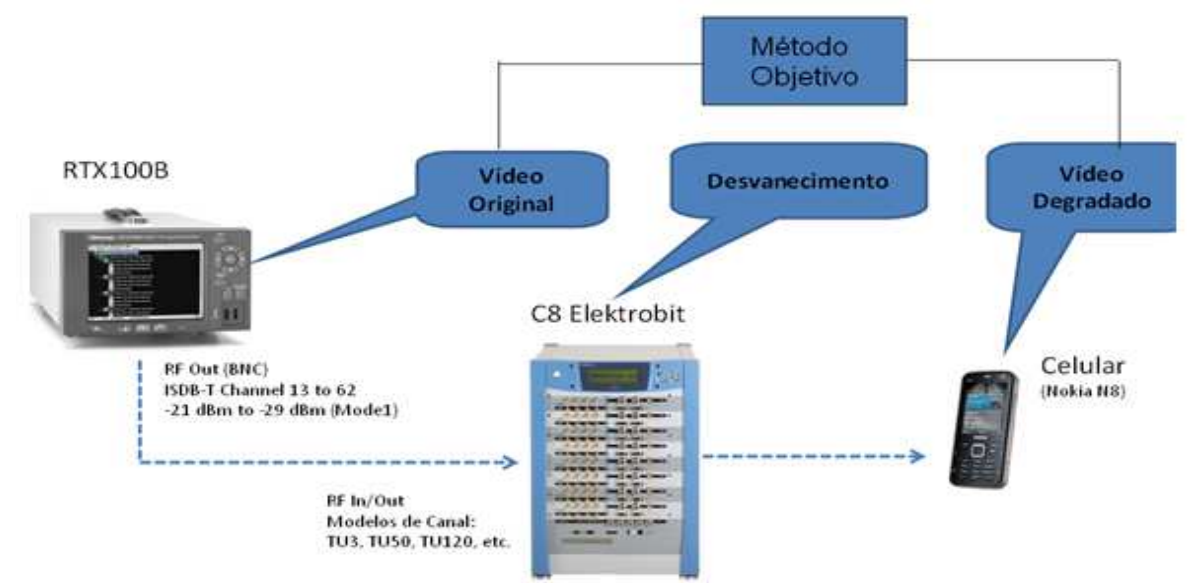

Figura B.1: Cenário de teste para TV Digital (RODRIGUEZ; BRESSAN, 2012).

A metodologia de teste é similar à empregada no serviço de streaming de vídeo, na seção 5.1. Para o caso da TV Digital, o arquivo degradado é salvado no aparelho celular, para logo ser transferido a um computador que tenha os softwares das métricas de avaliação de qualidade. Em seguida são descritas as principais características dos equipamentos utilizados nesse cenário de teste:

- Emulador de canal RF: O equipamento utilizado para emular o canal de RF é o EB Propsim C8 da empresa Elektrobit (Ericsson, 2012). Esse equipamento suporta multi-canal, com freqüências portadoras entre $350 \mathrm{MHz}$ e $6 \mathrm{GHz}$ e largura de canal de até $70 \mathrm{MHz}$. Esse equipamento emula os diferentes modelos de propagação que afetam a qualidade das comunicações de voz e vídeo sobre redes sem fio. Foram empregados diferentes modelos 
de canal: Constante a $50 \mathrm{~km} / \mathrm{h}$, Clássico a $50 \mathrm{~km} / \mathrm{h}$ e Veicular a $30 \mathrm{~km} / \mathrm{h}$ (VH30). O modelo constante foi utilizado para demonstrar o que acontece na situação em que o sinal de RF não sofre atenuação multipercurso, atraso e também para fins de calibração do cenário.

- Gerador de Sinal RF de ISDB-T (Integrated Service Digital BroadcastingTerrestrial): O equipamento utilizado é o RTX100B da empresa Agilent. Esse equipamento tem um modulador de acordo com o padrão que permite emitir o sinal de RF modulado diretamente, sem a necessidade de um gerador de fluxo separado de transporte, um modulador e um conversor para a saída do sinal de RF. Também tem a capacidade de transmitir em tempo real ou utilizando um arquivo de vídeo armazenado em disco rígido. Essa última opção foi utilizada nos testes desse trabalho.

Tabela B.1: Efeito do Fading na qualidade do vídeo-1

\begin{tabular}{|c|cc|cc|cc|}
\hline & PSNR (dB) & VQM & & SSIM & \\
\hline & $\begin{array}{c}\text { Valor } \\
\text { Índice }\end{array}$ & SD & $\begin{array}{c}\text { Valor } \\
\text { Índice }\end{array}$ & SD & $\begin{array}{c}\text { Valor } \\
\text { Índice }\end{array}$ & SD \\
\hline Constant50 & 29 & 2,32 & 1,91 & 0,11 & 0,92 & 0,05 \\
\hline Classical50 & 24 & 6,11 & 2,88 & 0,44 & 0,83 & 0,11 \\
\hline IndorOffice3 & 25 & 4,69 & 2,79 & 0,62 & 0,81 & 0,18 \\
\hline VH30 & 23 & 4,89 & 3,20 & 0,76 & 0,79 & 0,14 \\
\hline
\end{tabular}

Tabela B.2: Efeito do Fading na qualidade do vídeo-2

\begin{tabular}{|c|cc|cc|cc|}
\hline & PSNR (dB) & VQM & & SSIM & \\
\hline & $\begin{array}{c}\text { Valor } \\
\text { Índice }\end{array}$ & SD & $\begin{array}{c}\text { Valor } \\
\text { Índice }\end{array}$ & SD & $\begin{array}{c}\text { Valor } \\
\text { Índice }\end{array}$ & SD \\
\hline Constant50 & 27 & 3,01 & 2,12 & 0,21 & 0,90 & 0,09 \\
\hline Classical50 & 23 & 6,22 & 2,61 & 0,78 & 0,81 & 0,12 \\
\hline IndorOffice3 & 24 & 4,67 & 2,98 & 0,65 & 0,84 & 0,19 \\
\hline VH30 & 23 & 5,07 & 3,35 & 0,83 & 0,76 & 0,19 \\
\hline
\end{tabular}

Tabela B.3: Efeito do Fading na qualidade do vídeo-3

\begin{tabular}{|c|cc|cc|cc|}
\hline & PSNR (dB) & & VQM & & SSIM & \\
\hline & $\begin{array}{c}\text { Valor } \\
\text { Índice }\end{array}$ & SD & $\begin{array}{l}\text { Valor } \\
\text { Índice }\end{array}$ & SD & $\begin{array}{c}\text { Valor } \\
\text { Índice }\end{array}$ & SD \\
\hline Constant50 & 26 & 3,13 & 2,19 & 18 & 0,89 & 0,06 \\
\hline Classical50 & 22 & 6,78 & 2,99 & 0,82 & 0,76 & 0,14 \\
\hline IndorOffice3 & 21 & 4,91 & 3,13 & 0,76 & 0,81 & 0,20 \\
\hline VH30 & 22 & 5,11 & 3,51 & 0,85 & 0,75 & 0,17 \\
\hline
\end{tabular}

As Tabelas B.1, B.2 e B.3 extraídas de (RODRIGUEZ; BRESSAN, 2012) apresentam os resultados das métricas: PSNR (dB), VQM e SSIM assim como o 
desvio padrão (SD) obtidos no serviço de TV Digital, para os diferentes tipos de desvanecimento considerados.

São apresentados quatro diferentes modelos de desvanecimento, como era de se esperar, o modelo Constante (Constant 50) tem os maiores valores de qualidade em cada uma das métricas de qualidade, os outros 3 modelos de desvanecimento têm resultados semelhantes. Observa-se também que cada um dos 3 vídeos têm um grau de degradação diferente, da mesma forma como aconteceu no caso do streaming de vídeo em uma rede IP via UDP. 


\section{Apêndice C - Parâmetros de Informação Temporal (TI) e Informação Espacial (SI)}

Neste Apêndice serão descritos os conceitos dos parâmetros de Informação Temporal (TI - Temporal Information) e Informação Espacial (SI - Spatial Information) que são definidos na Recomendação ITU-T P.910, para logo ser apresentado o código em MATLAB que determina esses parâmetros.

\section{C.1 Parâmetro de Informação Espacial}

A informação espacial (SI), em termos gerais, define quão homogênea é a distribuição espacial de um quadro. O SI está baseado no filtro Sobel. Esse parâmetro é calculado da seguinte forma: cada quadro do vídeo no plano de luminância no instante "n" (Qn) é filtrado utilizando o filtro Sobel [Sobel(Qn)]; em seguida o desvio padrão (dp) é calculado para cada quadro filtrado, e finalmente é calculado o valor máximo dos desvios padrões achados para cada um dos quadros da seqüência de vídeo analisado. O calculo do SI é apresentado na equação c.1.

$$
S I=\operatorname{Max}(\operatorname{dp}[\operatorname{Sobel}(Q n)])
$$

\section{C.2 Parâmetro de Informação Temporal}

A informação temporal (TI) representa a variação dos quadros, considerando os valores dos pixels (no plano de luminância), localizados no mesmo espaço, e correspondentes a quadros consecutivos de um vídeo no domínio temporal. É definido a função de movimento $\operatorname{Mn}(\mathrm{i}, \mathrm{j})$, representada pela equação c.2. 


$$
M_{n}(i, j)=Q_{n}(i, j)-Q_{n-1}(i, j)
$$

Onde, $Q n(i, j)$ é o pixel na fila $i_{t h}$ e na coluna $j_{t} h$ do quadro $n_{t} h$ no tempo.

O parâmetro TI é calculado como o valor máximo correspondente aos desvios padrões achado para todos os $M n(i, j)$; como indicado na equação c.3.

$$
T I=\operatorname{Max}(d p[M n(i, j)])
$$

\section{C.3 Código empregado para calcular TI e SI}

Em seguida é apresentado o código, implementado em Matlab, utilizado para encontrar os parâmetros de Informação temporal e Informação Espacial (SI).

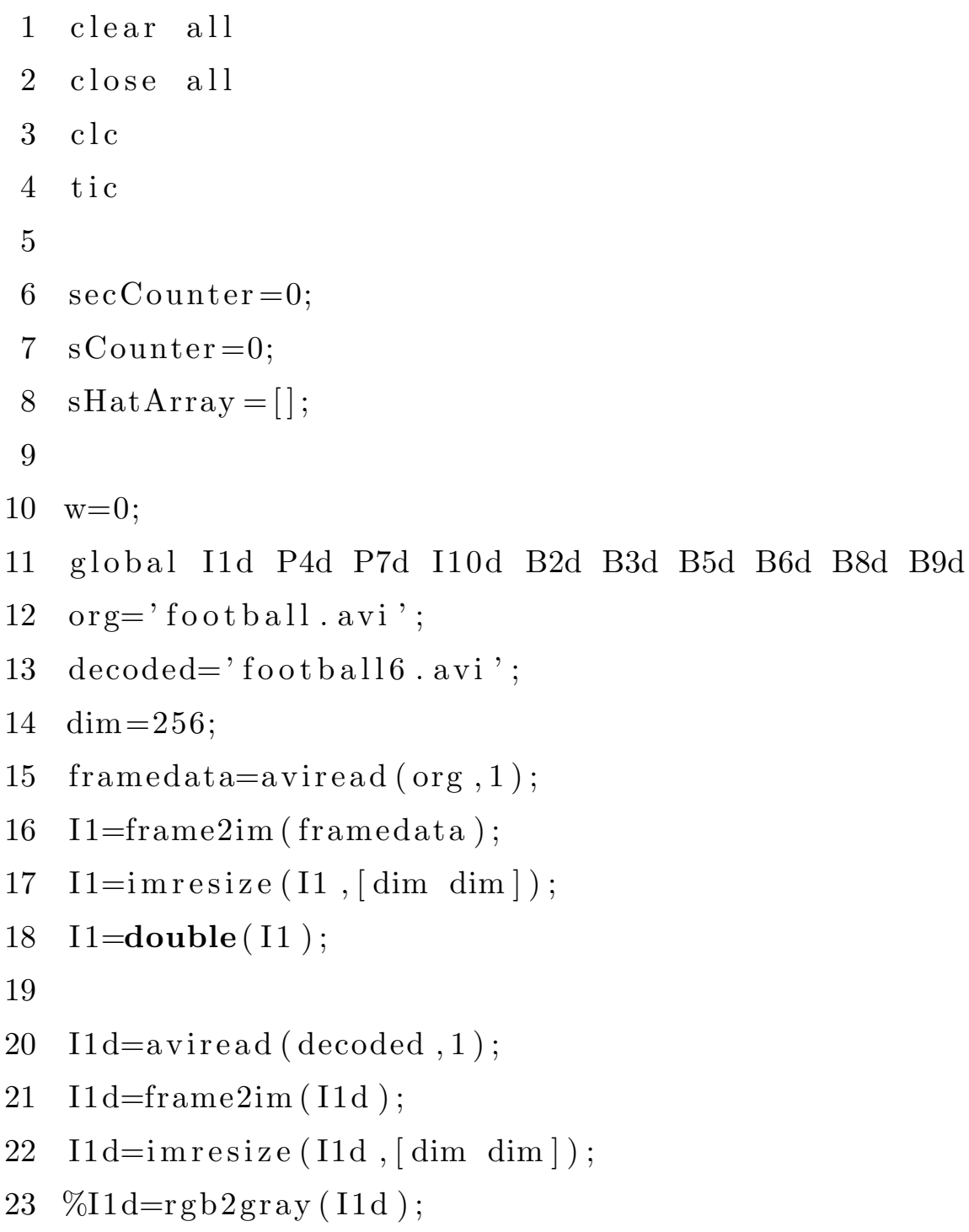


24 25

26

27

28

29

30

31

32

33

34

35

36

37

38

$39 \mathrm{w}=\mathrm{w}+1$;

40 [ originalSI (w, $1: \operatorname{dim})$, decodedSI (w, $1: \operatorname{dim})$, originalTI (w),

$41 \operatorname{decodedTI}(\mathrm{w})]=\operatorname{shat} 1(\mathrm{~B} 2, \mathrm{~B} 2 \mathrm{~d}, \mathrm{I} 1, \mathrm{I} 1 \mathrm{~d})$;

42

$43 \mathrm{w}=\mathrm{w}+1$;

44 [ originalSI (w, 1: dim), decodedSI (w, 1: dim), originalTI (w),

$45 \operatorname{decodedTI}(\mathrm{w})]=\operatorname{shat} 1(\mathrm{~B} 3, \mathrm{~B} 3 \mathrm{~d}, \mathrm{~B} 2, \mathrm{~B} 2 \mathrm{~d})$;

46

$47 \mathrm{w}=\mathrm{w}+1$;

48 [ originalSI (w, $1: \operatorname{dim})$, decodedSI (w, 1: dim), originalTI (w),

$49 \operatorname{decodedTI}(\mathrm{w})]=\operatorname{shat} 1(\mathrm{P} 4, \mathrm{P} 4 \mathrm{~d}, \mathrm{~B} 3, \mathrm{~B} 3 \mathrm{~d})$;

50

$51 \mathrm{w}=\mathrm{w}+1$;

52 originalSI (w, $1: \operatorname{dim})$, decodedSI (w, $1: \operatorname{dim})$, originalTI (w),

$53 \operatorname{decodedTI}(\mathrm{w})]=\operatorname{shat} 1(\mathrm{~B} 5, \mathrm{~B} 5 \mathrm{~d}, \mathrm{P} 4, \mathrm{P} 4 \mathrm{~d})$;

54

$55 \mathrm{w}=\mathrm{w}+1$;

56 [ originalSI (w, $1: \operatorname{dim})$, decodedSI (w, $1: \operatorname{dim})$, originalTI (w),

57 decodedTI $(\mathrm{w})]=\operatorname{shat} 1(\mathrm{~B} 6, \mathrm{~B} 6 \mathrm{~d}, \mathrm{~B} 5, \mathrm{~B} 5 \mathrm{~d})$;

58

$59 \mathrm{w}=\mathrm{w}+1$;

60 [ originalSI (w, $1: \operatorname{dim})$, decodedSI (w, $1: \operatorname{dim})$, originalTI (w),

61 decodedTI $(\mathrm{w})]=\operatorname{shat} 1(\mathrm{P} 7, \mathrm{P} 7 \mathrm{~d}, \mathrm{~B} 6, \mathrm{~B} 6 \mathrm{~d})$;

62

$63 \mathrm{w}=\mathrm{w}+1$; 
64 [ originalSI (w, $1: \operatorname{dim})$, decodedSI (w, $1: \operatorname{dim})$, originalTI (w),

$65 \operatorname{decodedTI}(\mathrm{w})]=\operatorname{shat} 1(\mathrm{~B} 8, \mathrm{~B} 8 \mathrm{~d}, \mathrm{P} 7, \mathrm{P} 7 \mathrm{~d})$;

66

$67 \mathrm{w}=\mathrm{w}+1$;

68 [ originalS I (w, $1: \operatorname{dim})$, decodedSI (w, $1: \operatorname{dim})$, originalTI $(w)$,

$69 \operatorname{decodedTI}(\mathrm{w})]=\operatorname{shat} 1(\mathrm{~B} 9, \mathrm{~B} 9 \mathrm{~d}, \mathrm{~B} 8, \mathrm{~B} 8 \mathrm{~d})$;

70

$71 \mathrm{w}=\mathrm{w}+1$;

72 [ originalSI (w, $1: \operatorname{dim})$, decodedSI (w, $1: \operatorname{dim})$, originalTI (w),

$73 \operatorname{decoded} \mathrm{TI}(\mathrm{w})]=\operatorname{shat} 1(\mathrm{I} 10, \mathrm{I} 10 \mathrm{~d}, \mathrm{~B} 9, \mathrm{~B} 9 \mathrm{~d})$;

74

75

secCounter $=$ secCounter +1 ;

76

if secCounter $==3$

77

sCounter $=$ SCounter +1 ;

78

result (sCounter) $=\operatorname{shat}($ originalSI, decodedSI,

79

originalTI, decodedTI);

80

secCounter $=0$;

81

$\mathrm{w}=0$;

82

end

83

84

$\mathrm{I} 1=\mathrm{I} 10$;

85

$\mathrm{I} 1 \mathrm{~d}=\mathrm{I} 10 \mathrm{~d}$;

86 end 